TE WHARE WĀNANGA O TE ŪPOKO O TE IKA A MĀUI

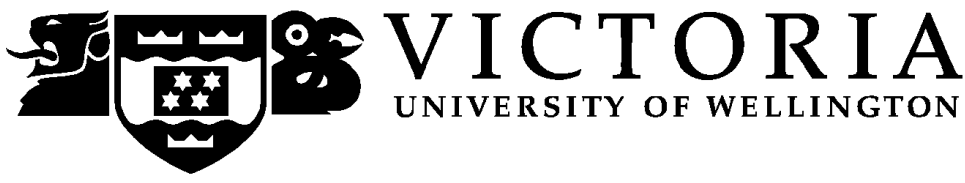

\title{
Carbon isotopic equilibrium of the surface waters as a proxy for climate change through the last glacial/interglacial cycle in the Southwest Pacific
}

Charles Reynolds Maxson IV

A thesis submitted to

Victoria University of Wellington

In partial fulfillment of the requirements for the degree of

Master of Science

In

Geology

School of Geography, Environment, and Earth Sciences Victoria University of Wellington 


\section{Contents}

Acknowledgements $\quad$ vii

Abstract vii

1 Introduction and background 1

1.1 Introduction . . . . . . . . . . . . . . . . . . . . . . 1

1.1.1 Outline of the thesis . . . . . . . . . . . 2

1.1.2 Carbon isotopes . . . . . . . . . . . . . . . 4

1.1 .3 Oceanography . . . . . . . . . . . . . . . 4

1.1.4 Foraminifera . . . . . . . . . . . . 17

1.2 Glacial/Interglacial change in $\delta^{13} C \ldots \ldots$. . . . . . . . . 19

1.2.1 Biologic pump . . . . . . . . . . . . . . . 19

1.2.2 Westerly wind changes . . . . . . . . . . . . . . 21

1.2.3 Ocean circulation . . . . . . . . . . . . . . . 23

1.3 Summary . . . . . . . . . . . . . . . . . 23

2 Modern distribution of $\delta^{13} C$ in the South Pacific 26

2.1 Abstract . . . . . . . . . . . . . . . . 26

2.2 Introduction . . . . . . . . . . . . . . . . . 27

2.3 Methods . . . . . . . . . . . . . . . . 27

2.3.1 Data . . . . . . . . . . . . . 27

2.3.2 Models . . . . . . . . . . . . . . . . . 28

2.4 Results . . . . . . . . . . . . . . . . . . . . . . . . 29

2.4.1 Observations of $\delta^{13} C \ldots \ldots \ldots \ldots$

2.5 Model . . . . . . . . . . . . . . . . . . 32

2.5.1 Initial attempts . . . . . . . . . . . . . . . . 32

2.5.2 Temperature, salinity, density, and oxygen model . . . . 33

2.6 Discussion . . . . . . . . . . . . . . . . . . 36

2.6.1 Spatial distribution of $\delta^{13} C$ in the surface waters of the SW Pacific . . . . . . . . . . . . . . . . 36

2.6.2 Comparison with other $\delta^{13} C_{D I C}$ datasets and models . . 38 
2.6.3 Drivers of $\delta^{13} C$ of surface waters . . . . . . . . . 41

2.7 Conclusion . . . . . . . . . . . . . . . . . . . . . . . 42

3 Modern water versus core top data 43

3.1 Introduction . . . . . . . . . . . . . . . . . . . 43

3.2 Methods . . . . . . . . . . . . . . . . . 43

3.2.1 Creating pre-industrial $\delta^{13} C$ model . . . . . . . . . . . 43

3.2 .2 Core tops . . . . . . . . . . . . . . . . . . . 44

3.3 Results . . . . . . . . . . . . . . . . . 47

3.3.1 Pre-industrial $\delta^{13} C$ Model . . . . . . . . . . . . . . 47

3.3.2 Model $\delta^{13} C$ versus core top $\delta^{13} C$ G. bulloides . . . . . . 50

3.3.3 Temperature from depth . . . . . . . . . . . . . . 50

3.3.4 Discussion . . . . . . . . . . . . . . . . . . . . 51

3.3.5 Model $\delta^{13} C$ versus core top $\delta^{13} C \ldots \ldots$. . . . . . 51

3.4 Conclusions . . . . . . . . . . . . . . . . . 52

4 Downcore study and climate reconstruction 53

4.1 Introduction . . . . . . . . . . . . . . . . . . . 53

4.2 Methods . . . . . . . . . . . . . . . . . 55

4.2 .1 Cores and data . . . . . . . . . . . . . . 55

4.2 .2 Age models . . . . . . . . . . . . . . . . . 56

4.2.3 Correcting G. bulloides $\delta^{13} C$ data . . . . . . . . . 56

4.2.4 Monte Carlo simulation _. . . . . . . . . . . 57

4.2.5 Temporal and Latitudinal changes in $\delta^{13} C \ldots . . . .58$

4.2 .6 Cross correlations . . . . . . . . . . . . . . . . . . . . 58

4.3 Results . . . . . . . . . . . . . . . . . . . . 58

4.3.1 Zones of study . . . . . . . . . . . . . . 58

4.3.2 $\quad \delta^{13} C$ versus Latitude . . . . . . . . . . . . . . . . 71

4.3 .3 Correlations . . . . . . . . . . . . . . . . . . . 72

4.4 Discussion . . . . . . . . . . . . . . . . . . . . . 74

4.4.1 G. bulloides $\delta^{13} C$ variations around New Zealand . . . . 74

$4.4 .2 \quad \delta^{13} C$ versus latitude . . . . . . . . . . . . 76

4.5 Synthesis . . . . . . . . . . . . . . . . 77

4.5.1 Glacial (25-21ka) . . . . . . . . . . . 77

4.5.2 LGM and Early deglaciation (21-15 ka) . . . . . . . 78

4.5.3 ACR and Early Holocene (15-10 ka) . . . . . . . . . 79

4.5.4 Mid to Late Holocene (10ka-present) . . . . . . . . . . 80

4.5.5 Drivers of the $\delta^{13} C$ changes and the carbon cycle . . . . 80

4.5.6 Circulation . . . . . . . . . . . . . . . . . 82 
4.5.7 Conclusion . . . . . . . . . . . . . . . . 83

4.5.8 Future work . . . . . . . . . . . . . 83

$\begin{array}{ll}\text { Appendix } & 85\end{array}$

A SST reconstruction comparison $\quad 85$

A.1 Methods .................... . . 85

A.2 Correlations ...................... . . 90

$\begin{array}{lr}\text { Bibliography } & 98\end{array}$ 


\section{List of Figures}

$1.1 \delta^{13} C$ trend to depth . . . . . . . . . . . . . . . . . 3

1.2 South Pacific transects . . . . . . . . . . . . . . . . . 6

1.3 Surface circulation . . . . . . . . . . . . . . . . 7

1.3 Intermediate water circulation . . . . . . . . . . . 8

1.3 Water masses and fronts around New Zealand . . . . . . . . . . 9

1.4 SW Pacific sub-tropical gyre . . . . . . . . . . . . . . 10

1.5 Schematic cross section of the Southern Ocean . . . . . . . . . . 12

1.6 Water masses of P15 to depth . . . . . . . . . . . . . . 14

1.6 Water masses of $\mathrm{P} 15$ to depth . . . . . . . . . . . . . . . . 15

1.6 Water masses of P15 to depth . . . . . . . . . . . . . . 16

2.1 Water mass $\delta^{13} C$ characteristics . . . . . . . . . . . . 30

2.2 Initial attempt . . . . . . . . . . . . . . . . . 32

2.3 Initial model residuals . . . . . . . . . . . . . . . . . . . . 34

2.3 TSdO model residuals . . . . . . . . . . . . . . . . . 35

2.4 Model seasons . . . . . . . . . . . . . . . . . . . . 37

2.5 Sonnerup GCM . . . . . . . . . . . . . . . . . . . . . . . 39

2.6 Seasonal Chlorophyll . . . . . . . . . . . . . . . . . 40

2.7 TAN1302 data vs. Model . . . . . . . . . . . . . . . . . . 41

3.1 Core top locations . . . . . . . . . . . . . . . . 44

3.2 Bemis temperature correction . . . . . . . . . . . . 46

3.3 Pre-industrial Model . . . . . . . . . . . . . . . . . . . 47

3.4 Depth from Temperature . . . . . . . . . . . . . . . . . . . . 49

3.5 Core top vs modern and pre-anthro data . . . . . . . . . . . . 51

4.1 Core top locations . . . . . . . . . . . . . . . 53

4.2 Bay of Plenty data . . . . . . . . . . . . . . . . . . 6 61

4.3 North Chatham Rise data . . . . . . . . . . . . . . . . . . 62

4.4 South Chatham Rise data . . . . . . . . . . . . . . . . . 64

4.5 Solandar Trough North data . . . . . . . . . . . . . . 66

4.6 Solander Trough South data . . . . . . . . . . . . . . . 68 
4.7 Polar Front data . . . . . . . . . . . . . . . . . . . . . . . . . 69

4.8 Zone $\delta^{13} C$ compilation . . . . . . . . . . . . . . 70

4.9 Latitude versus $\delta^{13} \mathrm{C}$ individual time slices . . . . . . . . . . 73

4.10 Zone comparison to other data sets . . . . . . . . . . 75

A.1.1MD97-2121 SST reconstruction . . . . . . . . . . . . . 87

A.1.2TAN0809-03 SST reconstruction . . . . . . . . . . . . . 88

A.1.3MD978-2120 SST reconstruction . . . . . . . . . . . . . 89

A.2.1Comparison to benthic data . . . . . . . . . . . . . 90 


\section{List of Tables}

1.1 Common acronyms used in this thesis. . . . . . . . . . 5

1.2 Chemical properties of water masses . . . . . . . . . . . . 13

2.1 Transect information . . . . . . . . . . . . . . . . . . . 28

2.2 Water-mass carbon characteristics . . . . . . . . . . 29

3.1 Depth from temperature data table . . . . . . . . . . . . . 45

3.2 Depth from temperature equations . . . . . . . . . . . . 46

3.3 Pre-industrial model creation . . . . . . . . . . . . . . . . . . . 48

4.1 Core information . . . . . . . . . . . . . . . 54

4.2 Time slices used for the latitude versus $\delta^{13} C$ plots. . . . . . . . . . . 55

4.3 Time slices used for the Monte Carlo simulations. . . . . . . . . . . . . 57

4.4 Bay of Plenty standard deviation . . . . . . . . . . . . . 58

4.5 Correlation 25-0ka . . . . . . . . . . . . . . . . 59

4.6 North Chatham Rise standard deviation . . . . . . . . . . . . 63

4.7 South Chatham Rise standard deviation . . . . . . . . . . . 65

4.8 Solander Trough North standard deviation . . . . . . . . . . . 67

4.9 Solander Trough South standard deviation . . . . . . . . . . . 67

4.10 Polar Front standard deviation . . . . . . . . . . . . . . . 71

A.1 SST reconstruction by core . . . . . . . . . . . . . . . 86

A.2 Correlations 25-15ka . . . . . . . . . . . . . . . . . . 91

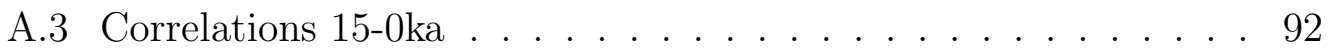

A.4 Correlations 25-20ka . . . . . . . . . . . . . . . . 93

A.5 Correlations $20-15 \mathrm{ka} \ldots \ldots . \ldots . \ldots . . \ldots 94$

A.6 Correlations 15-10ka . . . . . . . . . . . . . . . 95

A.7 Correlations 10-5ka . . . . . . . . . . . . . . 96

A.8 Correlations 5-0ka . . . . . . . . . . . . . . . . . . . . . . . 97 


\section{Acknowledgements}

First, thanks and gratitude to my supervisors: Helen Bostock and Andrew Mackintosh. Helen, for being a wonderful wealth of information and advice and bringing this project to me in the first place. I've had a wonderful time this past year and I have you to thank for that. To Andrew, for bringing in the slightly lost foreigner starting the whole process of introduction to Helen. As well as your patient, well thought out advice.

To all of those involved in collecting the cores and water samples in this study. To all those who analyzed the samples to create the data sets. This project could not have happened without you, and I thank you for it.

To Sara Mikaloff-Fletcher and Joe Prebble. Sara, for your advice and patience in explaining statistics to a total novice. Joe, for your advice and encouragement throughout.

To the AQUA community, thank you for welcoming me in and supporting and encouraging me in all my work. To all those aboard the R.V. Investigator. To the science crew: Kate Berry, Craig Neil, Erik van Ooijen, Bronte Tillbrook, Reece Brown, and to the rest of the crew, thank you. To Rolf Sonnerup, for his advice and his gracious offer of sending his climate model data.

To the Geology department at VUW. Thank you for inspiring me to achieve what I have and to all the advice and knowledge I gained for being part of this department.

To my fellow masters students. Aiden Milner, Hannah Brightley, Rackley Nolan, Andrea Davies, Josh Price, and Lauren Carter. Who talked politics and commiserated with the American. For all the lunches we shared. To the entire SGEES department, for the staff football team wins. To Matt Ryan, for bringing me into the dactyls.

To the VUWAFC football team. For letting me get my fix of football, and making the last two years enjoyable.

To all my friends, for supporting me through these last two years. I look forward to the free time I will now have to spend with you!

Most of all, to my family. For supporting me in everything, even if it takes me halfway across the world. 


\section{Abstract}

Carbon-13 is a relatively understudied geochemical property in the world ocean. The Southwest Pacific, in particular, is devoid of $\delta^{13} C$ data. This thesis therefore has two main objectives: to create a model to describe the modern distribution of $\delta^{13} \mathrm{C}$ around New Zealand $\left(30-70^{\circ} \mathrm{S}, 140^{\circ} \mathrm{E}-150^{\circ} \mathrm{W}\right)$, and to describe changes in $\delta^{13} C$ in a latitudinal transect of cores to the east and south of New Zealand. A model using multiple linear regression was created by comparing $\delta^{13} C$ with potential temperature, salinity, density, and oxygen data. This model matches well with ship board $\delta^{13} C$ measurements taken throughout the region. The resulting models were then compared to core top data to determine how well modern $\delta^{13} C$ values compare to the Holocene, pre-industrial values. A new model, based on previous pre-industrial models, was created at much higher resolution to recreate the pre-industrial $\delta^{13} C$ distribution. Core top values were found to be intermediate between Holocene and modern values. Down core $\delta^{13} C$ data was split into six regions based on oceanographic conditions to determine what caused and how $\delta^{13} C$ change occurred in the past. Data was run through 1000 iterations of a Monte Carlo simulation to determine a robust $\delta^{13} C$ curve back through time. The biologic pump was found to dominate the $\delta^{13} C$ levels in the region through iron fertilization and increased productivity in the polar zone. The LGM and deglacial $\delta^{13} C$ values reflect greater influence on $\delta^{13} C_{a t m}$, suggesting that an increase in upwelling along the Antarctic coast and a possible strengthening of the westerly wind belt caused changes in ocean circulation throughout the region. The ACR and Early Holocene periods show good correlation with atmospheric $\mathrm{CO}_{2}$ records, suggesting increasing temperatures may have increased productivity. The remainder of the Holocene to the present is mainly influenced by $\delta^{13} C_{a t m}$, suggesting relatively stable conditions in ocean and atmosphere. 


\section{Chapter 1}

\section{Introduction and background}

\subsection{Introduction}

The carbon cycle is intimately linked to the future of humanity. Release of carbon from fossil fuels has created a situation in which unprecedented amounts of carbon have been released into the atmosphere and have created an imbalance between the ocean-atmosphere system. How this system reacts to this imbalance will have global consequences that are becoming increasingly concerning in everyday life. To quantify how this imbalance will affect our planet we must look to carbon cycles of the present and past atmosphere and ocean. By looking at past, and different, equilibria of the carbon cycle we may glean what the future will hold for us.

The exact causes of the increase in atmospheric $\mathrm{CO}_{2}$ concentrations from the Last Glacial Maximum (LGM; $180 \mathrm{ppm}$ ) to the present interglacial (280 ppm; prior to industrialization) is still highly debated. The two main theories proscribe the biologic pump (Hertzberg et al., 2016) and/or the westerly winds (Anderson et al., 2009; Toggweiler et al., 2006) as the main regulator of atmospheric $\mathrm{CO}_{2}$ levels during the last glacial termination. The idea behind the biologic pump is that the Atlantic Meridional Overturning Circulation (AMOC) weakened at the end of the LGM, decreasing the upwelling of nutrients to surface waters. This caused a decrease in biologic density at the sea surface and reduced the amount of $\mathrm{CO}_{2}$ being drawn down by photosynthesis, causing $\mathrm{CO}_{2}$ to accumulate in the atmosphere and cause global warming (Hertzberg et al., 2016). The theory behind the westerly winds is that warming caused by an increase in northern hemisphere insolation caused a strengthening of the southern hemisphere westerly winds (Denton et al., 2010). This then caused increased upwelling of high $\mathrm{CO}_{2}$ content waters from the deep ocean which released $\mathrm{CO}_{2}$ into the atmosphere when it reached the sea surface and caused global warming. A recent study by Ferrari et al. (2014) suggest that 
multiple sources may be the cause for the glacial termination and other factors not yet considered may play a role as well. They argue that multiple factors in the chemistry, biology, and physics (circulation and westerly wind caused upwelling) may all be factors in the deglaciation and other factors such as sea ice may play a role.

Since carbon stable isotopes $\left(\delta^{13} C\right)$ are measured in conjunction with oxygen isotopes $\left(\delta^{18} O\right)$ there is a considerable amount of ${ }^{13} \mathrm{C}$ data from foraminifera from marine sediments available. Much of these data have not been studied because they are difficult to interpret since carbon stable isotopes are affected by multiple factors (temperature, vital effects, water-mass characteristics). Limited previous studies hint at the utility of such a database (Bostock et al., 2004; Neil et al., 2004). The purpose of this study to delve into this database to understand the distribution of carbon stable isotopes in the modern Southwest Pacific and Southern Oceans over the last 25 ka.

\section{Objectives:}

1) To understand the modern distribution of $\delta^{13} C$ in the SW Pacific and Southern Ocean and what is controlling it.

2) To investigate a latitudinal transect of cores from offshore New Zealand to determine the spatial and temporal changes in the $\delta^{13} C$ over the last 25 ka.

I hypothesize that the changes seen in the downcore data are primarily related to changes in the global carbon cycle since the last glacial period, with additional impacts from changes in the south westerly winds altering the local ocean circulation in the SW Pacific and Southern Ocean.

\subsubsection{Outline of the thesis}

Chapter 2 begins by determining the spatial variability of $\delta^{13} C$ in the modern SW Pacific Ocean. This is done by building a model based on modern oceanographic conditions to give us $1^{\circ}$ by $1^{\circ}$ resolution of $\delta^{13} C$ throughout the SW Pacific and Southern Oceans. The purpose of this is to produce a modern picture of carbon stable isotopes in the ocean. This will be used in Chapter 3 to compare with $\delta^{13} C$ analysed on the planktic foraminifer Globigerina bulloides from core tops to determine whether they reflect the distribution evident in the $\delta^{13} C_{D I C}$ (Dissolved Inorganic Carbon: DIC $=\left[\mathrm{CO}_{2(a q)}\right]+\left[\mathrm{HCO}_{3}{ }^{-}\right]+$ $\left[\mathrm{CO}_{3}{ }^{2-}\right]$ ) of surface waters around New Zealand. Then in Chapter 4 down core $\delta^{13} C$ data from $G$. bulloides will be corrected to reflect $\delta^{13} C_{D I C}$ at the time of foraminiferal test formation. A synthesis of the data will be compared against current hypotheses of climate change to form a chronology of climate change 


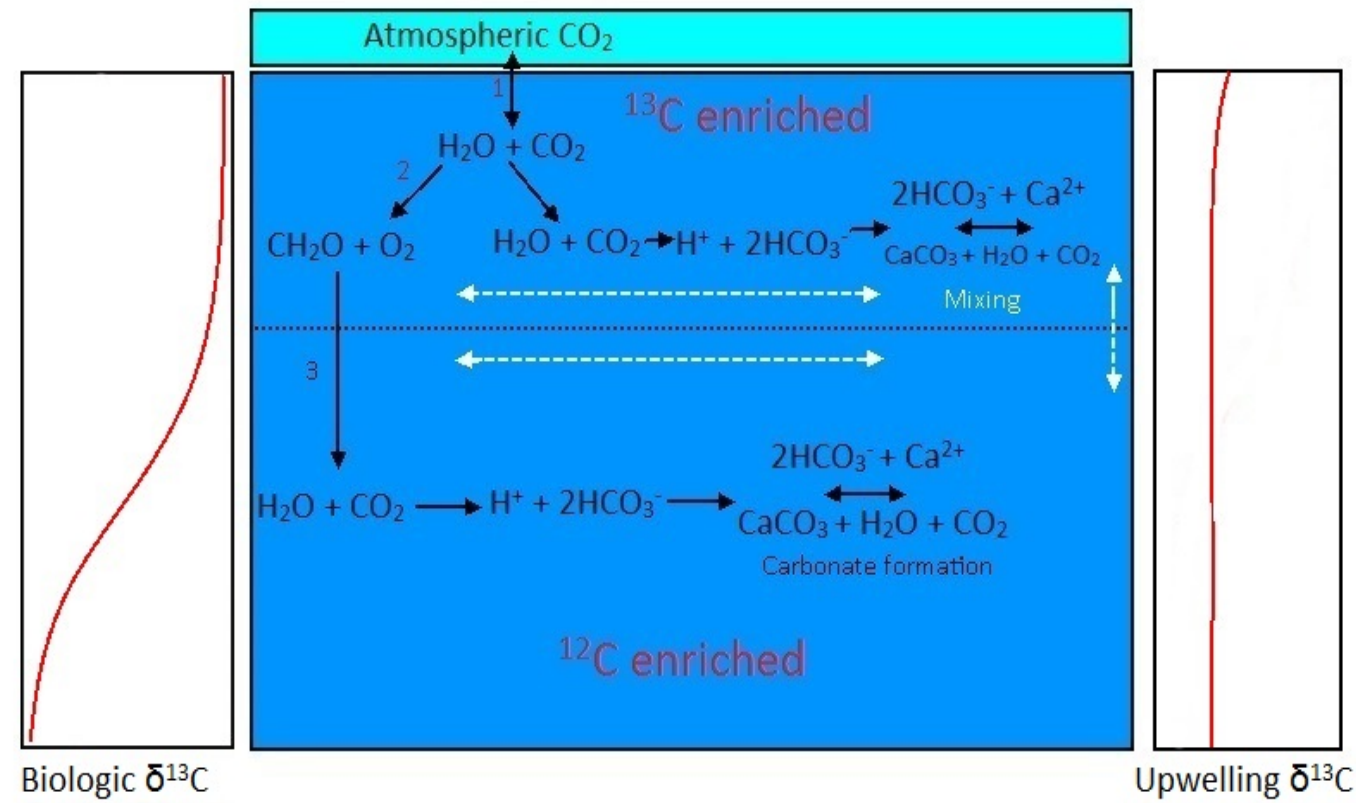

Figure 1.1: Diagram of how carbon cycles in the ocean. 1) Air-sea mixing dissolves atmospheric $\mathrm{CO}_{2}$ into the ocean. 2) Biology uptakes ${ }^{12} \mathrm{C}$ preferentially, enriching DIC (Dissolved Inorganic Carbon) in ${ }^{13} \mathrm{C}$, which is then recorded in $\mathrm{CaCO}_{3}$ formation. 3) As organisms die they respire and remineralize the organically stored ${ }^{12} \mathrm{C}$ and depleting deep water DIC of ${ }^{13} C$. The far left of the graph shows the biologically controlled $\delta^{13} C$ trend to depth. The far right shows a $\delta^{13} C$ trend to depth controlled by upwelling. Old, $\delta^{13} C$ depleted waters upwelling have very low $\delta^{13} C$ levels throughout the water column. White arrows show lateral mixing of water masses and upwelling. 
based on $\delta^{13} C_{D I C}$ data at the end of chapter 4 .

\subsubsection{Carbon isotopes}

Carbon stable isotopes $\left(\delta^{13} C_{D I C}\right)$ in the ocean are altered through three processes: Air-sea exchange, biological processes, and ocean circulation. Air-sea exchanges occur at the surface and are generally temperature controlled, with exchange lowering $\delta^{13} C$ at warm temperatures and raising it at cold temperatures (Zhang et al., 1995). In the Southern Ocean, this exchange is especially strong due to the strong westerly wind belt. Wind driven mixing in this region raises intermediate water levels of $\delta^{13} C_{D I C}$ to higher than would be expected by biologic processes in the region (Lynch-Stieglitz et al., 1995).

Biologic activity accounts for most $\delta^{13} C_{D I C}$ variability throughout the water column in the oceans (Figure 1.1). Primary producers (such as foraminifera, diatoms, and coccolithophores) preferentially take up ${ }^{12} C$ in the photic zone. This increases the $\delta^{13} C_{D I C}$ values of the surface ocean. These primary producers then die and sink to the seafloor. As they fall through the water column, the organic carbon is remineralized via respiration enriching intermediate and deep waters in ${ }^{12} C$. Thus, biologic activity produces a negative $\delta^{13} C_{D I C}$ gradient between the surface and deep ocean.

Ocean circulation can overprint the preformed biologic signal of ${ }^{13} C$ via mixing of water masses with different $\delta^{13} C_{D I C}$ values. Ocean circulation is the physical mechanism that can alter the productivity induced gradient through upwelling or via horizontal mixing as water travels around the oceans at depth and interacts with other water masses.

\subsubsection{Oceanography}

The SW Pacific and Pacific sector of the Southern Ocean (herein referred to as the Southern Ocean) are regions that are becoming important to the global conversation about climate change. Specifically, the Southern Ocean is important to the global carbon cycle because it is a major region of exchange between the atmospheric and oceanic carbon reservoirs (Sabine et al. 2004). In this section the current oceanographic conditions of the New Zealand region of the South Pacific and Southern Oceans $\left(30-70^{\circ} \mathrm{S}, 140^{\circ} \mathrm{E}-150^{\circ} \mathrm{W}\right.$; Figure 1.2) are described. Included in this discussion are the identifying properties of the water masses within the region along the transect $\mathrm{P} 15\left(170^{\circ} \mathrm{W}\right)$. This section was taken in February of 1996 and reflects summer values. This section was chosen as a representative of all the main transects of the region (SR3, 


\begin{tabular}{|l|l|}
\hline \multicolumn{2}{|c|}{ Study Zones } \\
\hline BoP & Bay of Plenty \\
\hline NCR & North Chatham Rise \\
\hline SCR & South Chatham Rise \\
\hline SolN & Solander Trough North \\
\hline SolS & Solander Trough South \\
\hline PF & Polar Front \\
\hline \multicolumn{2}{|l|}{ Oceanography } \\
\hline STW & Sub-tropical water \\
\hline STF & Sub-tropical front \\
\hline STFZ & Sub-tropical front zone \\
\hline STZ & Sub-tropical zone \\
\hline SAW & Sub-Antarctic water \\
\hline SAF & Sub-Antarctic front \\
\hline SAZ & Sub-Antarctic zone \\
\hline PF & Polar front \\
\hline PZ & Polar zone \\
\hline AASW & Antarctic surface water \\
\hline AAIW & Antarctic intermediate water \\
\hline SAMW & Sub-Antarctic mode water \\
\hline STMW & Sub-tropical mode water \\
\hline PDW & Pacific deep water \\
\hline CDW & Circumpolar deep water \\
\hline UCDW & Upper circumpolar deep water \\
\hline LCDW & Lower circumpolar deep water \\
\hline AABW & Antarctic bottom water \\
\hline NADW & North Atlantic deep water \\
\hline EAC & East Australian current \\
\hline EAuC & East Auckland current \\
\hline ACC & Antarctic circumpolar current \\
\hline DWBC & Deep western boundary current \\
\hline SEC & South Equatorial current \\
\hline
\end{tabular}

Table 1.1: Common acronyms used in this thesis. 


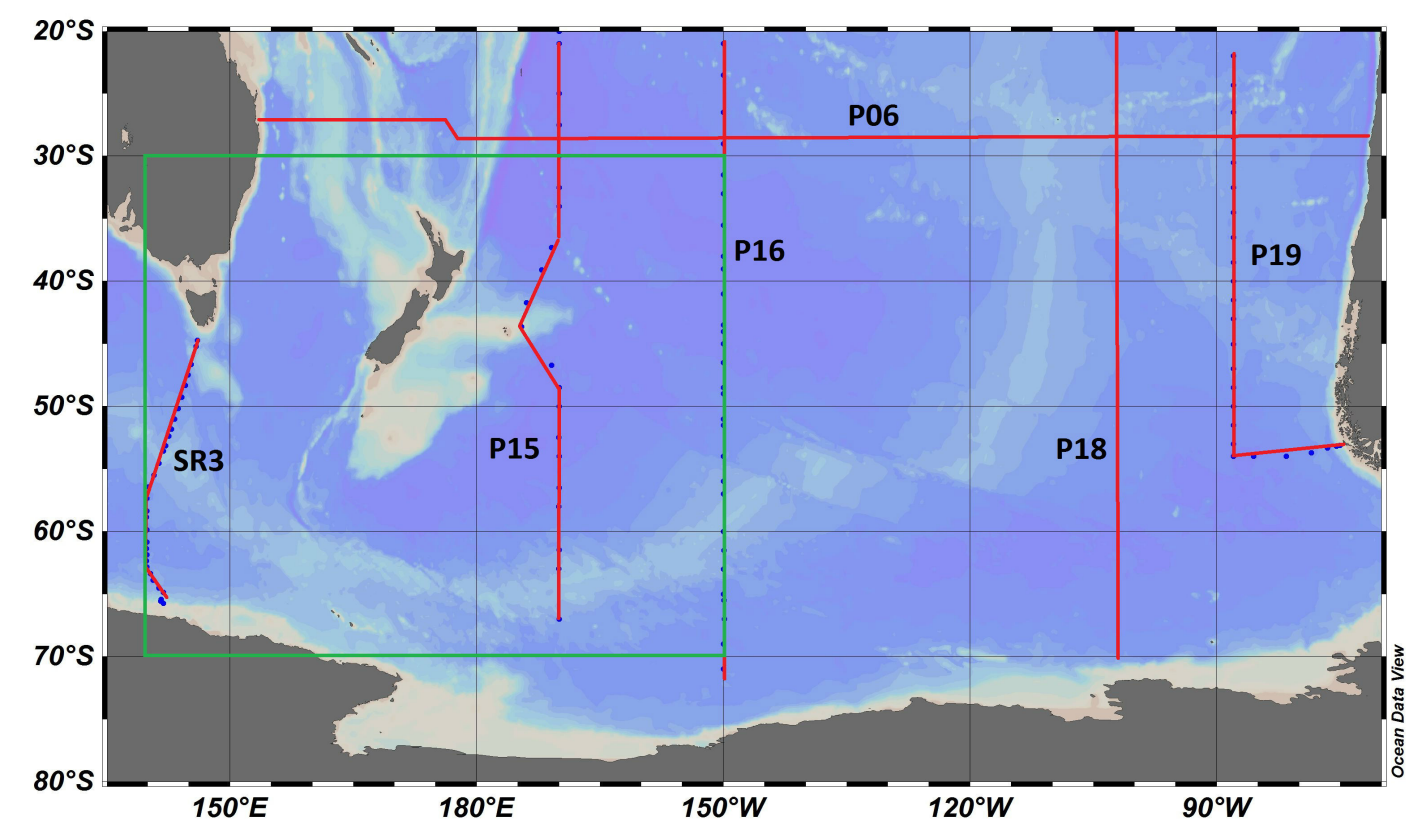

Figure 1.2: Six transects of ocean water data used for this study. Red lines indicate transects, green box indicates the region of study for this thesis, blue dots indicate locations of data collection. Section P15 described below.

P15, P16) because of its central location in the SW Pacific region.

In this study, the region is split into three distinct zones: the sub-tropical zone, sub-Antarctic zone, and polar zone (sometimes called the Antarctic zone). Boundaries between the zones comprise the three major oceanic fronts of the region (Figure 1.3). The fronts are the sub-tropical Front (STF; approximately $45^{\circ} \mathrm{S}$ ), Sub-Antarctic Front (SAF; approximately $55^{\circ} \mathrm{S}$ ), and the Antarctic Polar Front (PF; approximately $60^{\circ} \mathrm{S}$ ). Water masses in the Southwest Pacific/Southern Ocean are bounded by the fronts in three separate regions: the sub-tropical zone bounded by the STF in the south, the sub-Antarctic zone bounded in the north by the STF and in the south by the PF, and the polar zone bounded in the north by the PF and in the south by Antarctica. The area between the SAF and PF is the Antarctic Circumpolar Current (ACC). These three zones have distinct characteristics from each other. The fronts between the zones are usually characterized by large temperature, salinity, and density gradients, but also nutrient gradients in some cases. Note that the latitude given for each front is an approximate location for the modern front, as they vary due to topographic constraints, as well as varying seasonally (Kohfeld et al., 2013; Bostock et al., 2013; Sokolov and Rintoul 2009).

The major feature of the sub-tropical zone is the sub-tropical gyre (Figure 1.4). This gyre consists of four main currents found in all major oceans: western and eastern boundary currents, equatorial currents, and the STF. Western boundary currents are relatively strong currents which transport warm waters 


\section{Redacted due to copyright permissions}

(a) Surface

Figure 1.3: Circulation in the SW Pacific. Colors represent the approximate locations of fronts, water masses, and currents. Arrows represent direction of flow. $\mathrm{TF}=$ Tasman front, $\mathrm{STF}=$ subtropical front, $\mathrm{SAF}=$ sub Antarctic front, $\mathrm{PF}=$ Polar front $. \mathrm{STW}=$ subtropical water, $\mathrm{SAW}=$ sub Antarctic water, AASW= Antarctic surface waterColors represent the approximate locations of fronts, water masses, and currents. Arrows represent direction of flow. $\mathrm{TF}=$ Tasman front, $\mathrm{STF}=$ subtropical front, $\mathrm{SAF}=$ sub Antarctic front, $\mathrm{PF}=$ Polar front $. \mathrm{STW}=$ subtropical water, $\mathrm{SAW}=$ sub Antarctic water, AASW= Antarctic surface water. EAC= East Australian Current $(\mathrm{EACx}=\mathrm{EAC}$ extension$), \mathrm{EAUC}=$ East Auckland Current. Figure continued on next page. 


\section{Redacted due to copyright permissions}

(b) Intermediate

Figure 1.3: Colors represent the approximate locations of fronts, water masses, and currents. Arrows represent direction of flow. AAIW=Antarctic Intermediate water (numbered types from Bostock et al., 2013), SAMW=Sub Antarctic Mode water. Figure continued on next page. 


\section{Redacted due to copyright permissions}

(c) Deep

Figure 1.3: Colors represent the approximate locations of fronts, water masses, and currents. Arrows represent direction of flow. PDW= Pacific Deep water, LCDW/UCDW=Lower and Upper Circumpolar Deep water, AABW=Antarctic Bottom water. DWBC $=$ Deep Western Boundary Current. Figures from Chiswell et al., 2015. 


\section{Redacted due to copyright permissions}

Figure 1.4: Shown in peach is the sub-tropical gyre of the South Pacific. The gyre consists of an eastern and western boundary currents, shown here as the Peru/Chile current and East Australian current respectively. In the north it is bounded by the Equatorial current and the south by the Sub-Tropical Front (STF). Taken from Tomczack, 2005

poleward. In the South Pacific the main western boundary current is the East Australian Current which then flows into the East Auckland Current. The East Australian Current travels south along the Australian coast until $33^{\circ} \mathrm{S}$, where it turns east and travels across to New Zealand as the Tasman Front. Once there, the current traverses the east coast of the north island as the East Auckland Current and turns east into open ocean at $40^{\circ} \mathrm{S}$ along the northern Chatham Rise (Chiswell et al., 2015; Tomczak, 2005).

The STF is the southern boundary of this gyre. It is a front which typically sits around $40^{\circ} \mathrm{S}$ in most of the Southern Ocean, but is forced to $49^{\circ} \mathrm{S}$ in the SW Pacific by the shallow topography (Smith et al., 2013). In the open ocean the STF is wide, slow and diffuse as it travels across the Tasman and main South Pacific basins, but flow can strengthen at the edge of basins (such as the east coast of New Zealand; dynamic STF - Graham and De Boer (2013). East of New Zealand the STF is a narrow, strong dynamic front (Graham and De Boer, 2013; Smith et al., 2013).

Sub-tropical waters (STW) are defined as waters with a potential temperature $>15^{\circ} \mathrm{C}$ (Chiswell et al., 2015; Table 1.2) and are the most saline water in the region with a salinity $>35 \mathrm{psu}$. Nutrients are lowest of all the water-masses with levels $<0.25 \mu \mathrm{mol} / \mathrm{L}$.

The STF is also the boundary between the warm, salty, nutrient poor STW of the subtropical gyre and the cool, fresh, nutrient rich sub-Antarctic waters. Just south of the front this convergence creates a large region of high biologic activity due to the mixing of the water masses. At the STF, polar sourced sub-Antarctic waters and equatorial sourced STW mix, creating large surface 
temperature and salinity gradients seen in Figure 1.6a. The different surface water masses are clear in the oxygen and nutrients. Mixing occurs between the STF north to $35^{\circ} \mathrm{S}$ as sub-Antarctic waters crosses the STF, creating a high oxygen area north of the STF (Figure 1.6a,e). STW north of the front are low in macronutrients $\left(\mathrm{PO}_{4}, \mathrm{NO}_{3}{ }^{-}, \mathrm{SiO}_{4}\right)$ and high in micronutrients (such as iron) while Sub-Antarctic waters is high in macronutrients and low micronutrients (Chiswell et al., 2013). Iron availability restricts or enhances biologic productivity because iron is the limiting reactant in the chemical process of photosynthesis. Experiments have shown that increasing iron availability increases productivity and biomass in the ocean (Boyd et al., 2000; Gervais et al., 2002; Coale et al., 2004), exhibiting irons limiting role in biology. Therefore, mixing of STW and SAW at the STF creates a region well suited for biologic productivity due to the presence of both micro and macronutrients.

The SAF forms the northern boundary of the ACC. The SAF has multiple jets which transport most of the water in the ACC. Similarly to the STF the $\mathrm{SAF}$ is forced south around the New Zealand continent and associated ridges and plateau (Sokolov and Rintoul, 2009a;b). The PF is also deflected by the topography, and is made up of several jets, which are associated with most of the flow.

Sub-Antarctic waters (SAW) are defined as all water between the STF and SAF and has a relatively low salinity (34.25 $34.5 \mathrm{psu})$ and intermediate temperatures $\left(6-12^{\circ} C\right)$ (Tomczak 2005; Chiswell, 2015). The STF defines the boundary of waters sourced from the equator and waters sourced from the pole. Phosphate levels range from $0.5-1.5 \mu \mathrm{mol} / \mathrm{L}$, which is in stark contrast to the low phosphate sub-tropical waters.

The SAF forms the northern boundary of the ACC. The SAF has multiple jets which transport most of the water in the ACC. Similar to the STF the SAF is forced south around the Campbell Plateau and associated ridges (Sokolov and Rintoul, 2009a;b). The PF is also deflected by the topography, and is made up of multiple jets which are associated with most of the flow. The PF is associated with significant upwelling of cold, nutrient-rich lower circumpolar deep waters. The waters between the SAF and PF are not easily defined. They have been called various kinds of circumpolar surface waters (Heath, 1989a) or Antarctic surface waters (Sloyan and Rintoul, 2001). But the definition of Carter et al. (2008) as waters intermediate between sub-Antarctic waters and Antarctic surface waters seems to be the accepted definition (H. Bostock pers. comm; Chiswell et al., 2015).

To the south of the PF, Antarctic surface waters (AASW) are defined as all surface water from the PF to the Antarctic coast. Salinity levels are $<34$ psu 


\section{Redacted due to copyright permissions}

Figure 1.5: Schematic cross section of the Southern Ocean. Isopycnal lines show delineation of water masses. Bold arrows show flow direction, crosses show flow into page, dots; out of page. $\gamma^{n}$ show potential density surfaces, which are approximate water mass boundaries. Shaded areas show front zones to depth. Arrows at surface show subduction of water mass, small arrows at depth show mixing of water masses. Surface water masses as in figure 1.3 with $\mathrm{STFZ}=$ subtropical front zone and SACCF $=$ south antarctic circumpolar current front. SAMW=sub Antarctic mode water, $\mathrm{AAIW}=$ Antarctic intermediate water, $\mathrm{PDW}=$ Pacific deep water, $\mathrm{UCDW} / \mathrm{LCDW}=$ upper/lower circumpolar deep water, AABW=Antarctic bottom water. Taken from Chiswell et al. (2015)

with temperatures of $0-2^{\circ} \mathrm{C}$. These surface waters have relatively uniform properties from the PF south to Antarctica. This water mass is relatively thin since it is seasonal and circumpolar deep water is upwelling under it. It only reaches to $150 \mathrm{~m}$ depth at the $\mathrm{PF}$ and shoals to the south.

Below the surface waters of the sub-tropical zone and sub-Antarctic zone sit the sub-Antarctic mode water and Antarctic intermediate waters. sub-Antarctic mode water and Antarctic intermediate water form along the SAF formed by the subduction of Antarctic surface waters caused by deep winter mixing (>500 m; McCartney, 1977; Figure 1.5). Due to recent mixing in the surface waters and high rainfall along the SAF, these intermediate waters are fresher (low salinity), with high oxygen (Lynch-Stieglitz, 1994; Table 1.2).

Sub-Antarctic mode water (SAMW) sits just below the surface waters and above intermediate waters in the water column (Table 1.2). The distinguishing characteristics of SAMW are its temperature range $8-10^{\circ} \mathrm{C}$. That is a thick thermostad and associated pycnostad $\left(26.5-26.9 \mathrm{~kg} / \mathrm{m}^{3}\right)$ at $100500 \mathrm{~m}$ depth (Figure 1.6). SAMW differs very slightly from Antarctic intermediate water by slightly elevated levels of salinity ranging from 34.4-34.75 psu and phosphate levels with a range of $1.25-1.75 \mu \mathrm{mol} / \mathrm{L}$ respectively. Within transect $\mathrm{P} 15 \mathrm{~S}$, the Chatham Rise is a large bathymetric barrier. The barrier effect is most 


\begin{tabular}{l|l|l|l|l|l|l|}
\hline Water mass & Depth range $(\mathrm{m})$ & Latitude $\left({ }^{\circ} S\right)$ & \multicolumn{1}{l}{ PotTemp $\left({ }^{\circ} \mathrm{C}\right)$} & \multicolumn{1}{l}{ Salinity $(\mathrm{psu})$} & AOU $(\mu \mathrm{mol} / \mathrm{kg})$ & Phosphate $(\mu \mathrm{mol} / \mathrm{L})$ \\
\hline STW & $0-200$ & $<45$ & $>15$ & $>35$ & -20 & $<0.25$ \\
SAW & $0-200$ & $45-55$ & $6-12$ & $34.25-34.5$ & $0-10$ & $0.5-1.5$ \\
AASW & $0-200$ & $>55$ & $-2-2$ & $<34$ & $10-50$ & $1.5-2$ \\
SAMW & $200-500$ & $<55$ & $8-10$ & $34.4-34.75$ & $20-50$ & $0.75-1$ \\
AAIW & $500-1500$ & $<55$ & $4-8$ & $34.3-34.4$ & 50130 & $1.25-2$ \\
PDW & $1500-3000$ & $<50$ & $1-3$ & $34.25-34.5$ & $>175$ & $>2.5$ \\
UCDW & $200-2000$ & $>50$ & $1-3$ & $34.25-34.5$ & $150-175$ & 2.252 .5 \\
LCDW & $200-4000$ & $>50$ & $0-2$ & $34.5-34.75$ & $120-140$ & $2-2.25$ \\
AABW & $4000-$-bottom & Whole region & $-2-0$ & $34.5-34.75$ & $<50$ & $2-2.25$ \\
\hline
\end{tabular}

Table 1.2: Physical and chemical characteristics of the main water masses in this study.

prevalent in the oxygen and carbon sections (Figure 1.6) where elevated levels are seen to the south, and are blocked from penetrating north. There is no evidence for SAMW in the P15S transect, although SAMW is the dominant water mass on the Campbell Plateau just to the east of the transect (Morris et al, 2001). There is a weak pycnostad just south of $50^{\circ} S$ at 400 depth that suggests sub-Antarctic mode water is forming, but it may be swept east by the SAF/ACC, so the SAMW signal does not appear along this transect.

Antarctic intermediate water (AAIW) is the main intermediate water found throughout Southwest Pacific region and is defined as the salinity minimum (34.3-34.4 psu; Figure 2b) occupying 500-1500 m depth within the water column (Bostock et al., 2004, 2013; Chiswell et al., 2015; Table 1.2). The P15S transect shows a slight rise in salinity at the Chatham Rise. Oxygen is high as well with levels between $200-275 \mu \mathrm{mol} / \mathrm{kg}$ south of the rise and declining to the north as seen in Figure 1.6.

Below these intermediate waters sit the deep waters. In the South of the region these are Lower Circumpolar Deep Waters, which are a mix of Antarctic bottom waters, North Atlantic deep waters and other waters that are circulating around the ACC. These waters flow into the South Pacific Ocean along the deep western boundary current. The deep western boundary current, flows along with the ACC around the eastern flank of the Campbell Plateau until they reach the Bounty Trough where it detaches from the ACC and flows north around the Chatham Rise to the Kermadec Ridge (Chiswell et al.,2015), where it starts to mix with southward flowing old, high nutrient Pacific deep waters (Chiswell et al., 2015).

Pacific deep water (PDW) is the oldest water mass on the planet (Chiswell et al., 2015). It is passively formed by downward diffusion of cold, dense waters in the north Pacific and flows south. It is distinguished by its high nutrient, low oxygen signal. Specifically, phosphate levels $>2.35 \mu \mathrm{mol} / \mathrm{L}$ and oxygen levels $<175 \mu \mathrm{mol} / \mathrm{L}$ (Figure 1.6). In the south Pacific, south of the SAF, once 


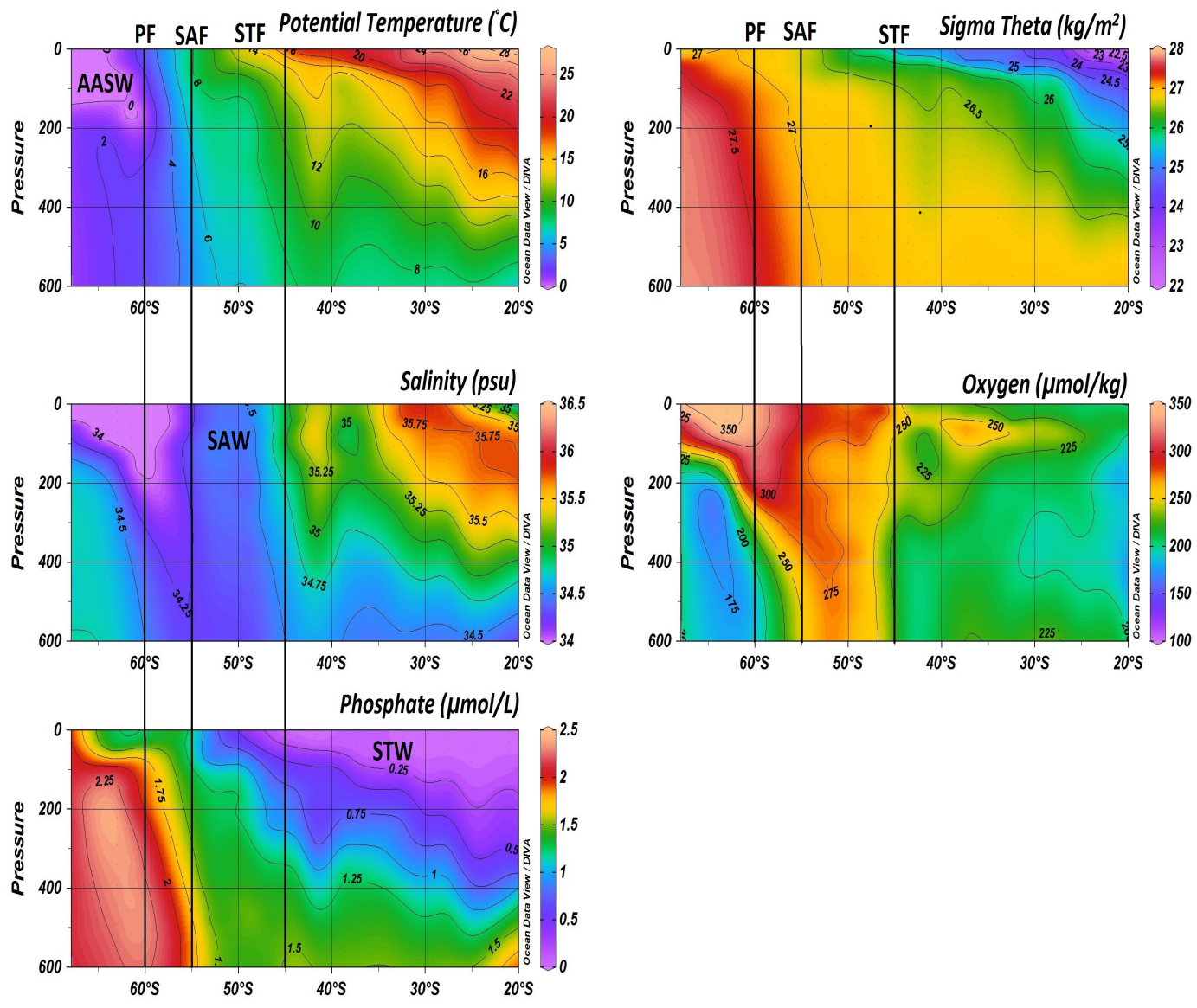

(a) Surface waters

Figure 1.6: Surface water chemical characteristics of transect P15. Figure continued on next page. 


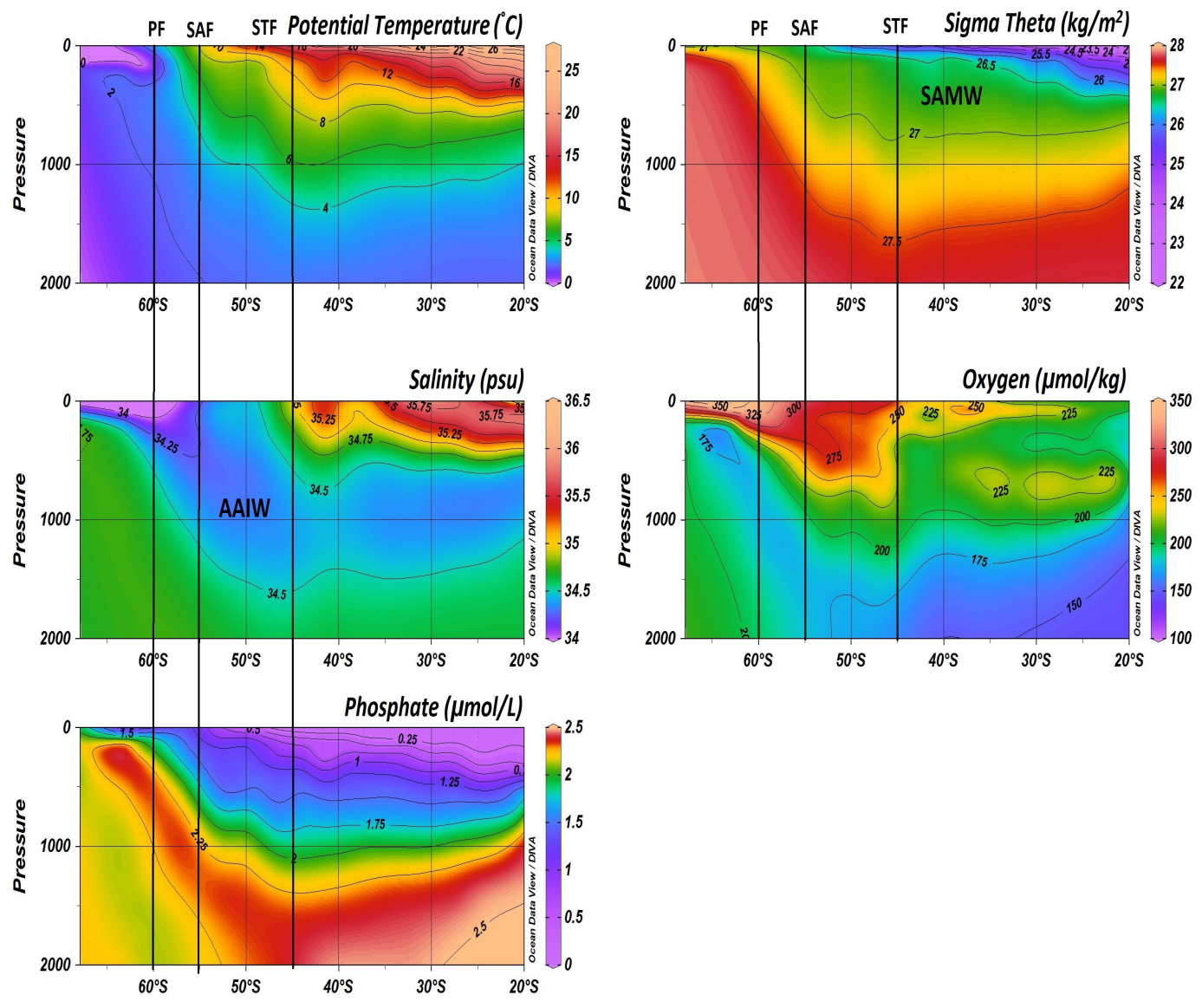

(b) Intermediate waters

Figure 1.6: Intermediate water chemical characteristics of transect P15. Figure continued on next page. 

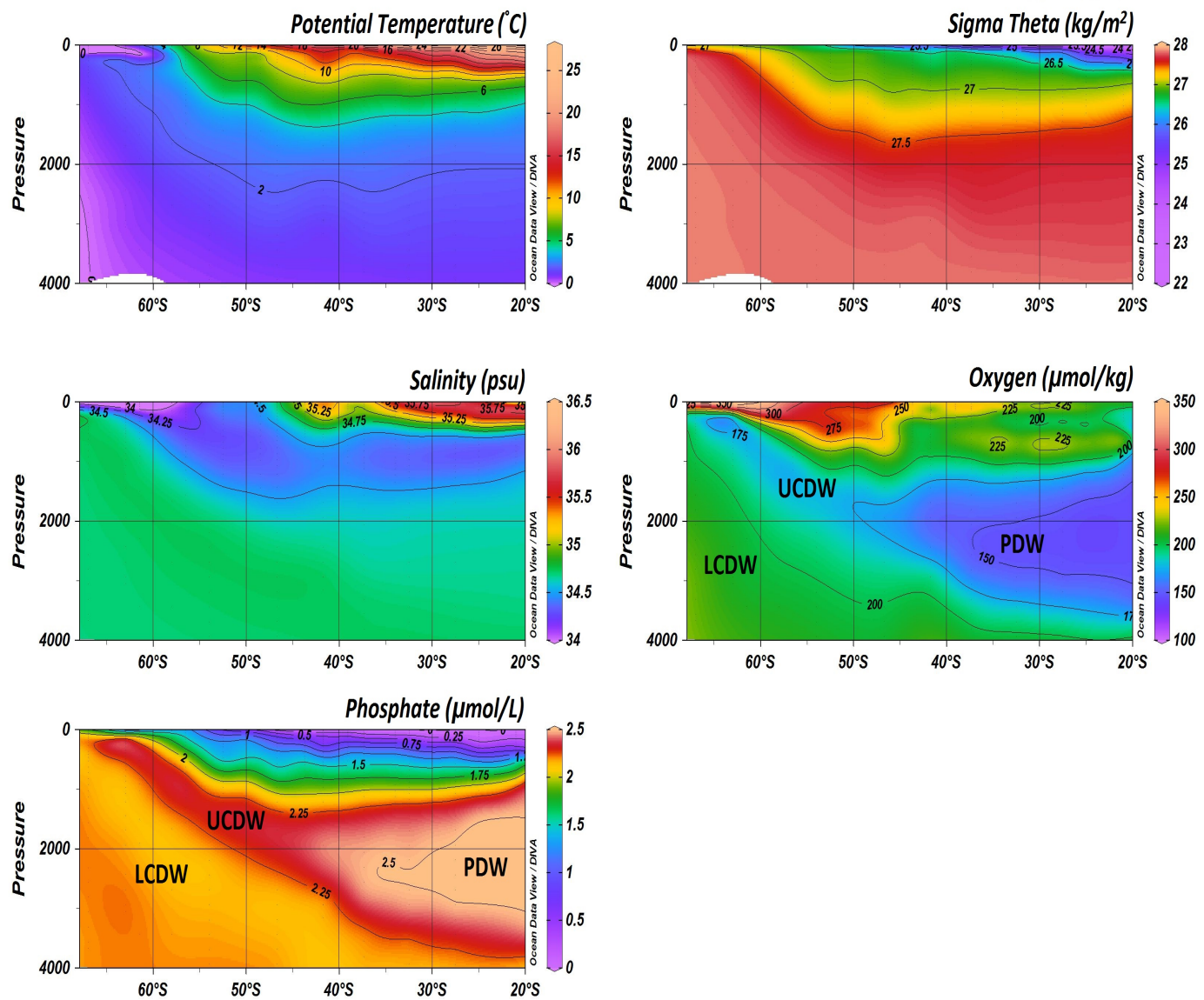

(c) Deep waters

Figure 1.6: Five physical and geochemical parameters that describe the water masses to depth along section P15. Water masses labelled where most obvious (ex:AASW on PotTemperature and STW on Nitrate). Sigma theta is potential density. Potential temperature measured in ${ }^{\circ} \mathrm{C}$, sigma theta in $\mathrm{kg} / \mathrm{m}^{3}$, salinity in psu, oxygen in $\mu \mathrm{mol} / \mathrm{kg}$, and phosphate in $\mu \mathrm{mol} / \mathrm{L}$ 
PDW enters the ACC, it mixes with circumpolar deep water which consists of Indian and Pacific deep water and other waters to form upper circumpolar deep water (Basak et al., 2015). This water mass is like Pacific deep water, but due to the mixing with the younger Indian Ocean deep water, has slightly different properties than PDW. Phosphate levels drop slightly, but retain their high within the ACC with levels between 2.25 and $2.35 \mu \mathrm{mol} / \mathrm{L}$. Oxygen levels of upper circumpolar deep waters are slightly higher than PDW (175-200 $\mu \mathrm{mol} / \mathrm{kg}$ ) due to mixing with the Indian Ocean deep water, but still relatively lower than the lower circumpolar deep water (Figure 1.6).

Lower Circumpolar Deep Water (LCDW) is slightly denser than Upper Circumpolar Deep Water at 27.55-28 $\mathrm{kg} / \mathrm{m}^{3}$ (Basak et al., 2015). LCDW is a mixture of North Atlantic deep water entering the ACC from the Atlantic and mixing with Antarctic bottom water along the boundary of the two water masses (defined as the $28 \mathrm{~kg} / \mathrm{m}^{3}$ pycnocline). LCDW upwells along the Antarctic coast and sinks along the continental margin with the densest waters $\left(>28 \mathrm{~kg} / \mathrm{m}^{3}\right)$ forming Antarctic bottom water and those $<28 \mathrm{~kg} / \mathrm{m}^{3}$ forming outflowing CDW (Figure 1.5). Both enter the New Zealand region within the deep western boundary current along the eastern flank of the Campbell Plateau (Figure 8). Antarctic bottom water flows north in the deep western boundary current and diffuses upward to mix with LCDW. LCDW flows north across the equator and into the north Pacific slowly mixing with PDW until they are indistinguishable from each other (in the north Pacific). Antarctic bottom water is not visible within the P15S section due to the low resolution of samples at depth and the few stations where the deep western boundary crosses P15S (Chiswell et al., 2015).

\subsubsection{Foraminifera}

Foraminifera are one of the most significant organisms in paleo-climate research due to their abundance throughout the worlds oceans. They form a calcareous shell (or test), with a range of different chambers, that has unique form within each species. This shell is a rich resource on paleoclimates because it partially incorporates the chemistry of the environment in which the organism lived. However, the environmental signal reflected in sea water $\delta^{13} C$ (and $\delta^{18} \mathrm{O}$ ) can be modified by varying amounts based on the varying chemistry of isotope incorporation of each species (vital effects). Therefore, understanding the chemistry of formation of these shells is imperative to any climate study utilizing these organisms.

This study will work with data from one species of foraminifera that live 
throughout the New Zealand region $\left(30^{\circ} S-70^{\circ} S\right)$ : Globigerina bulloides. G. bulloides is a non-symbiotic spinose species that is abundant in STW and SAW (Hemleben et al., 1989). It is representative of upwelling regions wherever it is found.

This study will utilize $\delta^{13} C$ as a proxy of climate change. The $\delta^{13} C$ of a foraminiferal test is controlled by five factors: Changes in exchange between terrestrial and oceanic carbon reservoirs, biologic productivity, water mass characteristics, species specific biological vital effects, and differential preservation (Hemleben et al., 1989).

1) Changes in terrestrial carbon storage are brought on by a change to glacial conditions that reduce plant growth by colder temperatures, increased aridity, and the presence of large ice sheets on land (Peterson et al., 2014). These conditions cause large quantities of carbon to move from the land to ocean, causing large depletions in $\delta^{13} C$, due to stored ${ }^{12} C$ entering the oceans, during glacial times (Peterson et al., 2014). These changes can also alter ocean carbon chemistry and therefore, $\mathrm{pH}$ and carbonate ion concentrations. The carbonate ion effect (as described by Spero et al., 1997) also lowers $\delta^{13} C$ levels in foram tests as $\left(\mathrm{CO}_{3}^{2-}\right) \mathrm{pH}$ levels increase. This affects all foram species, but the magnitude of this effect varies from species to species (Spero et al., 1997). 2) Biologic activity is the main influence on $\delta^{13} C$. Higher primary productivity will enrich the surface waters in ${ }^{13} C$, resulting in higher $\delta^{13} C$ in the foraminifera tests. Regions of lower productivity will have lower $\delta^{13} C$. This, in turn, changes the carbon isotopic characteristics of a water mass, which is also affected by air-sea exchange (Section 1.1.2). Through these two mechanisms, as a surface water mass circulates around an ocean basin, it mixes with other water masses that create new $\delta^{13} C$ characteristics of the surface waters. This mixing occurs to depth as well as spatially. As organisms die and sink, their shells and organic tissue are remineralized and they release their ${ }^{12} C$ back into the ocean, decreasing $\delta^{13} C_{D I C}$ at depth. A water mass at a certain depth then carries the discreet $\delta^{13} C$ signal of that depth and location through its circulation path, mixing with other regions and water masses, further changing the $\delta^{13} C_{D I C}$ signal as it travels.

3) Vital effects encompass all the ways a foraminifera actively fractionates isotopes when forming its shell. Carbonate precipitation within the cell of a foraminifera is thought to be controlled by two mechanisms: endocytosis or transmembrane ion transport via pumps and diffusion (Bentov et al., 2009; de Nooijer et al., 2014). Which mechanism is utilized more is poorly understood for planktic forams and varies from species to species. Furthermore, how these ions are transported within the cell is not well understood either: are the ions 
brought into the cell and stored for later use or are they directly transported to the precipitation site (de Nooijer et al., 2014) Precipitation rate controls the isotopic fractionation of the precipitated $\mathrm{CaCO}_{3}$ with slow precipitation favoring $\mathrm{Ca}^{13} \mathrm{CO}_{3}$ and fast precipitation favoring $\mathrm{Ca}^{12} \mathrm{CO}_{3}$ (Zeebe et al., 1999). Symbionts within a foraminifer may affect the rate of precipitation by changing the amount of DIC available to precipitate (de Nooijer et al., 2014) and changing the foraminiferal microenvironment by enriching it in ${ }^{13} C$ through photosynthesis (Bemis et al., 2000). The point is that isotopic fractionation due to vital effects within foraminifera is poorly understood. This fact must be taken into account when using $\delta^{13} C$ of foraminiferal tests to determine any paleoclimate conditions.

4) Differential preservation and dissolution accounts for changes in shell chemistry after the organism has died. Differences in shell structure and depth of deposition control isotopic variation within a shell (Bonneau et al., 1980; Erez and Honjo, 1981). Deposition at or below the calcite lysocline can cause partial dissolution of a shell due to the undersaturation of $\mathrm{CO}_{3}^{2-}$ of sea water at depth. Fluctuations in the depth of the lysocline and Carbonate Compensation Depth (CCD) through time must be considered for studies $>10^{6}$ yrs in length. The CCD in New Zealand region is located between $4000 \mathrm{~m}$ and $4600 \mathrm{~m}$ depth, with a shallower CCD northeast of New Zealand and a deeper CCD to the southeast (Bostock et al., 2011).

\subsection{Glacial/Interglacial change in $\delta^{13} C$}

\subsubsection{Biologic pump}

The biologic pump describes the process of primary productivity biologically fixing carbon at the ocean surface and transporting it to the deep ocean (Redfield, 1958). This mechanism is thought to be a major contributor to the variation in $\mathrm{CO}_{2}$ in transitions from interglacials to glacial periods and is influenced by the availability of nutrients (Watson et al., 2000; Martin, 1990). Increased nutrient availability is thought to increase efficiency of the biologic pump and draw down 40-50 ppm $\mathrm{CO}_{2}$ from the atmosphere and store it in the oceanic carbon reservoir during transitions from interglacial to glacial periods (Martinez-Garcia et al., 2009). Conversely, transitions from glacial to interglacial conditions should release the same amount of $\mathrm{CO}_{2}$ back into the atmosphere due to a decrease of efficiency in the biologic pump. Currently, nutrients reach the Southwest Pacific through upwelled deep waters that are transported north as SAW, AAIW, and SAMW (Chiswell et al, 2015). 
During glacial times, sea ice coverage was much more extensive and/or upwelling was much less vigorous than it is today (Buchanan et al., 2016; Gottschalk et al., 2016; Ferry et al., 2015). Therefore, there may have been considerably less macro-nutrients than today, but productivity may have been supplemented or enhanced by terrestrial dust fluxes bringing the micronutrient iron (Fe) into the oceans (Chase et al., 2003; Watson et al., 2000; Martin, 1990). Alternatively, a reorganization of oceanic circulation led to enhanced productivity (Bostock et al., 2015; Carter et al., 2008; Neil et al., 2004). Therefore, multiple mechanisms control how efficient the biologic pump is in a certain location. Determining how the biologic pump has changed in the New Zealand region, will provide a clearer picture of how much it has contributed to glacial/interglacial climate change.

\section{Dust flux}

Dust flux is synonymous with the iron fertilization hypothesis which was first described by Martin (1990). This hypothesis was used to explain why there is excess nitrate and phosphate in the Southern Ocean surface waters in modern times. Iron is essential to photosynthetic life on earth because chlorophyll cannot be synthesized without it (Reuter and Adez, 1987). Therefore, if iron is limited, there is an upper limit to any biologic activity regardless of other nutrient levels. Martin (1990) found that iron is limited in some regions of the ocean and that with an increase of (bioavailable) iron concentrations in the water, larger populations of photosynthetic organisms could be sustained, and the biologic pump could be more efficient. By looking at dust records from the Vostok ice core, he found that dust levels were inversely proportional to atmospheric $\mathrm{CO}_{2}$ levels, and hypothesized that increased terrestrial dust (Fe) export into the oceans was potentially a major factor in the $\mathrm{CO}_{2}$ drawdown that began the last glaciation (Martin, 1990).

Dust during glacial periods is much higher than interglacial periods but is spatially variable due to terrestrial biology coverage and wind patterns (Martinez-Garcia et al., 2009). Dust flux during the glacial was largest in the SO, specifically, the Atlantic sector (Maher et al., 2010; Martinez-Garcia et al., 2009). Dust flux is generally higher during glacial periods, but variability in source is not uncommon (Martinez-Garcia et al., 2009; Rothlisberger et al., 2002). Most dust during the LGM in the southern hemisphere was sourced mostly from Patagonia and southern South America (Martinez-Garcia et al., 2014; Maher et al., 2010; Chase et al., 2003; Rothlisberger et al., 2002). Modern dust fluxes in the New Zealand region are some of the lowest in the world at 
around $0.05 \mathrm{~g} / \mathrm{cm}^{2} / \mathrm{yr}$ (relative to the Atlantic at 0.1 to $0.15 \mathrm{~g} / \mathrm{cm}^{2} / \mathrm{yr}$ ) (Chase et al., 2003; Honjo et al., 2000). Although new evidence suggests that LGM dust flux was similar in the Pacific and Atlantic with levels of $>0.8 \mathrm{~g} / \mathrm{cm}^{2} / \mathrm{yr}$ (Lamy et al., 2014).

\section{Nutrient utilization}

If nutrient utilization were higher than the modern in the LGM, it may be inferred that iron fertilization had a significant impact on biology. An alternative hypothesis states that if more nutrients were available, iron fertilization had little effect on biology. Consensus is that during the glacial and LGM, nutrient utilization was higher based on $\delta^{15} N_{D I C}$ (Robinson and Sigman, 2008; Robinson et al., 2005; Crosta and Shemesh, 2002; Altabet and Francois, 1994; Francois et al., 1992). This suggests that iron fertilization was a significant impact on the biology levels during the glacial. However, impediments or reduction of upwelling in the $\mathrm{PZ}$ most likely reduced nutrient transport to the SAZ (Figure 4) (Bostock et al., 2013; Sigman et al., 2010; Robinson and Sigman, 2008).

\subsubsection{Westerly wind changes}

Evidence points to the upwelling of deep, carbon rich water releasing $\mathrm{CO}_{2}$ as another significant player in the $\mathrm{CO}_{2}$ rise at the end of the glacial. Debate over how this occurred has been divided into two hypotheses: First, during the glacial, shifts in the position and strength of the westerly wind belt reduced the intensity of the upwelling in the Southern Ocean, preventing deep water interaction with the atmosphere at the surface (Gottschalk et al., 2016; Anderson et al., 2009, Toggweiler et al., 2006). Second is that winter sea ice impeded upwelling deep water, coupled with a reorganization of circulation, isolating the deep water carbon reservoir and preventing it from interacting with the atmosphere (Ferry et al., 2015; McCave et al., 2008; Robinson and Sigman, 2008).

It is thought that an increase in wind strength, at the end of the glacial, corresponds to a poleward shift and increased upwelling (Rojas et al., 2009, 2013). Weaker winds are therefore thought to correspond to equatorward shifts and less upwelling. This is consistent with the modern westerly wind belt moving poleward with increasing $\mathrm{CO}_{2 a t m}$ levels over the past 40 years (Hurrel and van Loon, 1994). Given this is true, a weaker westerly wind belt would decrease Ekman transport to the north, which would decrease the flux of upwelled water coming to the surface. Sigman et al. (2010) argue that with a decreased up- 
welling regime, bottom water production would decrease as well, since bottom water production is tied to the upwelling of deep water. But AABW was the dominant deep water in the global ocean due to the slowdown in NADW production (McCave et al., 2008; Moy et al., 2006; Ninneman and Charles, 2002; Hall et al., 2001). This contradiction highlights that the westerlies cannot themselves control upwelling and isolate the deep water carbon pool.

\section{Sea ice}

Studies point to sea ice as an impediment to upwelling of deep waters along the Antarctic continental shelf during the glacial (Figure 1.5)(Buchanan et al., 2016; Gottschalk et al., 2016; Ferry et al., 2015; Robinson and Sigman, 2008; Stephens and Keeling, 2000). They argue sea ice limits the influence the atmosphere has on the surface waters compared to if there was no sea ice. But sea ice is a player in climate, growing and shrinking as temperatures rise and fall. Toggweiler et al. (2006) and Robinson and Sigman (2008) propose that sea ice and the westerlies are two links in an ocean-atmosphere feedback loop that can lead to glacial periods. As climate cools, the westerlies weaken and move north, upwelling decreases, and sea ice expands. As a result of decreased upwelling and increased sea ice cover, the deep water carbon reservoir decreases interaction with the atmosphere because less comes to the surface and there is less ocean-atmosphere exchange with a larger sea ice pack. This leads to a positive feedback that grows sea ice as the westerlies weaken and eventually isolates the deep water carbon pool from the atmosphere (Robinson and Sigman, 2008; Toggweiler et al., 2006).

During the deglaciation, the opposite would be the case: westerlies strengthen and sea ice shrinks in response to warming, which allows $\mathrm{CO}_{2}$ release from deep water to occur. With $\delta^{13} C_{D I C}$, a test of this hypothesis would be to look for large decreases in $\delta^{13} C_{D I C}$ values throughout the study region. As sea ice retreats, intermediate waters are imprinted with the low $\delta^{13} C_{D I C}$ signal of deep waters (Anderson et al., 2008; Toggweiler et al., 2006).

It has been shown that glacial periods have been controlled by the earths eccentricity cycle over the last 500ka (Hays et al., 1976; Lisiecki et al., 2008, Spero and Lea, 2002; Imbrie et al., 1992). Studies also link thermohaline circulation strength and Southern Ocean upwelling to these cycles as well (Lisiecki et al., 2008, Spero and Lea, 2002). They argue that an invigorated thermohaline circulation caused increased upwelling and NADW formation. An increase in upwelling would initially contribute low $\delta^{13} C_{D I C}$ values to the intermediate and surface waters by imprinting them with low $\delta^{13} C_{D I C}$ deep water signals 
(Spero and Lea, 2002). Simultaneously, as low $\delta^{13} C_{D I C} C_{2}$ was released from deep waters to the atmosphere, air-sea exchange would equilibrate surface waters with these lower values (Bostock et al., 2004; Spero and Lea, 2002).

\subsubsection{Ocean circulation}

Changes in westerly winds also caused a reorganization of regional ocean circulation. In the SW Pacific these changes manifested themselves as a change in the position of the STF. Intermediate waters in the glacial were sourced from the pole (Bostock et al., 2004, Neil et al., 2004). Weakened circulation in the glacial decreased transport from the sub-tropical gyre and East Australian Current, allowing polar sourced waters to dominate the New Zealand region. As temperatures rose during the deglaciation, increased transport of the East Australian Current and sub-tropical gyre brought salty, warm water south to the Bay of Plenty (Schiraldi et al., 2014). Increased transport allowed mixing and a shift south of the STF along the west coast of the South Island, causing a regime change in surface water in the Solander Trough.

The Antarctic cold reversal (ACR) is the only other significant reorganization event in the study period. It represents an interruption of the warming trend from the deglaciation in the southern hemisphere (Jouzel et al., 1995). Essentially what the ACR encompasses is a regression in terms of oceanic SST, circulation and productivity (Pedro et al., 2015; Ferry et al., 2015; Samson et al., 2005). A decrease in SST and increase in sea-ice characterize this period (14-12.5ka) around New Zealand (Pedro et al., 2015; Ferry et al., 2015; Samson et al., 2005).

\subsection{Summary}

This thesis will attempt to quantify three things. First, the modern distribution of $\delta^{13} C$ in the Southwest Pacific and Southern Ocean. Second, how comparable are core top $\delta^{13} C$ values and modern $\delta^{13} C$ values in the ocean? Third, downcore changes in $\delta^{13} C$ and the reasons behind the changes. In chapter 2 , models of $\delta^{13} C$ will be utilized to create a surface distribution based on a multiple linear regression comparing modern water chemistry to $\delta^{13} C$. The New Zealand region is very sparse in $\delta^{13} C$ data, and this will be the first attempt at high resolution modelling for the region. Chapter 3 will take this model and compare surface $\delta^{13} C_{D I C}$ to core top foram $\delta^{13} C$ values. Before this can be done, a model of pre-industrial $\delta^{13} C$ must be made to accurately compare core top data with model $\delta^{13} C_{D I C}$. This chapter is a much a test of the models from 
the previous chapter as it is a link between water and core chemistry. Chapter 4 looks back through time at changes in $\delta^{13} C$. The cores have been split into regions based on oceanographic conditions. Three main hypotheses have been identified from the literature to describe glacial/interglacial transitions:

1. The biologic pump becomes inefficient, drawing down less $\mathrm{CO}_{2}$ from the atmosphere and allowing atmospheric $\mathrm{CO}_{2}$ levels to rise, causing warming.

2. The Southern Hemisphere westerly wind belt moves south and strengthens, increasing upwelling in the Southern Ocean and releasing $\mathrm{CO}_{2}$ from the deep ocean carbon reservoir.

3. Changes in the Meridional Overturning Circulation promoting upwelling and $\mathrm{CO}_{2}$ release from the deep ocean carbon reservoir.

I hypothesize that the changes seen in the downcore data are primarily related to changes in the global carbon cycle since the last glacial period, with additional impacts from changes in the south westerly winds altering ocean circulation in the SW Pacific and Southern Ocean.

In each chapter, I attempt to answer specific research questions:

Chapter 2

- How does $\delta^{13} C$ relate to other oceanographic parameters? Can these parameters accurately depict $\delta^{13} C$ distribution?

- What is the latitudinal change of $\delta^{13} C$ ? Does the model accurately capture it?

- Does $\delta^{13} C$ characterize water-masses and, if so, what are the different water-mass $\delta^{13} C$ signals?

Chapter 3

- Are core top $\delta^{13} C$ values like modern values?

- Does Globigerina bulloides capture surface water $\delta^{13} C$ values?

- Does core top foraminiferal $\delta^{13} C$ accurately depict modern or pre-industrial $\delta^{13} C_{D I C}$ values? Or is there no correlation?

Chapter 4

- Does the latitudinal $\delta^{13} C_{\text {foram }}$ distribution change through time? 
- How does the $\delta^{13} C_{\text {foram }}$ compare by zone and time slice?

- Based on all available knowledge, what could be causing the changes seen in $\delta^{13} C_{\text {foram }}$ through time? 


\section{Chapter 2}

\section{Modern distribution of $\delta^{13} C$ in the South Pacific}

\subsection{Abstract}

The aim of this chapter is to use a model to describe the distribution of surface water $\delta^{13} C$ in the New Zealand region $\left(30-70^{\circ} S, 140^{\circ} E-150^{\circ} \mathrm{W}\right)$. A lack of $\delta^{13} C$ data in the region makes it difficult to accurately define the $\delta^{13} C$ distribution in the region. Therefore, comparing $\delta^{13} C$ to more commonly measured oceanographic parameters was considered useful. $\delta^{13} C$ data was taken from World Ocean Circulation Experiment (WOCE) and Global Ocean Shipbased Hydrographic Investigation Program (GOSHIP) transects P06, P15S, P16, and P19 to run through a multiple linear regression (MLR). To test the MLR of these transects, the model was boostrapped into the data of transects SR3 and P18. It was found that $\delta^{13} C$ significantly corresponds $\left(R^{2}>0.75\right)$ to six parameters (potential temperature, salinity, potential density, phosphate, silicate, and oxygen). Each transect was then split into three zones based on oceanographic conditions at the surface: sub-tropical zone $\left(30-45^{\circ} \mathrm{S}\right)$, sub-Antarctic zone $\left(45-55^{\circ} \mathrm{S}\right)$, and polar zone $\left(55-70^{\circ} \mathrm{S}\right)$. Multiple linear regression equations were found for each region based on the fit of the above stated transects. These data and zones were found to poorly constrain $\delta^{13} C$ distribution around New Zealand ( $\mathrm{SAZ}$ and PZ $\left.\mathrm{R}^{2}=0.91 ; \mathrm{STZ} \mathrm{R} \mathrm{R}^{2}=0.55\right)$. Therefore, a new model was created by the same multiple linear regression technique using temperature, salinity, density, and oxygen $\left(R^{2}=0.92\right.$ for the whole region). This new regression equation was applied to the World Ocean Atlas hydrographic dataset to create a model of $\delta^{13} C$ throughout the region. 


\section{$2.2 \quad$ Introduction}

In this chapter I will describe the modern distribution of $\delta^{13} C$ measured on dissolved inorganic carbon in the water from the Southwest Pacific and Southern Ocean and how it compares to the physical oceanography. Understanding the modern $\delta^{13} C$ distribution is essential to understanding how $\delta^{13} C$ may have changed in the past. Due to this dearth of data there are large portions of the study region that have no measured $\delta^{13} C$ data. To expand the data coverage in this region I have used multiple linear regression (MLR) to extrapolate $\delta^{13} C$ data for the entire region in order to determine the spatial variation of modern $\delta^{13} C$.

\subsection{Methods}

\subsubsection{Data}

Data for this chapter were obtained from World Ocean Circulation Experiment (WOCE)/GOSHIPS transects across the South Pacific and Southern Ocean (Figure 1.2). WOCE operated in the 1990s and its objective was to obtain sufficient tracer data to create a profile of the chemical and physical properties of the modern ocean. GOSHIPS is the next generation of WOCE and its goal is to obtain sufficient information from the oceans to quantify changes caused by anthropogenic $\mathrm{CO}_{2}$ production. The transects used in this study are longitudinal transects SR3 $\left(140^{\circ} \mathrm{E}\right), \mathrm{P} 15\left(170^{\circ} \mathrm{E}\right), \mathrm{P} 16\left(170^{\circ} \mathrm{W}\right), \mathrm{P} 18\left(103^{\circ} \mathrm{W}\right)$, and $\mathrm{P} 19\left(88^{\circ} \mathrm{W}\right)$, and latitudinal transect P06 $\left(32^{\circ} S\right)$ see Table $2.1 /$ Figure 1.2 . In both WOCE and GOSHIPS, many geochemical tracers have been measured or derived to understand physical and chemical mixing and changes in the modern ocean. These tracers include: temperature, salinity, oxygen (Dissolved $\mathrm{O}_{2}$, AOU (Apparent Oxygen Utilization), $\mathrm{O}_{2}$ saturation), nutrients (nitrate $\left(\mathrm{NO}_{3}\right)$, phosphate $\left(\mathrm{PO}_{4}\right)$, silicate $\left.\left(\mathrm{SiO}_{2}\right)\right)$, and carbon (total dissolved $\mathrm{CO}_{2}$ ( $\mathrm{TCO}_{2}$; herein referred to as Dissolved Inorganic Carbon), alkalinity, ${ }^{14} \mathrm{C}$, $\delta^{13} C$, chlorofluorocarbons (CFC)).

$\delta^{13} C$ is measured on Dissolved Inorganic Carbon (DIC). On the ship, water samples are collected from Niskin bottles on the CTD that have sampled different depths of the ocean. These samples of DIC and $\delta^{13} C$ are preserved with $\mathrm{HgCl}_{2}$ to prevent $\mathrm{CO}_{2}$ generation via respiration before being stored and shipped to a lab for analysis. In the laboratory, samples are acidified and various gasses are used to extract the $\mathrm{CO}_{2}$ (McNichol et al., 2000, Quay et al., 1992). The $\mathrm{CO}_{2}$ gas is run through the mass spectrometer, and based on the 


\begin{tabular}{|l|l|l|l|}
\hline Transect & Dates & Ship & Principal scientist \\
\hline SR3 & $04 / 01 / 2011-06 / 02 / 2011$ & RV Aurora Australis & S. Rintoul \\
\hline P15S & $05 / 01 / 1996-10 / 03 / 1996$ & RV Discoverer & J. Bullister/R. Feely \\
\hline P16 & $09 / 01 / 2005-19 / 02 / 2005$ & RV Revelle & B. Sloyan/J. Swift \\
\hline P18 & $15 / 12 / 2007-23 / 02 / 2008$ & RV Ronald H. Brown & J. Bullister \\
\hline P19 & $22 / 02 / 1993-13 / 04 / 1993$ & RV Knorr & S. Rintoul \\
\hline P06 & $21 / 11 / 2009-10 / 02 / 2010$ & RV Melville & A. Macdonald/R.Curry \\
\hline
\end{tabular}

Table 2.1: List of transects used for this study. All data found at https://cchdo.ucsd.edu/

atomic weight of the molecule, carbon and oxygen isotope values are produced. Analysis error of $\delta^{13} C$ via these methods is cited as $0.03-0.05 \%$ ( McNichol et al., 2000, Quay et al., 1992).

AOU is the Apparent Oxygen Utilization and is derived from dissolved oxygen. It is the difference of expected oxygen levels (based on chemical properties of the water) and measured oxygen levels. Properties such as temperature and biologic productivity can change AOU in a water-mass. AOU is measured in units of $\mu \mathrm{mol} / \mathrm{L}$. In the World Ocean Atlas (WOA) database, AOU is given in units of $\mathrm{mL} / \mathrm{L}$. Thus, conversion was needed. The equation $(44.6596 * \mathrm{AOU})$ $* 1 / \mathrm{d}$ was used to correct the AOU data. AOU are the data in $\mathrm{mL} / \mathrm{L}$, $\mathrm{d}$ is the seawater density calculated from the equation of Millero and Poisson (1980).

As the WOCE/GOSHIP transects are so far apart (>20 degrees longitude) there are large areas of the ocean that we have no $\delta^{13} C$ data. I used a multiple linear regression algorithm using hydrographic and geochemical tracers to interpolate the $\delta^{13} C$ between the transect lines. This is especially important in the New Zealand region as the fronts and currents are complex due to the underlying topography and there are sparse $\delta^{13} C$ data available (Figure 1.2).

\subsubsection{Models}

The program $\mathrm{R}$ was used to develop the MLR models. Within $\mathrm{R}$, the $\mathrm{lm}$ function was used to fit the proxy data to that of the $\delta^{13} C$ (Chambers, 1992; Wilkinson and Rogers, 1973). Our baseline confidence interval was $R^{2}>0.75$ for any fit. This value was chosen because I thought it reasonable to expect $75 \%$ of the $\delta^{13} C$ variance to be explained by the regression. Data from longitudinal transects P15, P16, and P19 (Figure 1.2) were used to fit the $\delta^{13} C$ data in each of the zones. These three were chosen because they were all sampled during austral summer (Jan-Mar). Once run, the coefficients of each parameter were determined and model values created. Data from two other longitudinal 
transects SR3 and P18 (Figure 1.2, Table 2.1) were then bootstrapped into the model to test its validity (Bootstrapping is estimating values from one dataset using a regression and then testing the regression on another, independent, dataset). These two transects were sampled at different times of the year and were used to test whether the model is able to capture seasonal variability.

The residuals between the model and the data were plotted against latitude, depth, and density. By plotting the residuals against latitude it was hoped to determine if there were any regions that had large residuals and needed to be considered separately. Depth and density versus residuals were then used to determine if any single water mass was somehow skewing the data. The final model was created by selecting the model that was the best fit of the data and applying the model equation to WOA seasonal data (climatology). The data have $1^{\circ} \mathrm{x} 1^{\circ}$ resolution and are available for all the world seas and oceans. Seasonal data from WOA was used to create a model for each season. Only the region of study is considered by the model and will be used to match each $\delta^{13} C$ value to core tops in Chapter 3 of this thesis.

\subsection{Results}

\subsubsection{Observations of $\delta^{13} C$}

Surface waters will have a significant role in this study. Planktic foraminifera live and build their individual tests in these waters. Understanding how they form their $\delta^{13} C$ signatures will elucidate any changes we see in down core studies. As stated in chapter 1, STW are sourced from the north in the

\begin{tabular}{|l|l|}
\hline Water mass & $\delta^{13} C \mathbf{( \% )}$ \\
\hline STW & $1.25-1.9$ \\
\hline SAW & $1.75-2$ \\
\hline AASW & $0.75-1.25$ \\
\hline SAMW & $1-1.5$ \\
\hline AAIW & $1-1.5$ \\
\hline PDW & $0-0.5$ \\
\hline UCDW & $0.25-0.5$ \\
\hline LCDW & $0.25-0.5$ \\
\hline AABW & $0.5-0.75$ \\
\hline
\end{tabular}

Table 2.2: $\delta^{13} C$ values of the different water-masses. zone has the highest biologic productivity in the entire New Zealand region, saltiest waters in the region with a low macronutrient signal. STW has a low $\delta^{13} C$ signature because of the low nutrient signal of the subtropical gyre (Figure 2.1a) (Chiswell et al., 2015; Tomczak, 2005). Through biologic production and transport along the sub-tropical gyre, these waters lose their nutrients and gain the higher $\delta^{13} C$ levels (1.25-1.7\% ) seen in the New Zealand region (Table 2.2).

It is only the convergence with the cooler, more nutrient rich SAW at the STF that creates the zone of high productivity of the STFZ. This New Zealand region. They are the warmest, 


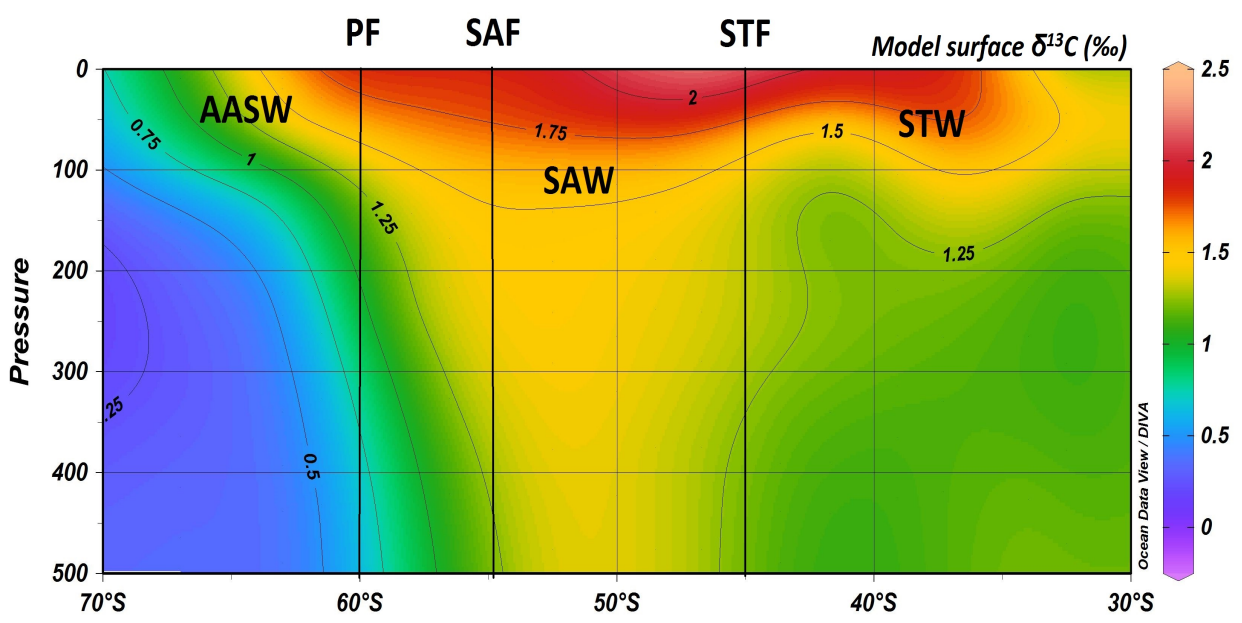

(a) Surface

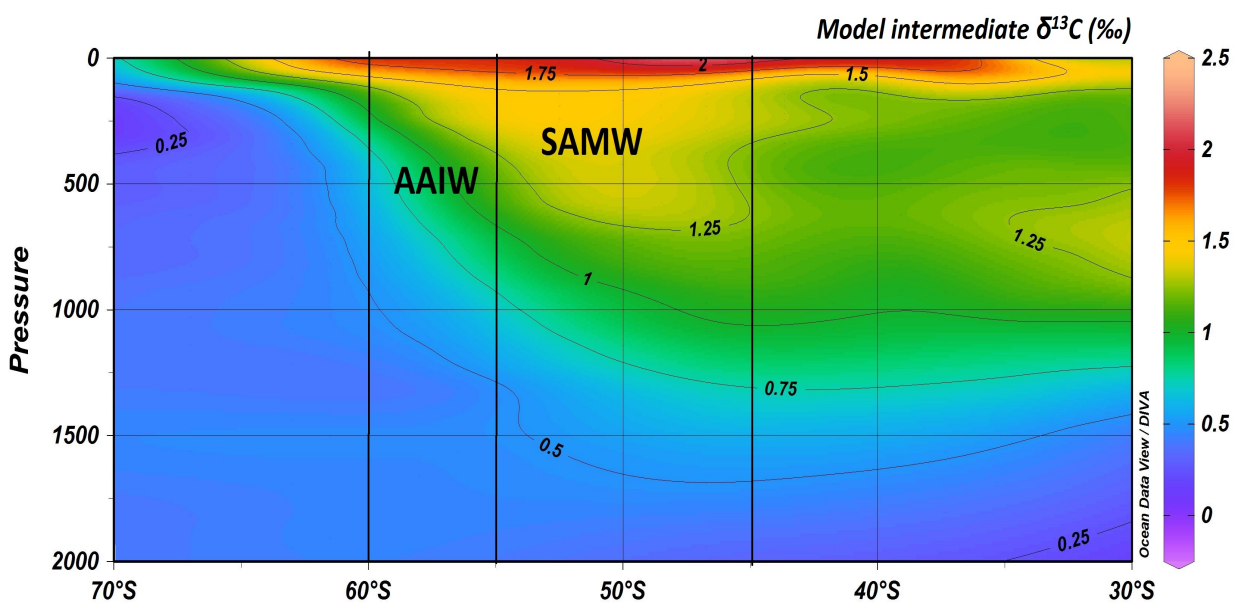

(b) Intermediate

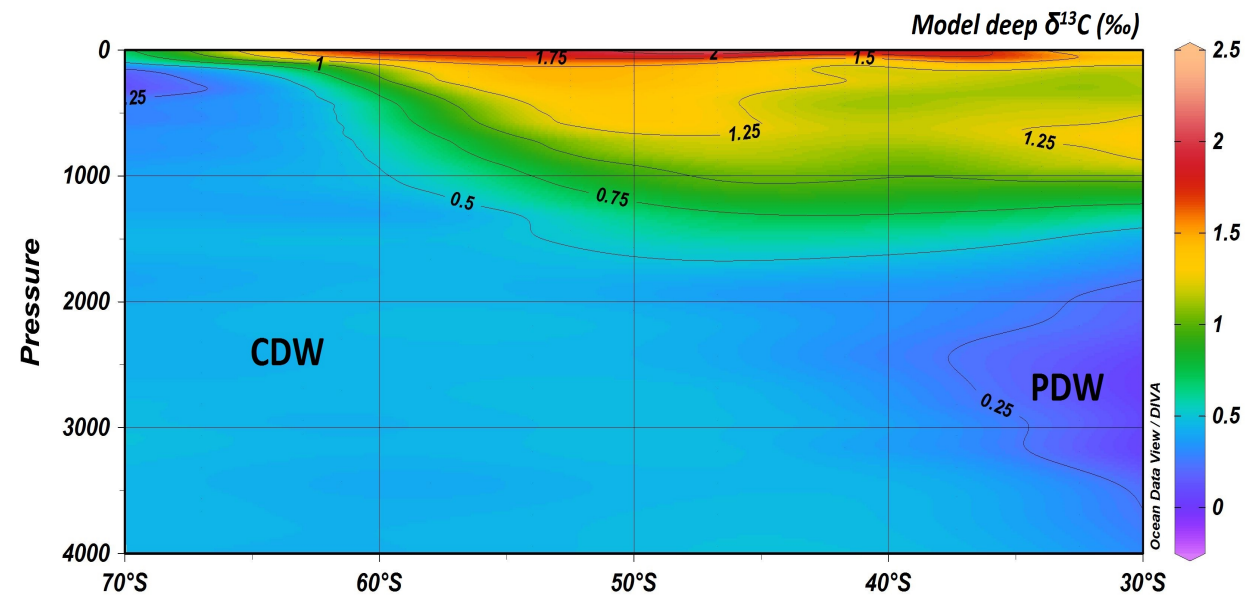

(c) Deep

Figure 2.1: $\delta^{13} C$ taken from transect P15S. (a) Surface waters. The $\delta^{13} C$ of surface waters around the STF are high, with the highest values just south due to mixing of STW and SAW. (b) Intermediate waters. AAIW is seen subducting south of the SAF and SAMW to the north of the SAF. (c) Deep waters. CDW is homogenous in $\delta^{13} C$ signal and PDW is seen in the low latitudes of the deep section with its characteristic low $\delta^{13} C$ signal. 
and therefore the highest $\delta^{13} C(1.75-2 \%$ ) (Table 2.2). Although productivity changes with each season (section 4.3, this chapter), the region around the STF to the east of New Zealand always has the highest values of $\delta^{13} C$.

SAW and AASW have an interlinked $\delta^{13} C$ history. They ultimately form from upwelled circumpolar deep water south of the PF. Antarctic surface water formed from lower circumpolar deep water flows toward the Antarctic continent and if conditions are right, sinks to form Antarctic bottom water. Surface waters forming from upper circumpolar deep water flow to the north by Ekman transport. They carry the high nutrient, low $\delta^{13} C$ signal of deep water. They mix across and eventually flow into the sub-Antarctcic zone as SAW. This high nutrient signal of SAW is inherited from the bottom waters as they upwell and are the reason why the sub-Antarctcic zone is a high productivity zone during the summer. Although they carry a low $\delta^{13} C$ signature, the high productivity seen throughout the year raises the $\delta^{13} C$ levels to those seen in Table 2.2.

The cold, well mixed surface waters of the Southern Ocean absorb a lot of $\mathrm{CO}_{2}$ from the atmosphere and this is then subducted and stored in intermediate waters. The $\delta^{13} C$ of the AAIW is higher than expected by up to $1 \%$ due to the high air-sea exchange at the source region (Lynch-Stieglitz et al., 1994; Figure 2.3).

Carbon within the intermediate waters is relatively uniform (Figure 2.1b, Table 2.2). It ranges from $1-1.5 \%$ (Bostock et al., 2013). The $\delta^{13} C$ varies across the Chatham Rise as different AAIW types are found to the north and south (Bostock et al., 2013). South of the rise the $\delta^{13} C$ is between $1.25 \%$ and $1.5 \%$ and north of the rise the $\delta^{13} C$ in the AAIW is lower at $1-1.25 \%$. In other transects from the S. Pacific (P16, SR3, P18, P19) that are not blocked by bathymetric highs, the high $\delta^{13} C$ signal $(1.25-1.5 \%$ ) is carried north into the subtropical gyre.

The four deep waters are PDW, UCDW/LCDW and AABW (Chiswell et al., 2015). The carbon signatures of each are usually low due to the remineralization of ${ }^{12} C$ at depth in the water column (Figure 1.1,2.1c; Table 2.2). PDW has the lowest values in the Pacific $(<0.5 \%$ ). This is because it is also the oldest water in the Pacific. Due to its age and mixing, it retains very low $\delta^{13} C$ content as it forms and travels south. $\mathrm{CDW} \delta^{13} \mathrm{C}$ is uniform at $0.5 \%$. These waters ultimately start out as NADW in the North Atlantic. NADW forms in the North Atlantic and flows south until it reaches the Southern Ocean and upwells along the Antarctic coast as LCDW. LCDW sinks along the continent either as LCDW or AABW. As these two water masses flow north they mix and eventually start to mix with PDW as it travels south. This mixed water 


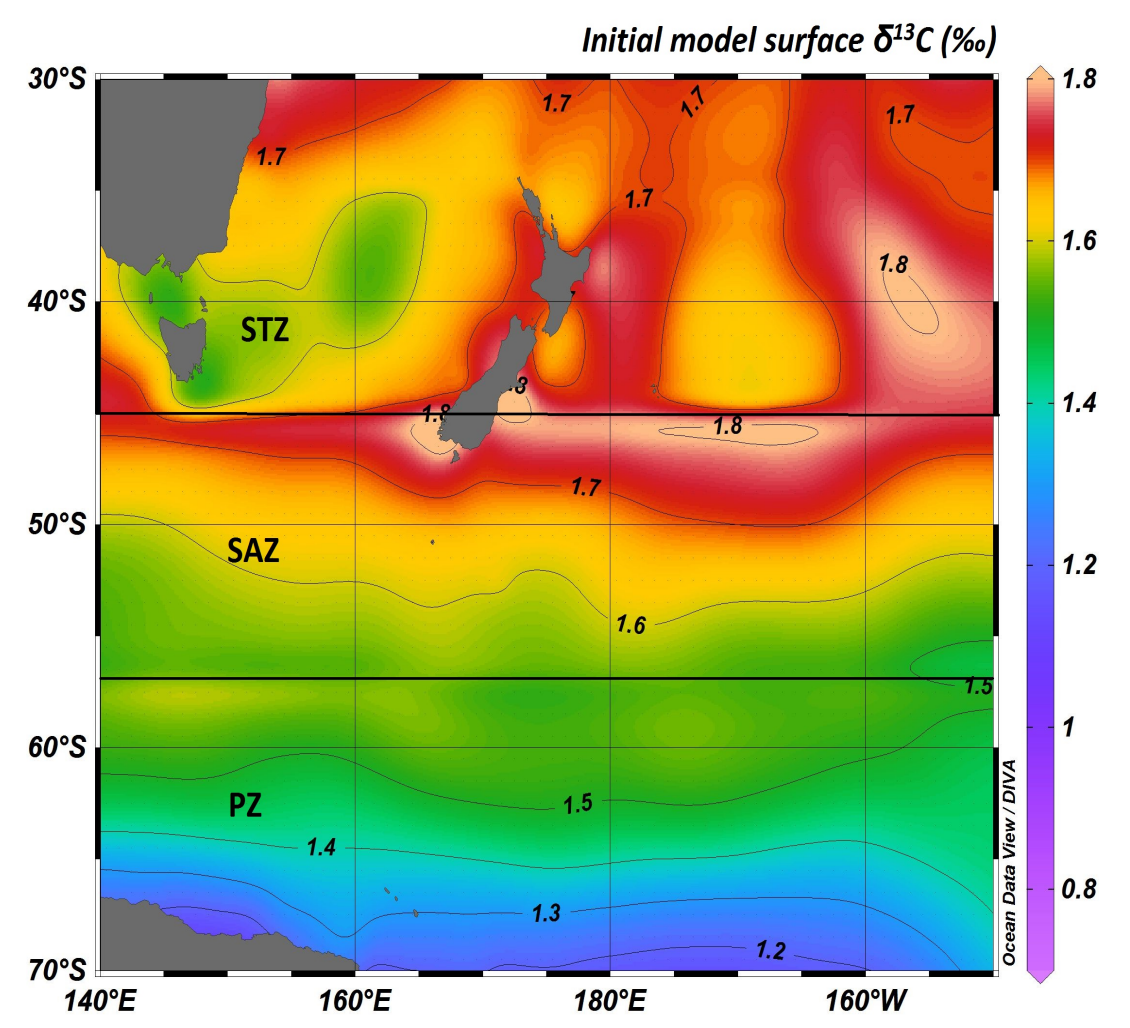

Figure 2.2: Initial attempt at modelling $\delta^{13} C_{D I C}$ in the surface waters. The region was split into three zones (labelled on figure), black lines indicate latitudinal location of each zone boundary. Creating zones in this fashion led to linear boundary conditions for each zone (seen most clearly at the STZ/SAZ boundary). STZ $\delta^{13} C$ values are anomalous and do not reflect observed $\delta^{13} C$ well in this model. These two factors led me to remove this model from the study and create a new one.

mass enters the PZ as UCDW. Essentially, the NADW $\delta^{13} C$ signal equilibrates with the atmosphere for a short time as it upwells as LCDW. This signal is transferred to the relatively high $\delta^{13} C$ level of AABW (0.5-0.75\%) through mixing with first LCDW and then PDW.

\subsection{Model}

\subsubsection{Initial attempts}

Initially all the data from south of $30^{\circ} S$ was used to develop the MLR model. I chose potential temperature, potential density, AOU, phosphate, silicate, and salinity as our parameters to model $\delta^{13} C$. They were chosen because they are the most widely sampled parameters in the datasets used in this study.

This resulted in a poor fit (Figure 2.2). I kept the same parameters and split the study area into three separate regions: the subtropical Zone (STZ) bounded by $30^{\circ} \mathrm{S}$ in the north and the STF in the south, the sub Antarctic 
Zone (SAZ) bounded in the north by the STF and in the south by the PF, and the Polar Zone (PZ) bounded in the north by the PF and in the south by Antarctica. These three zones have distinct characteristics from each other.

Using this method two models were created to find the best fits for the region. The first model simply modelled each zone separately and was pieced together to create a model of the entire region. The second combined data from the SAZ and PZ into one zone and this Antarctic zone model data was merged to the STZ model data to create a model of the region. Both models, in the SAZ and PZ, had $R^{2}>0.9$ and were thought to recreate the $\delta^{13} C$ distribution well within the SW Pacific region (Figure 2.2, 2.3).

Unfortunately, these models produced large residuals in the north of the STZ (Figure 2.1b), due to increasing $\delta^{13} C$ model values to the north. A large peak in $\delta^{13} C$ values was seen to the east of the Chatham Rise. This is to be expected (discussed in section 4.3), but not for the summer season and we could not identify any natural cause of this peak. Additionally, the boundary at $45^{\circ} \mathrm{S}$ was completely linear and did not reflect the actual meandering of the STF at all. The SAZ and PZ merged quite well and had few problems that could be seen. Overall, I found these models to be representative of the $\delta^{13} C$ distribution south of the STF. The STF and the STZ were not good representations of the $\delta^{13} C$ distribution and rethinking of the models was needed.

\subsubsection{Temperature, salinity, density, and oxygen model}

This MLR model utilizes only potential temperature, salinity, density, and oxygen to estimate $\delta^{13} C$ in the model region (Figure 2.4b). This was done as it was thought that poor phosphate and silicate data may be producing the large residuals in the previous model north of the STF and east of New Zealand. The model created has an $R^{2}=0.91$. A single model can be used for the entire Southwest Pacific and Southern Ocean region and there is no need to split it into different zones. By using one equation this eliminated any artificial internal boundaries and allowed the data to express the natural distribution. The large $\delta^{13} C$ values north of the STF that are seen in the one and two zone models above is not present.

Once created, I used data from the WOA database and created models for the other three seasons (spring, autumn, and winter) (Figure 2.4 a,c,d). Our threshold for the residuals was set at $+/-0.2 \%$. The residuals show that our model residuals fall within our threshold and seem to agree with the observed data. There are occasional outliers within the dataset, this could be from poor data within the observed or the WOA dataset. The depth versus residuals 


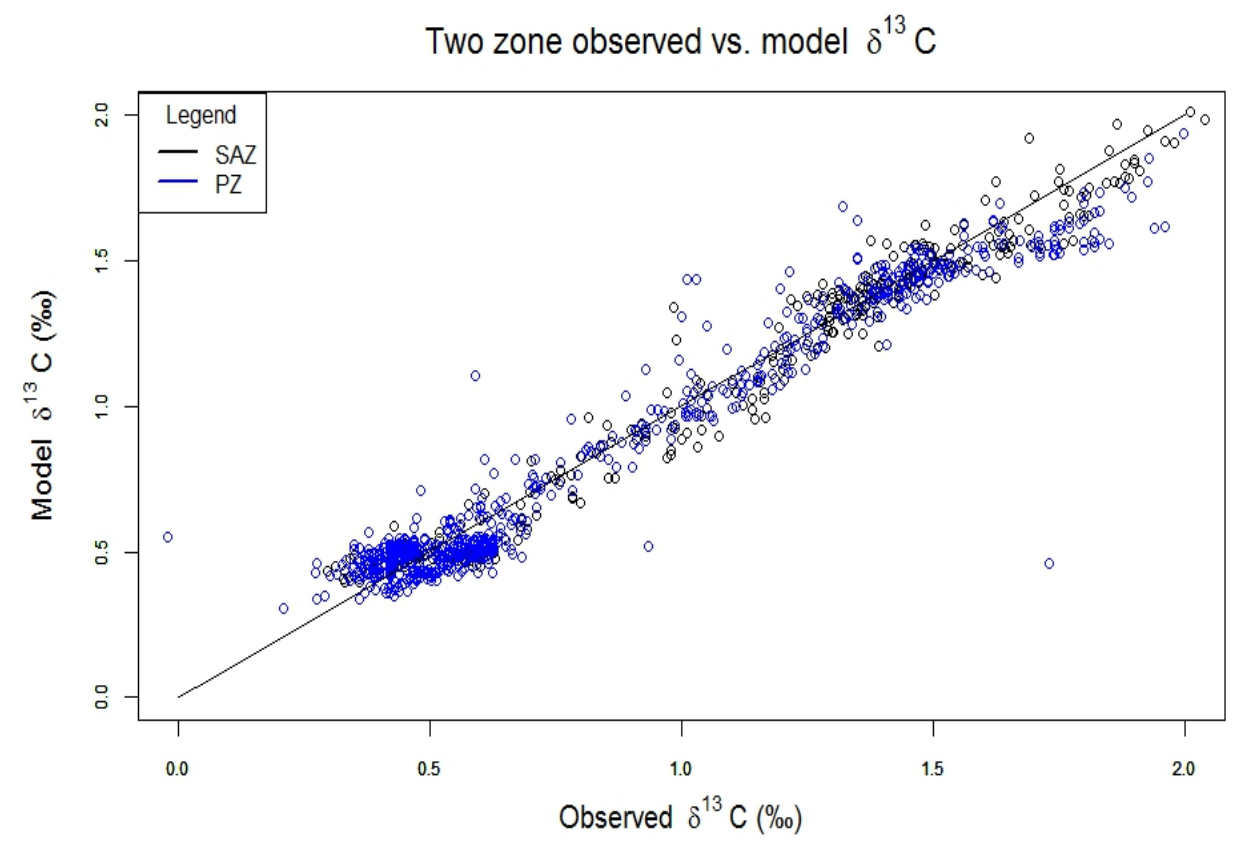

(a) Initial model versus actual data

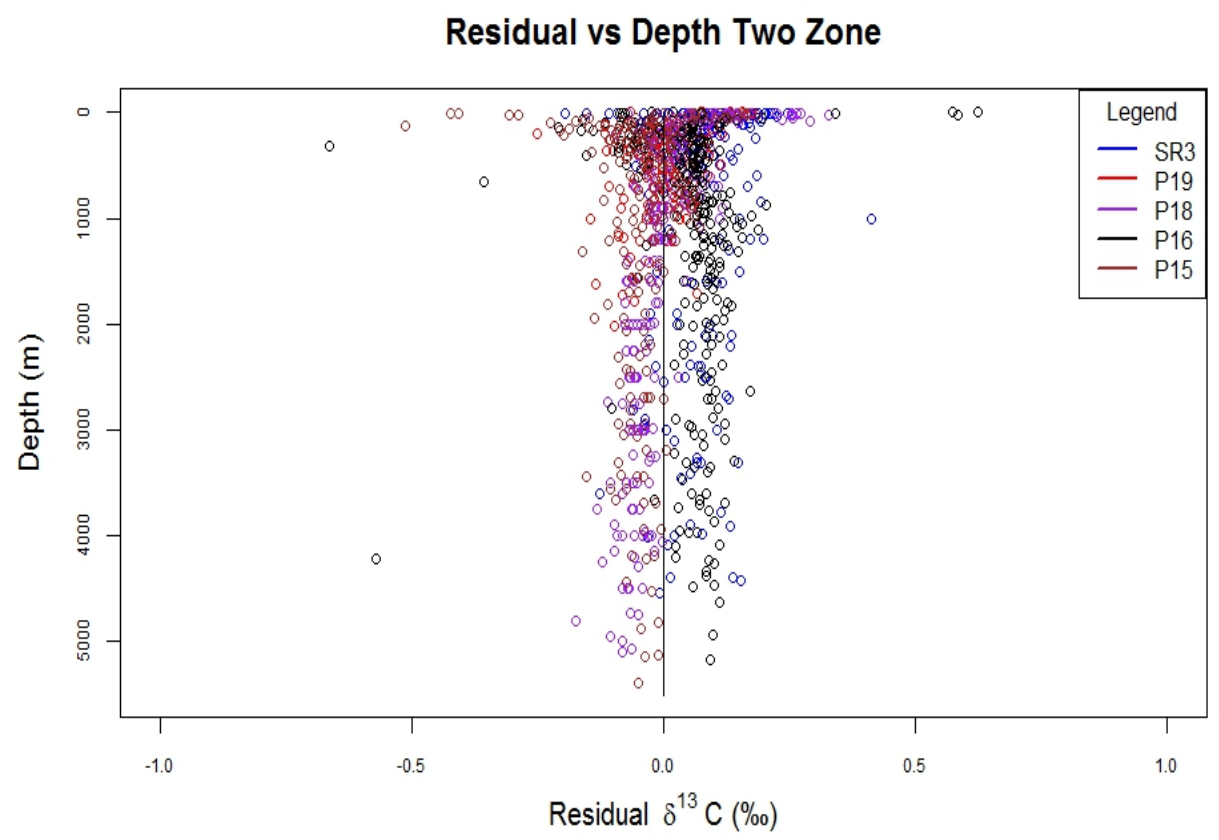

(b) Initial model residuals to depth

Figure 2.3: Residuals of the initial attempt at modelling. (a) Observed versus model $\delta^{13} C$ values for the initial two zone model along transect P16. This distribution is similar to the T,S,d,O distribution in (c) and suggests a good model fit. (b) Residuals to depth of the two zone model for transect P15. This shows the variability of the two zone model and how poor it could be in one transect and not another. Large residuals in the intermediate and deep waters caused this model to be rejected for use in this study. Figure continued on next page. 


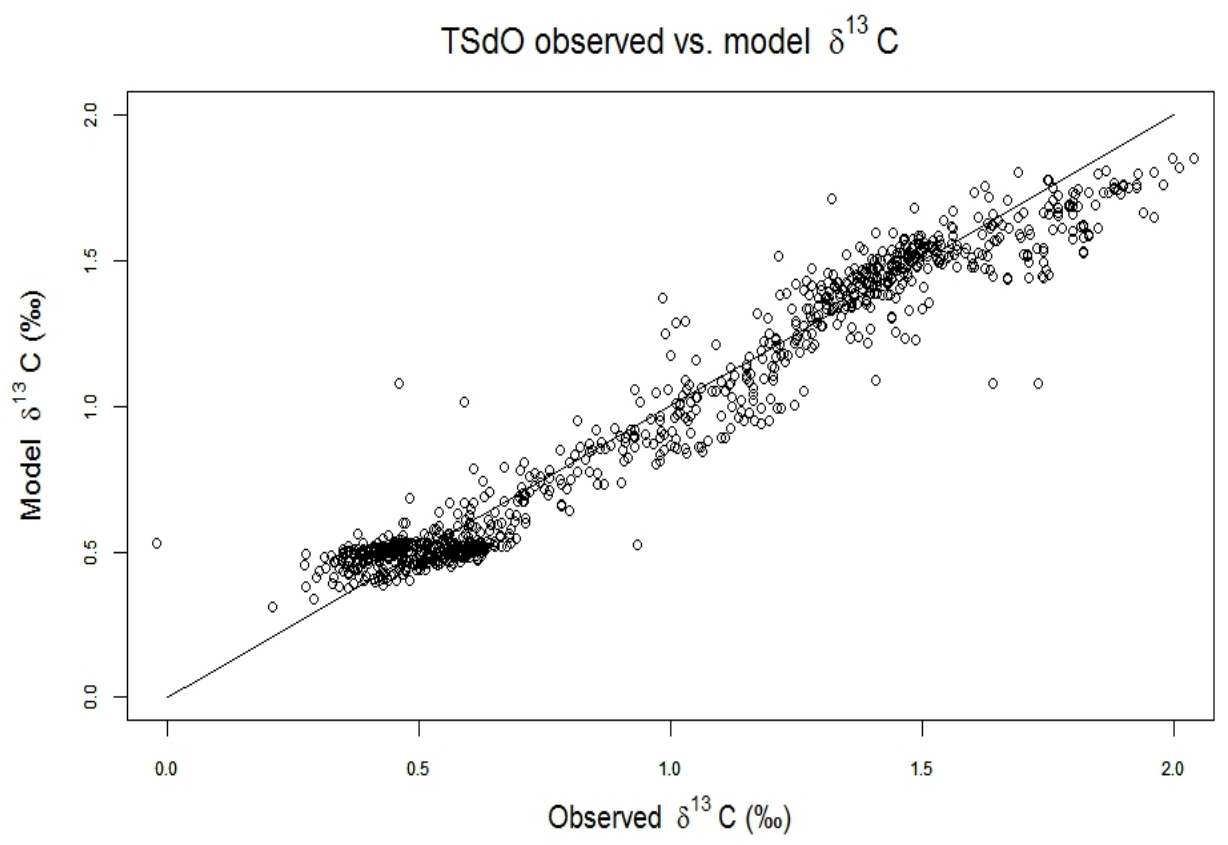

(c) T,S,d,O Model versus actual data

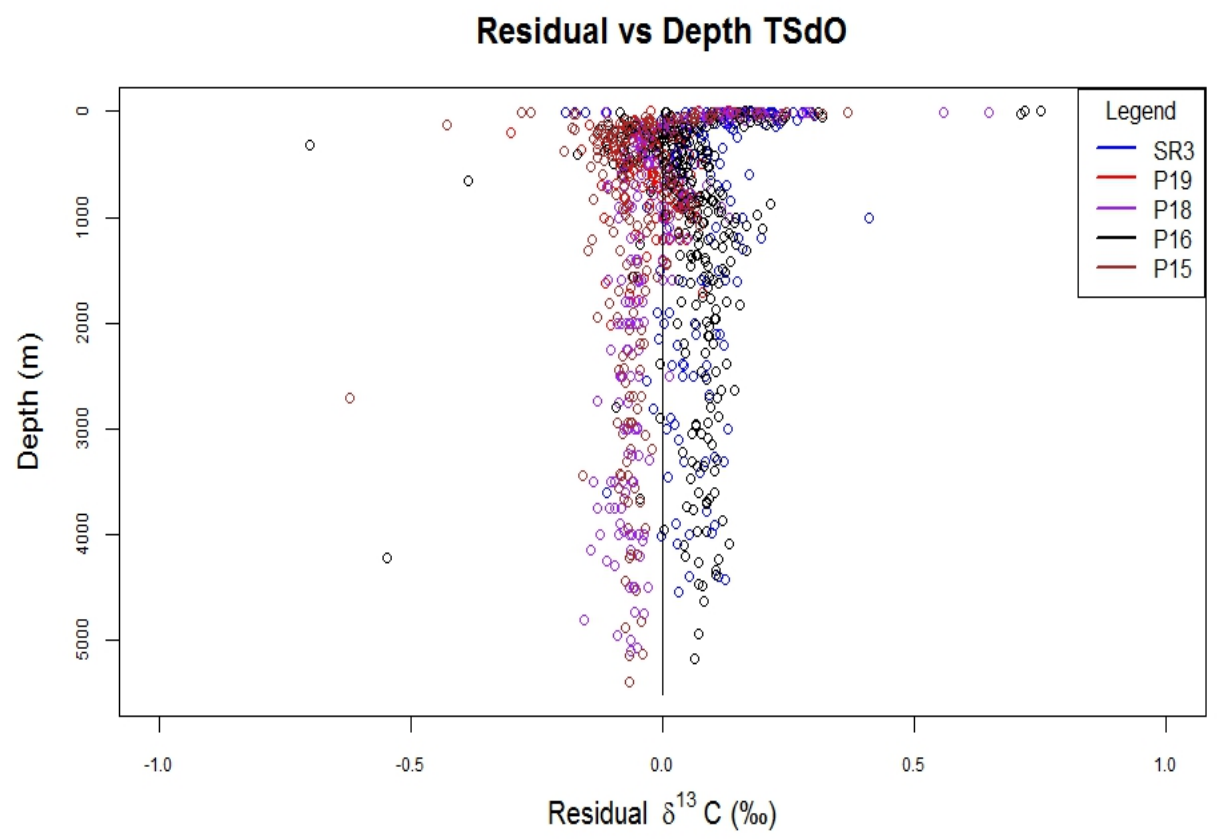

(d) T,S,d,O Residuals to depth

Figure 2.3: Residuals of the initial and T,S,d,O model. (c) shows how well the actual and model data compare throughout the different transects. (d) shows residuals to depth. Surface residuals are high due to seasonal variability and are expected. Residuals to depth are much more consistent and well within the error threshold. 
plot (Figure 2.3b) shows high residual values at the surface. This is because of the large seasonal variation of biological production at the surface (See section 4.3). It can be said that our model falls within our error parameters and agrees well with observed data from the region.

\subsection{Discussion}

\subsubsection{Spatial distribution of $\delta^{13} C$ in the surface waters of the SW Pacific}

This model was created to describe latitudinal and longitudinal changes in $\delta^{13} C$ for the SW Pacific and Southern Ocean. Due to the sparsity of water data in this region, there are large swaths of ocean that are difficult to accurately determine $\delta^{13} C$ levels. This is complicated by the complex bathymetry and circulation of the region which disallows simple latitudinal extrapolation from transect lines. This study takes these data and creates a model that accurately represents the $\delta^{13} C$ of the transects and applies it to ocean climatology datasets to recreate the $\delta^{13} C$ distribution of the study region.

The spring (Oct-Dec) (Figure 2.4a) model shows a wide band $\left(40^{\circ}-55^{\circ} \mathrm{S}\right)$ of intermediate $\delta^{13} C$ levels (1.6-1.7\% ) to the west of New Zealand. In the east, the intermediate band is wider $\left(35^{\circ}-55^{\circ} S\right)$ with a narrow band $\left(40^{\circ}-50^{\circ} S\right)$ of high $\delta^{13} C$ values $(>1.7 \%$ ) that trends to the east and north. The gradient from the STF to the PF is low at $\Delta \delta^{13} C=-0.3 \%$. South of the PF the gradient greatly increases as levels drop by $0.8 \%$ from the PF to the Antarctic coast. This is the largest gradient seen south of the PF in any season.

In the surface oceans summer (Jan-Mar)(Figure 2.4b) maps shows a narrow band of elevated $\delta^{13} C$ levels $\left(>1.7 \%\right.$ ) south of the STF $\left(45^{\circ}-55^{\circ} S\right)$. This corresponds well to the high productivity zone south of the STF within the $\mathrm{SAZ}\left(45^{\circ}-55^{\circ} \mathrm{S}\right)$ that is a consequence of seasonal temperature and productivity changes around the front (Chiswell et al., 2013). Two major peaks in $\delta^{13} C$ levels are seen in this graph: the larger $(>1.8 \%$ immediately adjacent to New Zealand $\left(160^{\circ} \mathrm{E}-180^{\circ}, 45^{\circ}-50^{\circ} \mathrm{S}\right)$, and the smaller to the $\mathrm{SE}\left(165^{\circ} \mathrm{E}, 50^{\circ} \mathrm{S}\right)$. The larger is due to mixing among the islands of the Campbell Plateau and the high productivity of the near shore environments of New Zealand (Chiswell et al., 2013). The smaller peak may be due to general mixing at the front. There is no seamount or islands in this region north of the STF but may be due to wind mixing and/or a deep mixed layer in the area. High values of $\delta^{13} C$ are pushed farther south during this season due to warmer conditions. A $\delta^{13} C$ decrease from the STF to the PF $\left(45^{\circ}-60^{\circ} S\right)$ of $\Delta \delta^{13} C=-0.2 \%$ is evident. 


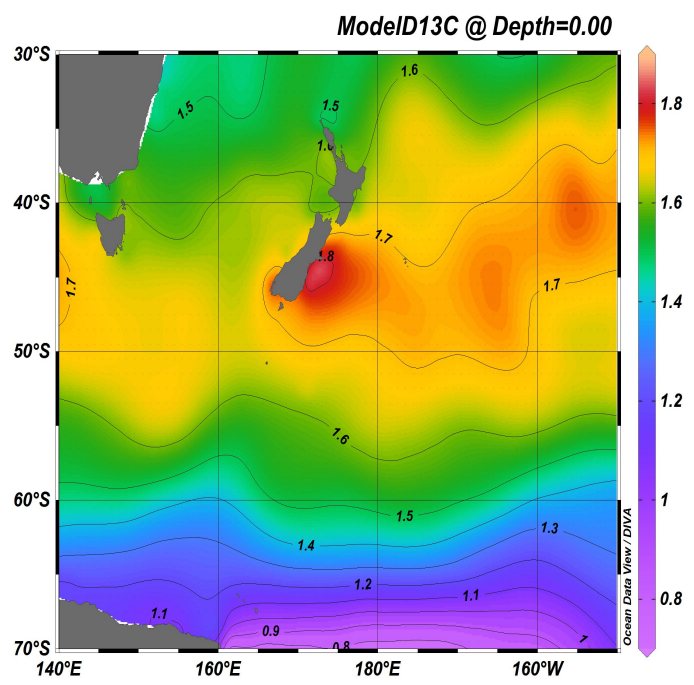

(a) Spring

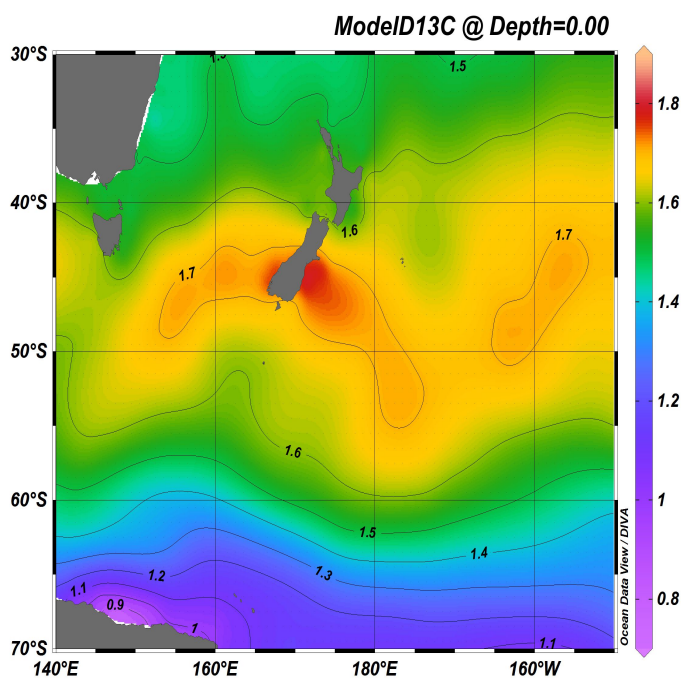

(c) Autumn

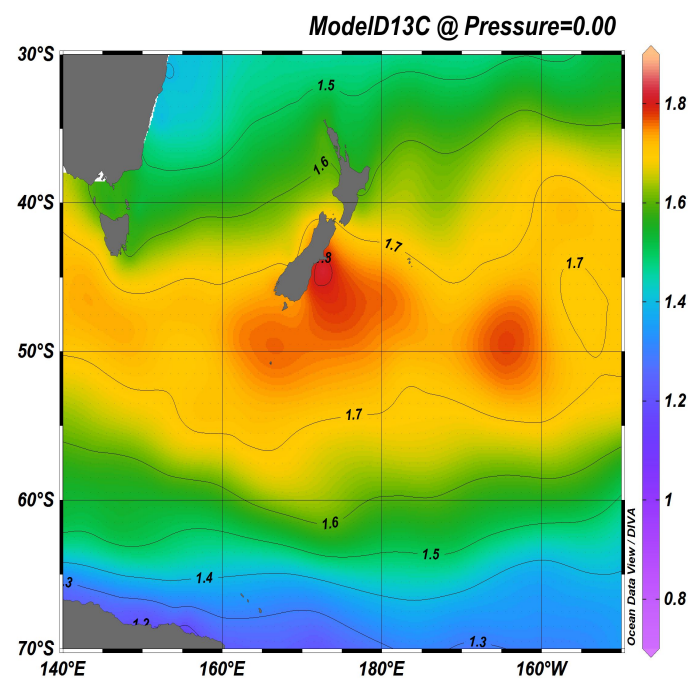

(b) Summer

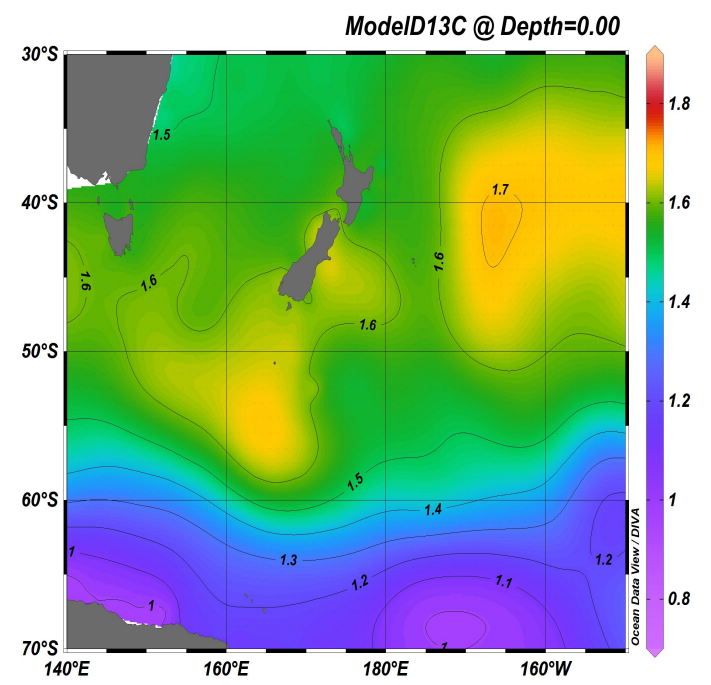

(d) Winter

Figure 2.4: Models of $\delta^{13} C$ based on the MLR using the WOA seasonal database. When compared to the seasonal chlorophyll distributions, the model matches up well and shows the robust fit for each season. Contours in 0.1 per mil. 
While south of the $\mathrm{PF}\left(60^{\circ} \mathrm{S}-70^{\circ} \mathrm{S}\right)$ is $\Delta \delta^{13} \mathrm{C}=-0.4 \%$ is due to the upwelling of low $\delta^{13} C \mathrm{CDW}$ in the region.

Autumn (Apr-Jun) (Figure 2.4c) is transitional between winter (high $\delta^{13} C$ values in the north) and summer (high $\delta^{13} C$ values in the south). The summer band of high values $(>1.7 \%$ ) seen south of the STF is breaking up with intrusions north and south of intermediate values (1.6-1.7\% ) all around New Zealand (Figure 2.4c). High values are present in small patches to the west of the South Island $\left(45^{\circ} S\right)$ trending SW to $\left(50^{\circ} S, 180^{\circ}\right)$. Small patches of high $\delta^{13} \mathrm{C}$ levels are seen to the east at $160^{\circ} \mathrm{W}$ and $150^{\circ} \mathrm{W}$ between 40 and $50^{\circ} \mathrm{S}$, show the slowing of biologic productivity in the region as summer transitions to winter. The gradient in the region from the STF to the PF has decreased from summer due to the lower values pervasive in this region and has an average value of $0.1 \%$. South of the PF the gradient is higher at $0.4 \% 0-0.5 \%$ ochange from north to south.

Winter (July-Sep) (Figure 2.4d) has the lowest change of all the seasons with $\Delta \delta^{13} C=-0.6 \%$ from the STF to the Antarctic coast. There are small regions of intermediate $\delta^{13} C$ levels at the Campbell Plateau (centred at $55^{\circ} \mathrm{S}, 165^{\circ} \mathrm{E}$ ) and in the STW east of New Zealand north of $45^{\circ} \mathrm{S}$ that have values $>1.6 \%$ and one small peak at $40^{\circ} S$. Low $\delta^{13} C$ waters $(<1.6 \%$ ) intrude from the north and south around the Chatham Rise and from the north in the Tasman Sea. The Tasman Sea has low $\delta^{13} C$ values of $1.5 \%-1.6 \%$ o that are the lowest seen east of New Zealand throughout the year and reflect the low biologic productivity in winter.

\subsubsection{Comparison with other $\delta^{13} C_{D I C}$ datasets and mod- els}

Data from latitudinal transects have recorded the $\delta^{13} C$ latitudinal variation through all three major ocean basins. Quay et al. (2003) found that in all major ocean basins, $\delta^{13} C$ has a local minimum in the subtropical gyre that rises to a peak between $35^{\circ} S$ and $50^{\circ} S\left(45^{\circ} S\right.$ in the Pacific) and falls to the lowest values in the Southern Ocean. Our model recreates this trend well. Our peak lies at the STF $\left(45^{\circ} \mathrm{S}\right)$ with a shallow gradient between the STF and the $\mathrm{PF}$ and a steeper gradient from the PF to the Antarctic coast.

McNeil et al., (2001) utilize a multiple linear regression approach to tracking $\delta^{13} C$ and DIC in the water column. Although their model is relatively simple, as it looks mostly at latitudinal transects at discreet depths, it showcases the power of the multiple linear regression. They model $\delta^{13} C$ based on potential density, AOU, salinity, and alkalinity (McNeil et al, 2001). This approach 


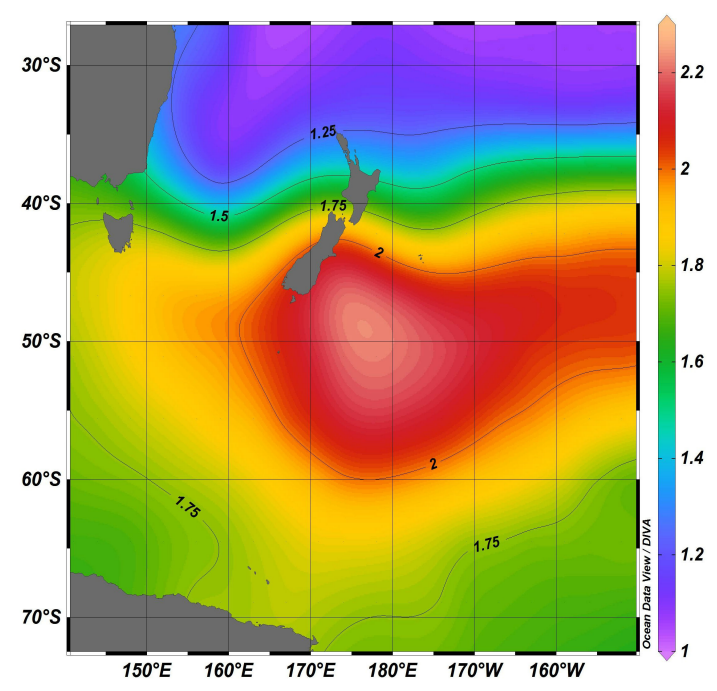

Figure 2.5: Sonnerup et al., (2012) GCM $\delta^{13} C$ distribution for the year 2003. This model is lower resolution than the models created for this thesis. This model also poorly constrains the $\delta^{13} C$ distribution around New Zealand. Contours in 0.1 per mil.

modelled the $\delta^{13} C$ well with an $R^{2}=0.99$. This model is quite like the model created for this chapter, but limited in its scale relative to this study.

Sonnerup et al. (2012) create a global climate model (GCM) to track the oceanic Suess effect (the Suess effect being the increase in fossil fuel carbon with low $\delta^{13} C$ in the atmosphere; Suess, 1955) The Sonnerup et al. model creates a $\delta^{13} C$ map going back 250 years (model years 2003 (Figure 2.5) and 1750 (Figure 3.3b) utilized in this study). Their model is slightly less resolved than the one created using the MLR above $\left(4.5^{\circ} \times 4.5^{\circ}\right.$ versus $1^{\circ} \times 1^{\circ}$ resolution for our model from the WOA) and uses a combination of surface circulation and wind patterns to recreate $\delta^{13} C$ levels at the surface. They use annual data as their model base and the results are different from this study. The gradient from $45^{\circ}$ to $65^{\circ} \mathrm{S}$ is very shallow with the lowest $\delta^{13} \mathrm{C}$ values of $1.65 \%$ much higher than is seen in observed data (Bass et al., 2014). $\delta^{13} C$ values in the north at $30^{\circ} \mathrm{S}$ are much lower $(<1.25 \%$ ) than observed values (Quay et al., 2003). In contrast, values at this latitude are $1.4 \%$ both in our model and studies such as Quay et al. (2003). Longitudinal variation is also better with high values east of New Zealand (between $45^{\circ}$ and $60^{\circ} \mathrm{S}$ ) that are seen in our models and chlorophyll data (next section).

Similar studies from underway data taken from ships can give us an idea of what the current gradient is. Bass et al., (2014) describe underway data from the R.V. Tangaroa taken on a transect that runs from the SW coast of the South Island (at the STF) to the Antarctic continent in February and March 2013 (Figure 2.7a,b). It correlates temperature and latitude with $\delta^{13} C$. 


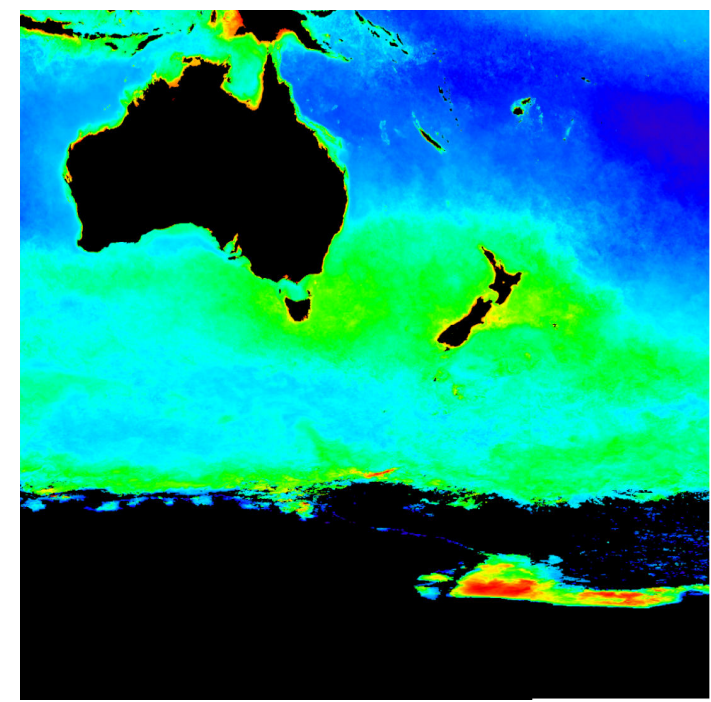

(a) Spring

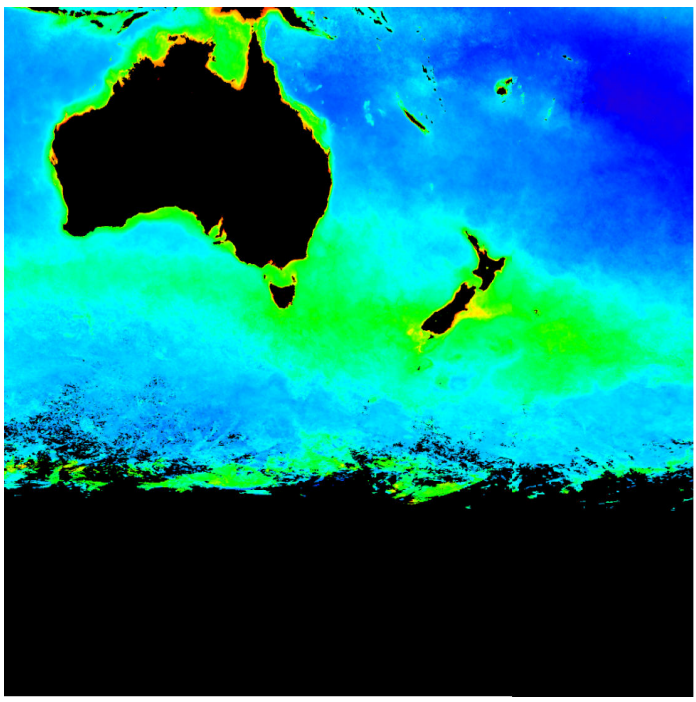

(c) Autumn

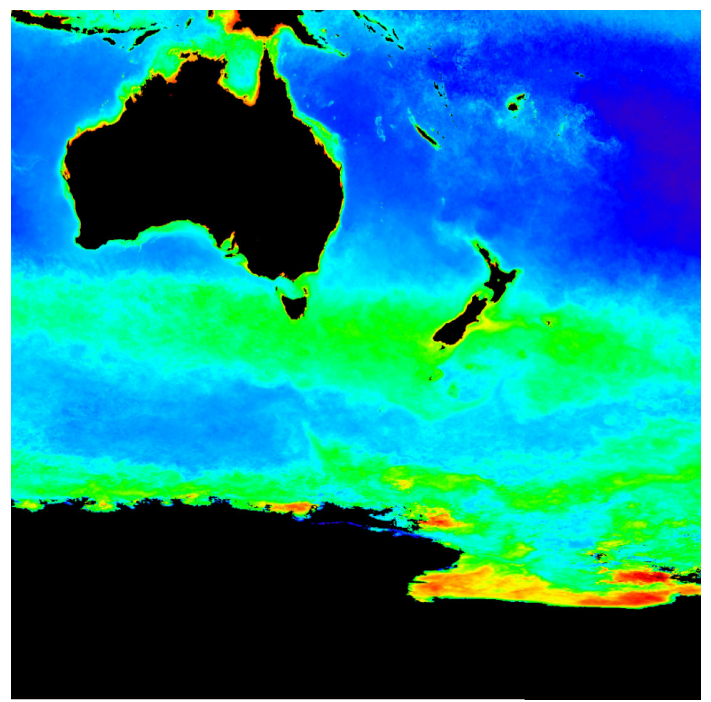

(b) Summer

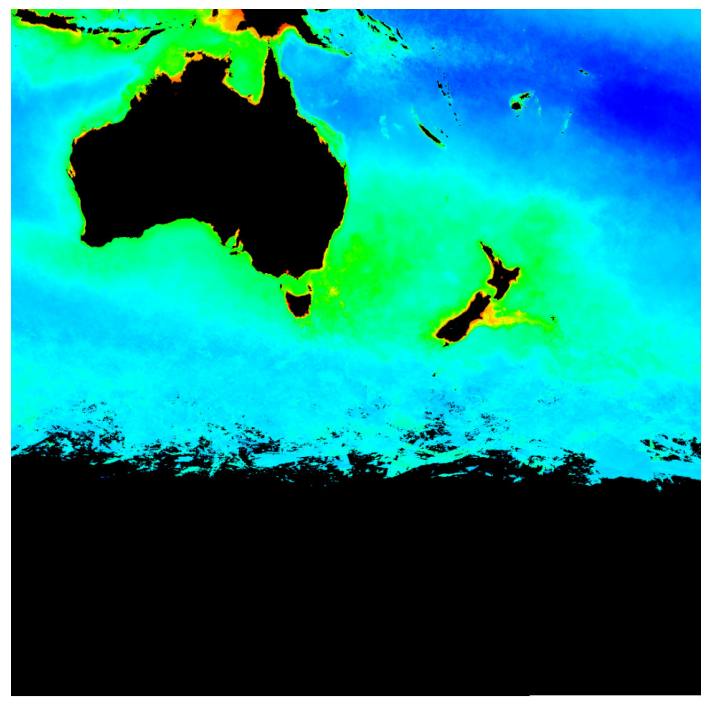

(d) Winter

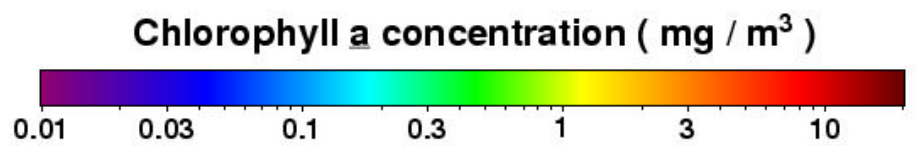

(e)

Figure 2.6: Seasonal chlorophyll measurements from SeaWifs in the New Zealand region. Note the similarity in the distribution to the model seasons. 


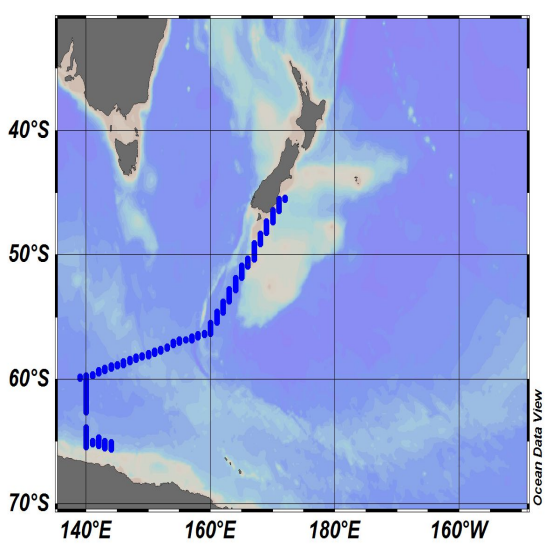

(a) TAN1302 transect

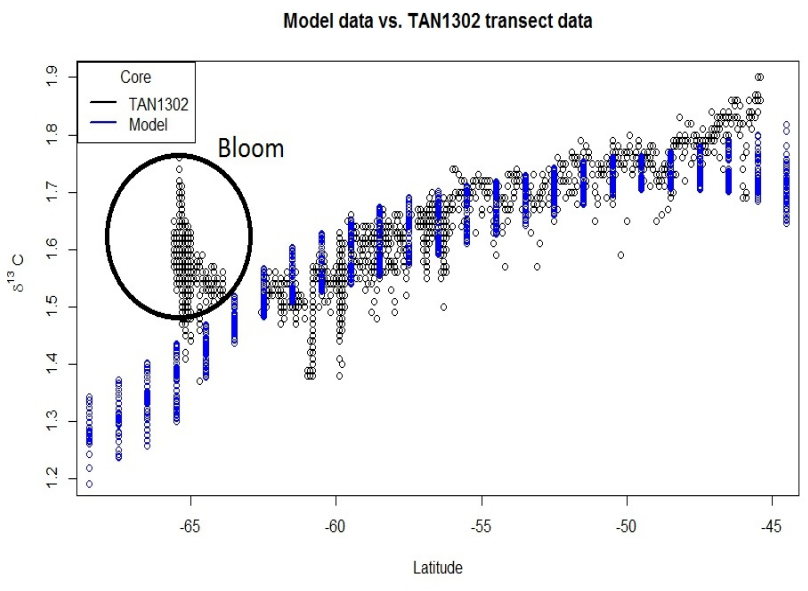

(b) TAN1302 data vs. Model

Figure 2.7: a) Map of transect TAN1302. b) $\delta^{13} C$ of TAN1302 vs. model data from the same transect in the summer model. High values at $65^{\circ} \mathrm{S}$ of the TAN data are due to a phytoplankton bloom present during sampling (Bass et al., 2014). The trend between the two is very similar and shows how robust the models are.

As latitude gets higher, temperature gets lower, and so do $\delta^{13} C$ values. This data matches well to the model from $45^{\circ} \mathrm{S}$ to $62^{\circ} \mathrm{S}$ (Figure 2.7b). The ship data have a large range of $\delta^{13} \mathrm{C}$ values at $65^{\circ} \mathrm{S}$ that are higher than our model data. Our studies and Bass et al., (2014) both agree that upwelling waters with low $\delta^{13} C$ values are the dominant control of $\delta^{13} C$ levels south of the PF. They concluded that a local bloom is most likely cause of the elevated $\delta^{13} C$ levels seen at $65^{\circ} \mathrm{S}$ in their underway data, which is not evident in the annual and seasonal data used for this MLR model study approach.

\subsubsection{Drivers of $\delta^{13} C$ of surface waters}

Chlorophyll is a measure of primary productivity at the sea surface. The density of biomass is measured by satellites (SeaWiFS) measuring the intensity of certain wavelengths of light emitted by chlorophyll. Satellite imagery can give ocean wide distributions throughout the year to quantify how surface phytoplankton abundance changes through seasons and interannually time. For comparison against this data we obtained seasonal climatologies of chlorophyll (2012-2016) from NASA SeaWiFS database (NASA). Figure 2.6 shows all four seasons of this data.

Chiswell et al., (2013) describe satellite imagery from around New Zealand taken between 1998 and 2010 to fully describe seasonal change in chlorophyll. They describe blooms east of New Zealand in STW that occur in spring and autumn while in the summer large scale blooms occur in the SAW (Chiswell 
et al., 2013). Our findings (section 4.1) show that the surface $\delta^{13} C$ match well with the distribution of surface water chlorophyll. In the summer (Figure $2.6 \mathrm{~b}$ ), our model shows increased levels of $\delta^{13} C$ throughout the SAZ with highs at the STF. Spring and autumn (Figure 2.6a,c) blooms occur with changes in the strength of the westerlies that generate blooms along the STF and in the STZ through various mixing and entrainment processes (Chiswell et al., 2013).

Spring blooms are highly variable in space and therefore do not show up well in annual datasets (2.6a). We interpret the variable spring blooms as manifesting themselves in the wide band of $\delta^{13} \mathrm{C}$ levels $>1.6 \%$ between $35^{\circ} \mathrm{S}$ and $55^{\circ} \mathrm{S}$ in the spring model. This wide band bounds the range of spatial variability to the north and south of these blooms. The band of high $\delta^{13} C$ values $(>1.7 \%$ ) within the region possibly corresponds to areas of consistently high biological productivity from year to year.

The models are in general agreement with these findings. Since the models are averaged over 60 years there is less variation in latitude than is seen in the most recent chlorophyll data. But the seasonal trends are the same. Chiswell et al.(2013) describe spring and autumn as having equatorward and poleward transport over time as surface water masses shift latitudinally. Thus, both seasons have peaks in chlorophyll around the STF, which is seen in both seasons in the model. The models show similar distributions of $\delta^{13} C$ around New Zealand. In the satellite data the STF is a well defined boundary. The summer model captures this quite well near to New Zealand. West of Tasmania and east of the Chatham Rise there is shifting north of the STF not seen in the recent chlorophyll data.

\subsection{Conclusion}

In the South Pacific and Southern Oceans $\delta^{13} C$ is variable both by latitude and with depth. $\delta^{13} C$ values vary through air-sea exchange, biologic activity, and especially oceanic circulation. To constrain the current $\delta^{13} C$ variability, a set of MLR models were created. These models utilized six oceanographic parameters to model $\delta^{13} C$ variability: AOU, potential temperature, potential density, phosphate, silicate, and salinity. AOU, density, temperature, and salinity were found to constrain $\delta^{13} C$ best. These MLR models were used to produce a map of the $\delta^{13} C$ of the surface waters across the South Pacific (Figure 2.4) which shows a strong correlation to chlorophyll-a evident from satellite data, indicating that surface $\delta^{13} C$ is reflecting the primary productivity. Modern $\delta^{13} C$ values in the surface waters of the Southwest Pacific and Southern Ocean will now be used to compare with the core tops in the next chapter. 


\section{Chapter 3}

\section{Modern water versus core top data}

\subsection{Introduction}

In Chapter 2 I developed a model to show the modern $\delta^{13} C$ spatial distribution for the SW Pacific and Southern Ocean (Figure 3.1). In this chapter I will compare the spring model from Chapter 2 as a base for a pre-industrial model that recreates the $\delta^{13} C$ distribution at the beginning of the industrial revolution (1750 AD). Core top $\delta^{13} C$ data from planktic foraminifera $G$. bulloides is compared to this pre-industrial $\delta^{13} C$ model after testing for the depth habitat of $G$. bulloides. If the model $\delta^{13} C$ surface distribution matches well with core top data, the model can be said to faithfully describe the $\delta^{13} C$ captured by G. bulloides. Down core data from this same species may then be used to reconstruct past climate based on the $\delta^{13} C$ record (Chapter 4).

\subsection{Methods}

\subsubsection{Creating pre-industrial $\delta^{13} C$ model}

The pre-industrial $\delta^{13} C$ model uses the spring $\delta^{13} C$ model from Chapter 2 as its base (Figure 3.3a). A global climate model created by Sonnerup et al. (2012) was utilized to quantify pre-industrial $\delta^{13} C$ levels in the oceans. This model utilized surface ocean circulation, air circulation, and atmospheric $\mathrm{CO}_{2}$ levels from $1750 \mathrm{AD}$ to compare how anthropogenic $\mathrm{CO}_{2}$ has affected the surface ocean $\delta^{13} C$ levels since the beginning of the industrial revolution. Surface distributions were obtained from the model for the years 1750, 1970, 1990, and 2003. The model has a $4^{\circ}$ by $4.5^{\circ}$ resolution. Each point (lat/long) from the $1750 \mathrm{AD}$ Sonnerup et al. model $\delta^{13} C$ was compared to the same point 


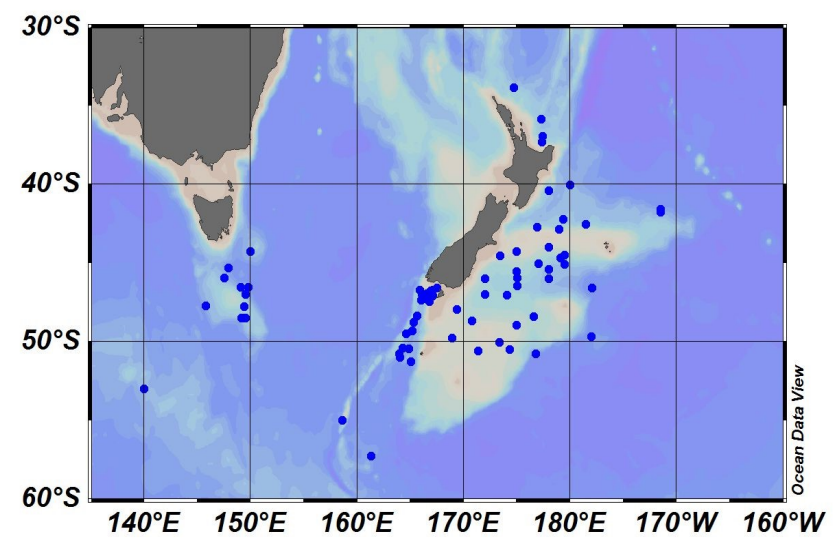

Figure 3.1: Location of all core tops used in this study.

on our model from Chapter 2 (Table 3.3). The difference $\left(\Delta \delta^{13} C\right)$ between the Sonnerup model and mine was determined to create a $1^{\circ} \mathrm{x} 1^{\circ}$ resolution model. Each degree was assigned a $\Delta \delta^{13} C$ value and was added to our model to create the pre-industrial distribution of $\delta^{13} C$. Longitudinal variation was not considered because the variation is minimal compared to latitudinal variation.

\subsubsection{Core tops}

The remainder of this study relies on data analyzed from the foraminifera G. bulloides that have been picked from core tops around New Zealand. Before this data can be interpreted, it must be corrected so the $\delta^{13} C$ of the foraminifera can be related back to the $\delta^{13} C$ of the surface waters. In this chapter I will correct core top data, but these corrections also apply to the down core data in Chapter 4.

\section{Correcting G. bulloides $\delta^{13} C$ data}

King and Howard (2004) determined that G. bulloides $\delta^{13} C$ test values are dominated by the temperature of the water in which they are formed. They also show that the experimental disequilibrium from the ambient seawater equation $(\mathrm{y}=(-0.11 * \mathrm{~T})-0.77$; Figure 3.2) determined by Bemis et al. (2000) describes disequilibrium at all modern oceanic temperatures in this region (0$25^{\circ} \mathrm{C}$ ). This equation was used to determine disequilibrium in G. bulloides through time and correct $G$. bulloides $\delta^{13} C$ data to compare better with the $\delta^{13} C$ of the dissolved inorganic carbon (DIC) in the surface waters. Further corrections will be discussed in Chapter 4 for down core studies. All further discussion is about corrected core top data. 


\begin{tabular}{|l|l|l|l|l|l|l|}
\hline Zone & $\left.\delta^{18} O \mathbf{( \% o}\right)$ & $\delta^{18} O$ error $(+/-)$ & Temperature $\left({ }^{\circ} \mathbf{C}\right)$ & T error $(+/-)$ & Depth $(\mathbf{m})$ & D error $(+/-)$ \\
\hline Bay of Plenty & 0.14 & 0.08 & 15.9 & 0.34 & $\mathbf{8 0 . 3}$ & 20 \\
\hline North Chatham Rise & 0.42 & 0.08 & 14.71 & 0.34 & $\mathbf{3 9 . 9}$ & 22 \\
\hline Solander Trough North & 1.4 & 0.08 & 10.73 & 0.31 & $\mathbf{1 0 . 4}$ & 59 \\
\hline Solander Trough South & 1.6 & 0.08 & 9.91 & 0.31 & $\mathbf{5 0 . 3}$ & 57 \\
\hline
\end{tabular}

Table 3.1: Data used to estimate G. bulloides habitat depth in the water column. Oxygen isotope data from core tops is on the left with estimated error. The temperature estimated using the Epstein equation and the associated error. Finally, the depth from our temperature data with associated error (equations in Table 3.2).

\section{G. bulloides depth habitat from temperature}

The first step is to test where G. bulloides lives in the water column, the literature suggests that this planktic foraminifera lives in the upper $400 \mathrm{~m}$ of the water column (Hemleben et al., 1989). It is important to establish whether $G$. bulloides lives in the mixed layer or in the thermocline. The depth of the thermocline varies seasonally and has different sea water properties to the overlying mixed layer. To determine the habitat depth of the $G$. bulloides the $\delta^{18} O$ core top data from all our cores was taken (that had them) and compared to the spring temperature data from the WOA database. G. bulloides is known to reproduce in spring and thus test growth likely captures the oceanic conditions of this season (Hemleben et al., 1989; King and Howard 2001; Northcote and Neil, 2005). Sediment trap studies of the region (both the NCR and SCR, as well as the southern flank of the Campbell Plateau) show the seasonality of various foraminiferal species. G. bulloides is found to bloom solely in spring. Usually early spring in September or October in the SCR. While in the NCR, there is a late spring (Dec) bloom (King and Howard 2001; Northcote and Neil, 2005).

To determine this a potential temperature profile was taken from the WOA data base that corresponded to the location of each core top. Next, the $\delta^{18} O$ value of each core top was used to calculate the temperature via the equation from Epstein and Mayeda (1953): $\left(\mathrm{T}(\mathrm{C})=16.5-\left(4.3 * \delta^{18} O\right)+\left(0.14 * \delta^{18} O\right)\right.$. An average error value of $+/-0.08 \%$ was assumed for each $\delta^{18} O$ data point and included in the temperature equation to get a temperature error.

Lastly, a nonlinear least squares regression was run to develop an equation that compare the temperature and error from the core tops with the temperature and depth from the water column from the WOA. All $\delta^{18} O$, temperature, and depth data and errors are shown in Table 3.1. The Epstein and Mayeda temperature equation is shown above and the non-linear equations to compute depth from temperature are found in Table 3.2. 
Redacted due to

copyright permissions

Figure 3.2: Temperature correction equation from Bemis et al. (2000). Figure taken from King and Howard, 2004. This figure shows their sediment trap G. bulloides data correction curve vs. the Bemis curve.

\section{Core top versus model data}

\begin{tabular}{|l|l|}
\hline Zone & Equation \\
\hline BoP & $\mathrm{D}=(\log (\mathrm{T})-2.85) /-0.00107$ \\
\hline NCR & $\mathrm{D}=(\log (\mathrm{T})-2.73) /-0.000988$ \\
\hline SolN & $\mathrm{D}=(\log (\mathrm{T})-2.38) /-0.000468$ \\
\hline SolS & $\mathrm{D}=(\log (\mathrm{T})-2.32) /-0.000525$ \\
\hline
\end{tabular}

Table 3.2: Equations used to derive depth (D) from temperature $(\mathrm{T})$. The equations hold the original form of $\mathrm{T}=e^{((a+(b * D)))}$.
This study comprises of 23 cores and approximately 80 core tops from around the New Zealand region. Most of these cores contain core top data that is used in this chapter. The locations of these core tops are shown in Figure 3.1. To test the observations from the models of Chapter 2 and the pre-industrial model described

above, a plot of $\delta^{13} C$ versus latitude should show any differences in the model and core top. Due to the high variation seen in $\delta^{13} C$ data, a trend is difficult to see in these data (Figure 3.5). To determine a statistically significant trend in the data, a Monte Carlo simulation was run. A Monte Carlo simulation accounts for error in both the $\mathrm{x}$ and $\mathrm{y}$ parameters of a plot (latitude and $\delta^{13} C$ respectively in this study) and randomly generates a cloud of data in a normal distribution based on the error parameters. The resulting dataset is much larger than the original, providing trends that are clearer and more statistically significant.

For this chapter, the error of the $\delta^{13} C$ of $G$. bulloides was assumed to be one standard deviation of the core top data set. This was chosen because no measurement error was given and these data were analyzed by many different groups. An error or $0.2^{\circ}$ was attributed to the latitude measurements. No error was given for these data, and although probably much smaller, this generous value was chosen as an upper limit rather than absolute error. 


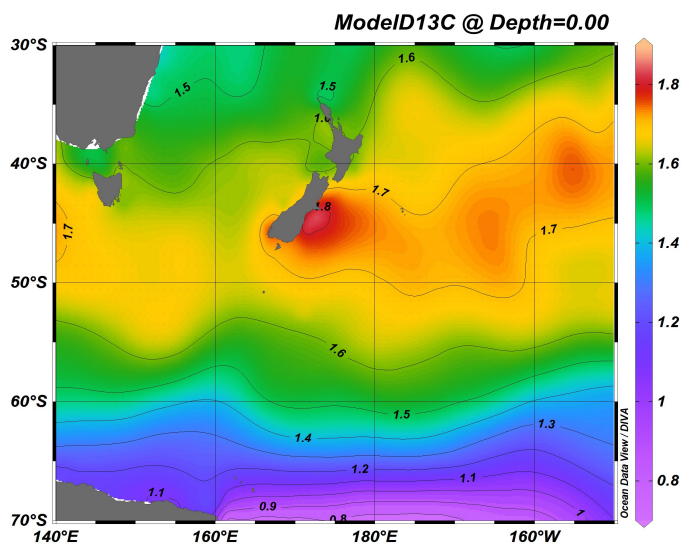

(a) Spring Model

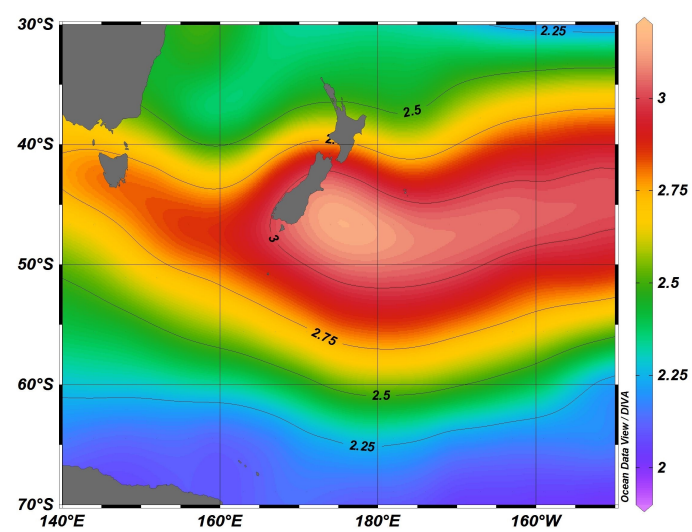

(b) Sonnerup $1750 \mathrm{GCM}$

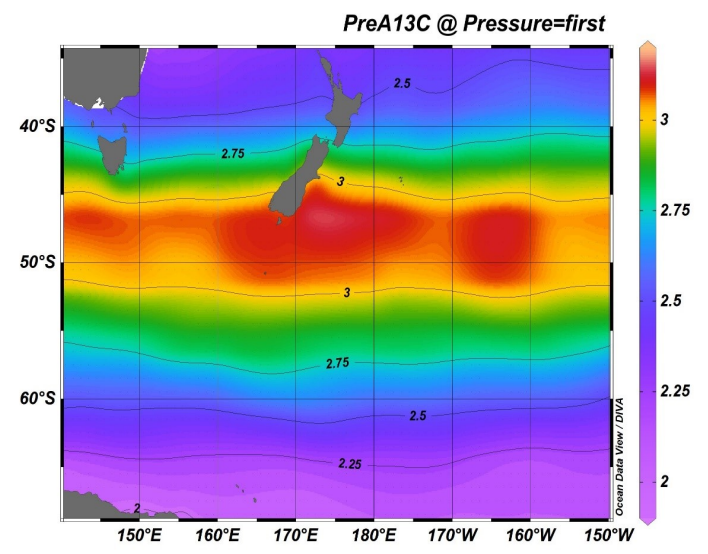

(c) Pre-industrial Model

Figure 3.3: The two models used to create the pre-industrial model for this study. a) The spring model has been described in the previous chapter. b) The Sonnerup GCM is a low resoluiton model based on wind and sea circulation to estimate preindustrial $\delta^{13} C$ around New Zealand. c) The resulting pre-industrial model that was created from a) and b)

Finally, these data were grouped into the zones of study throughout the region by latitude and averaged for each zone. All data for each zone was averaged for the core top data and plotted against an average value of the zone from the spring and pre-industrial models (Figure 3.5). This is another test of the model validity and correlation to the core top data.

\subsection{Results}

\subsubsection{Pre-industrial $\delta^{13} C$ Model}

The pre-industrial model created for this thesis was based off the GCM created by Sonnerup et al. (2012) for the year 1750. The distribution of which has been discussed in previous chapter, although for a different year 2003 (Chapter 



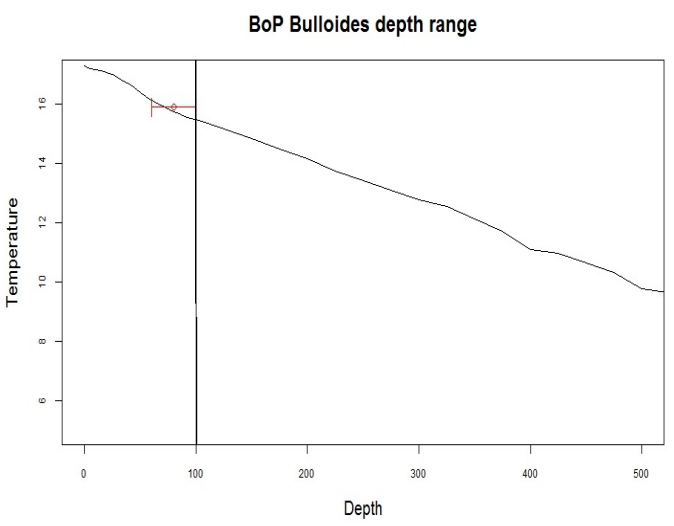

(a) $\mathrm{BoP}$

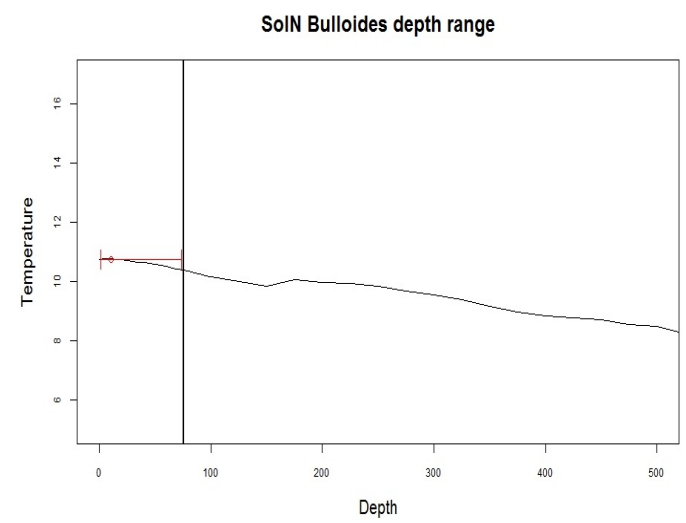

(c) SolN

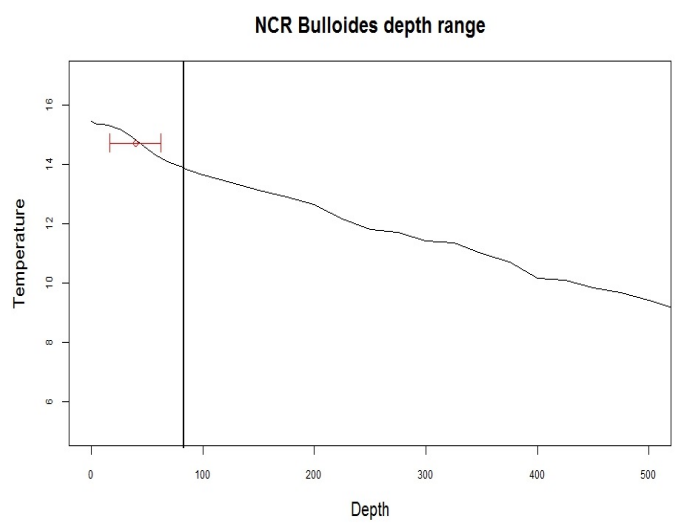

(b) NCR

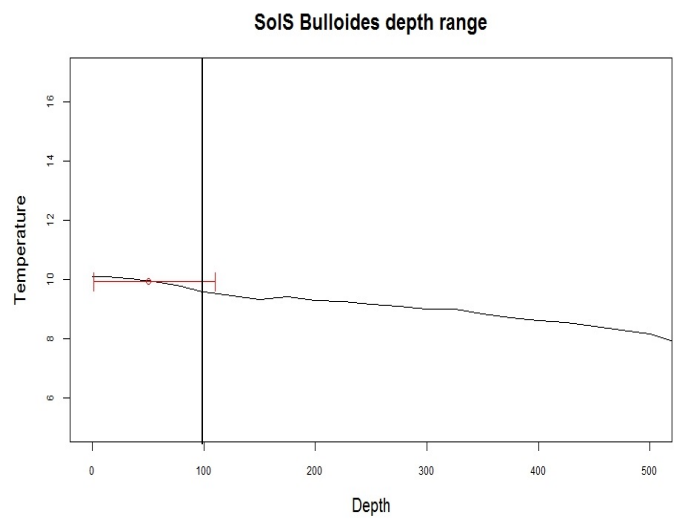

(d) SolS

Figure 3.4: Depth of habitat for G. bulloides based on the temperature obtained from $\delta^{18} O$. This temperature was compared to spring temperatures of each region and plotted with error. The vertical black line is my estimation of the mixed layer depth based on the temperature curve. It falls generally around $100 \mathrm{~m}$ depth as discussed in this chapter. 
1750 latitudinal gradient from the Sonnerup model and adding it to the spring model) and thus there are less longitudinal differences. In general, there are no unexpected high or low values in places that are much different than the summer model and therefore it is assumed to be suitable for comparing to the core top data.

\subsubsection{Model $\delta^{13} C$ versus core top $\delta^{13} C$ G. bulloides}

Core tops are thought to have dates ranging from the present back to 500 years BP (although some have not been dated and so may be considerably older). This time contains the inception and domination of the anthropogenic signal in $\delta^{13} C$ records (Suess effect). Therefore, due to age uncertainty in the core top this can lead to large differences between the $\delta^{13} C$ G. bulloides from the core tops and pre-industrial and modern $\delta^{13} C$ conditions. Figure 6 shows the Monte Carlo simulation trend of the core top data versus the pre-anthro and modern model $\delta^{13} C$ data sets. The two model data sets were taken as transects along $180^{\circ}$ since most of the core top data is east of New Zealand, and therefore, the model transect should reflect the core data well. Both the modern and pre-industrial models show a peak at the STF $\left(45^{\circ} \mathrm{S}\right)$ and declining values to the north and south. In this figure the modern data has relatively small $\delta^{13} C$ variation relative to the other two data sets. The core top data shows a similar trend, but with two peaks. The higher $\delta^{13} C$ value peak is on $45^{\circ} \mathrm{S}$, the second peak is at approximately $49^{\circ} \mathrm{S}$.

\subsubsection{Temperature from depth}

Four of our six zones (excluding the SCR and PF zones) have core tops. Table 3.1 describes all pertinent values, including: $\delta^{18} O$ values and error, calculated temperature from the $\delta^{18} O$ and associated error, and the calculated depth from temperature and error in that depth range for each zone, these are also shown in Figure 7a-d. The large depth error of both Solander zones are taken to mean that the depth range spans the surface to $100 \mathrm{~m}$ depth. All values from all the zones show that the range is constrained to the upper $110 \mathrm{~m}$ of the water column. These results suggest that the planktic G. bulloides live within the upper mixed layer of the ocean (typically the upper $100 \mathrm{~m}$ ). 


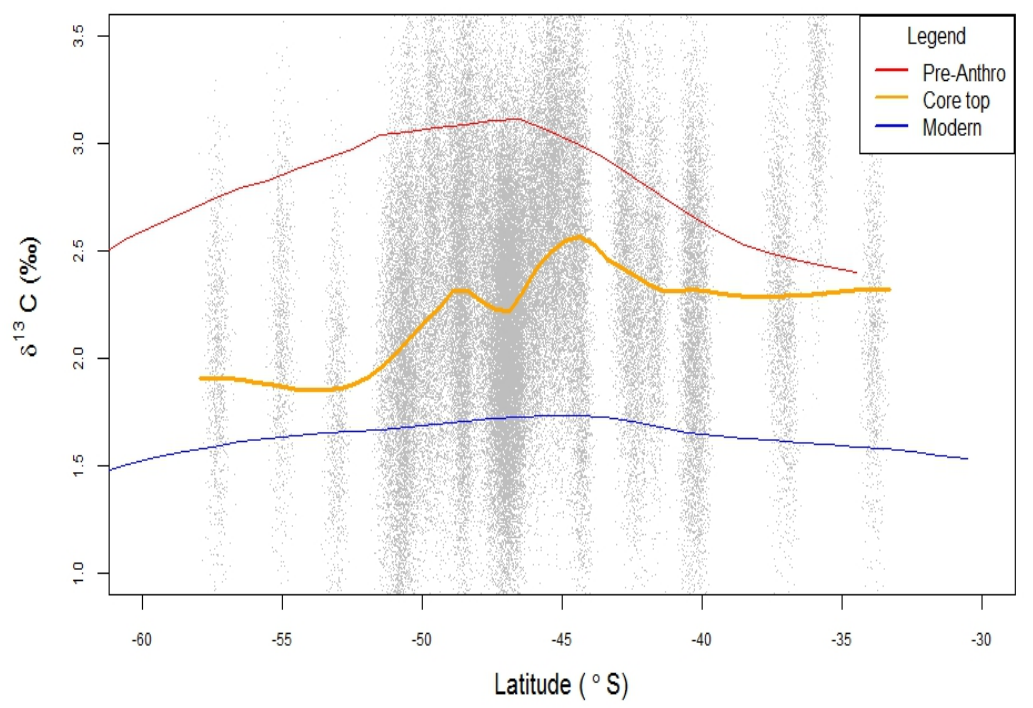

Figure 3.5: Core top $\delta^{13} C$ data plotted against a transect $\left(180^{\circ}\right)$ from the preanthro and spring models. Core tops show two distinct peaks, which is the STF at both the Chatham Rise and Solander Trough. Core top values plot between the modern and pre-anthro data, showing that they record the transition from Holocene to modern values.

\subsubsection{Discussion}

\subsubsection{Model $\delta^{13} C$ versus core top $\delta^{13} C$}

Figure 3.5 shows both the modern and pre-anthro latitudinal variation plotted against the core top latitudinal variation. In the model data, the expected $\delta^{13} C$ variation is seen: a high at the $\mathrm{STF}$ with values dropping to the north and south (Sonnerup et al., 1999, 2012; Schmittner et al., 2013; Quay et al., 2003). This peak is due to the mixing at the STF that generates zone of high biologic activity throughout the year (Chiswell et al., 2003; Murphy et al., 2001). The models and core top data capture this well. This is especially true of the core top data as it captures the STF in two places.

There is a discrepancy in the location of the $\delta^{13} C$ peak in the models and the actual location of the STF $\left(45^{\circ} \mathrm{S}\right)$. The peak is located at approximately $47^{\circ} \mathrm{S}$ in the models, south of the actual STF location. This location is at approximately the same latitude as the low between the two STF peaks in the core top $\delta^{13} C$ data. This can be accounted for by the distribution of biology during the summer. Since the modern distribution curve is from the summer model from Chapter 2, and the pre-anthro model uses this same model as the base, the summer distribution of $\delta^{13} C$ (biology) is imprinted upon the curves. This distribution has a $\delta^{13} C$ high just south of the location of the STF 
(Chiswell et al., 2013), and thus, does not line up with the accepted location of the STF.

The most significant characteristic of Figure 3.5 is that the core top data plots as intermediate to the pre-anthro and modern $\delta^{13} C$ values. This suggests that these core top values are either a mix of pre-anthro and modern values, or a range of age values in between these two conditions. By plotting the data points it is clearly seen that the data represents a range of ages and associated $\delta^{13} C$ values between the pre-anthro and modern conditions. By plotting these core top values we show that they capture the transition between the preanthro and modern conditions. Overall, the pre-anthro model describes the latitudinal trend of $\delta^{13} C$ well. There are problems arising from the longitudinal variation and linear contours, but it matches our core top data.

\subsection{Conclusions}

In this chapter the stable isotopes from the G. bulloides measured in core tops were compared to the surface/mixed layer water properties of the modern and pre-anthropogenic period (1750 AD) from different regions around New Zealand. The oxygen stable isotopes were used to show that the G. bulloides live in the upper $100 \mathrm{~m}$ of the water column in all the regions, this means that they live in the upper mixed layer of the oceans. The $\delta^{13} C G$. bulloides temperature corrected core top data was then compared to the modern summer $\delta^{13} C$ model (Chapter 2) and the pre-anthro $\delta^{13} C$ model. The results suggest that the $\delta^{13} C G$. bulloides corrected temperature data from the core tops sit between the modern and pre-anthro $\delta^{13} C_{D I C}$ values for the surface waters of the SW Pacific. 


\section{Chapter 4}

\section{Downcore study and climate reconstruction}

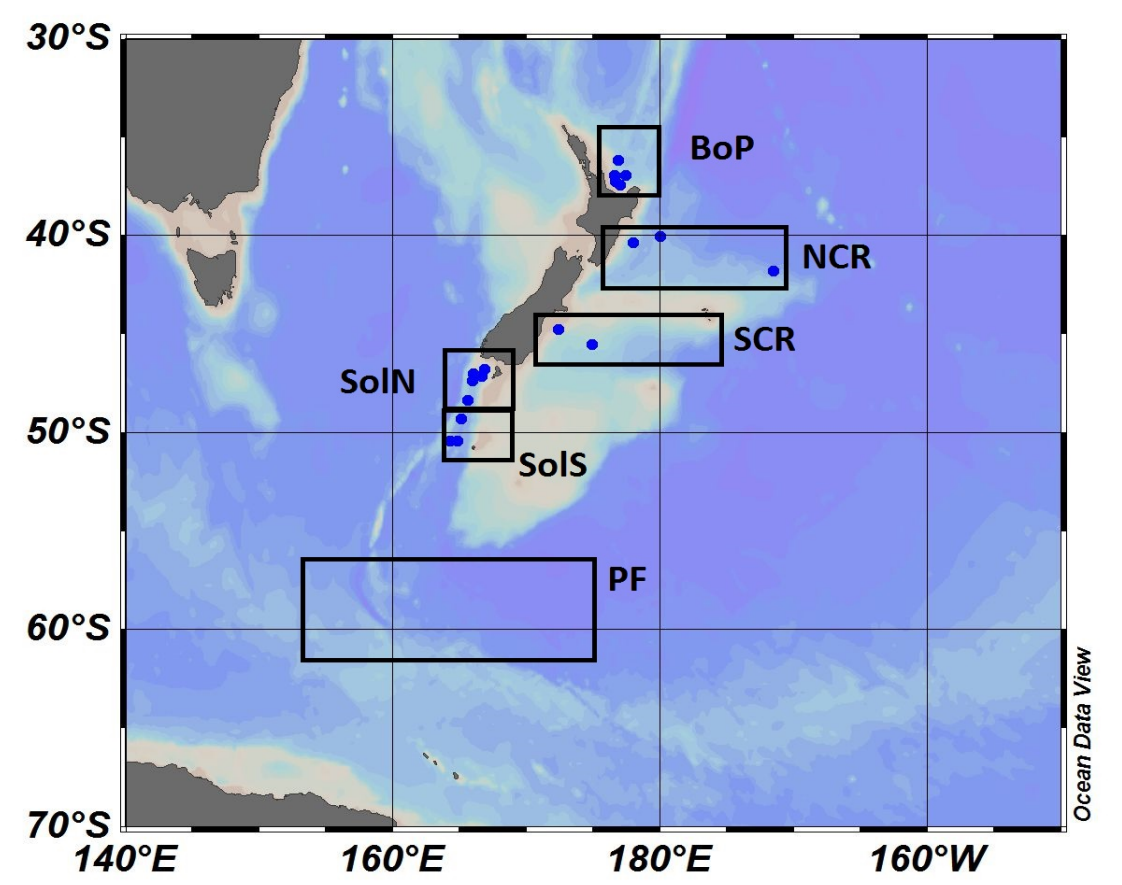

Figure 4.1: Location of all cores used in this study. Boxes indicate the six zones used to separate all cores.

\subsection{Introduction}

Chapter 4 of this thesis comprises the downcore portion of the study. The cores are divided into zones based on oceanographic conditions. For each zone the $\delta^{13} C$ of $G$. bulloides is described and compared to other $\delta^{13} C G$. bulloides histories from the literature to determine how and why the climate changed from a $\delta^{13} C$ perspective. 


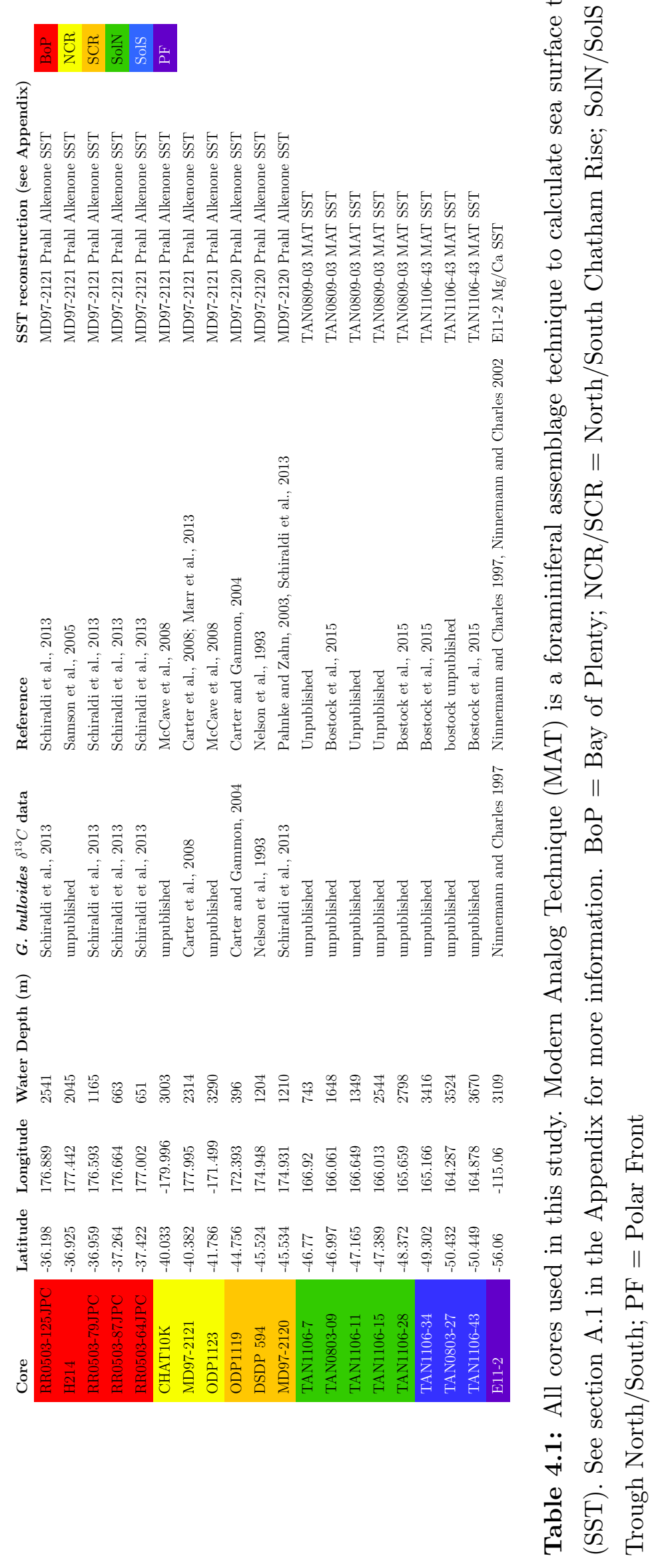


This comparison will be the final test of my hypothesis that the westerly wind belt, biologic pump, and circulation changes worked in concert to alter the carbon cycle on glacial/interglacial timescales.

\subsection{Methods}

\subsubsection{Cores and data}

All the core data from this study was previously analyzed, with some published, but much of it unpublished. Cores for this study were selected for their location (Figure 4.1) and resolution, with the hope of having $<1000$ year resolution through the last $25 \mathrm{ka}$ to look at changes in the $\delta^{13} \mathrm{C}$ and carbon cycle across the last glacial. Table 4.1 shows the information on each core and the

\begin{tabular}{|l|l|}
\hline Time slice & Age (ka) \\
\hline Early Holocene (EH) & $2-4$ \\
\hline Mid Holocene (MH) & $6-8$ \\
\hline Late Holocene (LH) & $10-12$ \\
\hline Antarctic Cold Reversal (ACR) & $13-15$ \\
\hline Early Deglacial (ED) & $16-18$ \\
\hline Last Glacial Maximum (LGM) & $18-20$ \\
\hline Glacial (G) & $22-24$ \\
\hline
\end{tabular}

Table 4.2: Time slices used for the latitude versus $\delta^{13} C$ plots. oceanographic conditions. Several previous studies have looked at the $G$. bulloides $\delta^{13} C$ data from this region. Schiraldi et al. (2014) conducted a study using a series of cores from the Bay of Plenty (BoP). The data from the BoP cores are used in this study and are considered the sub-tropical end member with the addition of data from core H214 (Samson et al, 2005). Chatham Rise and Solander Trough cores were chosen for their proximity to the Sub-Tropical Front (STF). The STF is an important productivity zone and any changes in it are thought to be significant, so cores bounding each location to the north and south were thought important. The North and South Chatham Rise (NCR and SCR) both center around the MD97 cores taken in each zone (MD97-2121, MD97-2120 respectively) because are high resolution $(<1000$ years) cores. The other cores in the zones were used to provide additional data. Solander Trough cores are relatively low resolution. By combining them together (creating one large dataset from all cores), they provide a high-resolution dataset similar to the individual MD97 cores. Unfortunately, there are no cores between the Sub-Antarctic Front (SAF) and Polar Front (PF) due to scouring of the sea floor by the very strong currents of the Antarctic Circumpolar Current (ACC) in this region. The PF core used in this study is E11-2 found in the Eastern Pacific. It is the only core available south of the Polar Front with $G$. bulloides data. It is a low resolution core ( $>2000$ years) with incomplete age coverage from $25 \mathrm{ka}$ to $15 \mathrm{ka}$. 


\subsubsection{Age models}

Age models are the backbone of marine core paleoclimate studies. Poor age constraint can lead to misinterpretation of data and incorrect conclusions. The chronology for most of the cores in this study was previously developed. For the cores that did not have age models two methods were used: comparing the $\delta^{18} O$ record against a global benthic $\delta^{18} O$ stack record (e.g. LR04; Lisiecki and Raymo, 2005) and radiocarbon ages. Radiocarbon data need to be corrected for the reservoir ages of the core location. These were obtained through the model created by Fairbanks et al., (2005); Butzin et al. (2005); and Cao et al. (2007) (http://radiocarbon.LDEO.columbia.edu/). These values along with conventional radiocarbon dates were run through the application Calib 7.1 using the MARINE calibration curve to obtain calibrated ages (http://calib.org/calib/calib.html; calendar years before present (BP), which for radiocarbon is 1950 AD prior to the Nuclear Bomb testing which overwhelmed the natural radiocarbon signal). These calibrated ages provided tie points for the $\delta^{18} \mathrm{O}$ age model.

\subsubsection{Correcting $G$. bulloides $\delta^{13} C$ data}

As discussed in the previous chapter comparing the core tops to the modern $\delta^{13} C_{D I C}$ in the ocean, King and Howard (2004) determined that the difference between $G$. bulloides $\delta^{13} C$ test values and $\delta^{13} C_{D I C}$ values is dependent on the temperature of the water in which they are formed. They also show that the experimental disequilibrium from ambient seawater equation $\left(\mathrm{y}=\left(-0.11^{*} \mathrm{~T}\right)\right.$ 0.77; Figure 3.2) determined by Bemis et al. (2000) can be used to correct for the disequilibrium at all modern oceanic temperatures $\left(0-25^{\circ} \mathrm{C}\right)$. This equation was used to determine disequilibrium in $G$. bulloides through time and correct the $\delta^{13} C G$. bulloides data to equivalent DIC values. SST reconstructions were not present in most cores, for those that have SST estimates different paleoproxy methods were used. Later in this chapter, SST reconstructions are used for the temperature correction of the $\delta^{13} C G$. bulloides. A test of the different SST proxies can be found in the appendix (Section A.1). This test was done to better understand each proxy and which would work best for this study.

For the Late Holocene timeslice, SST was assumed to have not changed from the modern SST values. For each zone, the model from Chapter 1 was used to approximate spring SST at each core location. The model has a resolution of $0.5^{\circ}$, if a core was located within $0.25^{\circ}$ of a model point, the SST from that location was used. If a core was located equidistant between two points, the SST from each point was averaged and given as the temperature. 
Once a temperature was assigned to each core within a zone, all temperatures were averaged to get a temperature for the region.

Previous researchers have also identified a difference in $\delta^{13} C$ between the Holocene and the glacial periods, suggesting that this is due to changes in the terrestrial carbon reservoir. This offset is thought to be the result of less vegetation due to the presence of glaciers over the land. $\Delta \delta^{13} C$ between the Holocene and glacial period has been determined to be approximately $0.34 \%$ (Peterson et al., 2014). Unfortunately, it is not clear how the $\Delta \delta^{13} C$ changed between the Glacial and Holocene. I have assumed that the $\Delta \delta^{13} C$ started to change at the end of the glacial (18ka) and that Holocene values of $\delta^{13} C$ were reached at $7 \mathrm{ka}$ (Lambeck and Chappell, 2001). A linear interpolation was applied to this $\Delta \delta^{13} \mathrm{C}$ dataset between $18 \mathrm{ka}$ and $7 \mathrm{ka}$. All data older than $18 \mathrm{ka}$ had $\delta^{13} C$ set lower by $0.34 \%$ (Peterson et al., 2014). All data younger than 18ka and older than $7 \mathrm{ka}$ had a linear growth through time starting at $-0.34 \%$ o at $18 \mathrm{ka}$ and ending at $0 \%$ at $7 \mathrm{ka}$. All data in the Holocene younger than $7 \mathrm{ka}$ remained unchanged.

\subsubsection{Monte Carlo simulation}

\begin{tabular}{|l|l|}
\hline Time slice & Age $\mathbf{( k a )}$ \\
\hline Late Holocene & $0-8$ \\
\hline Early Holocene & $8-12$ \\
\hline ACR & $12-14$ \\
\hline Early Deglacial & $14-18$ \\
\hline LGM & $18-21$ \\
\hline Glacial & $21-25$ \\
\hline
\end{tabular}

Table 4.3: Time slices used for the Monte Carlo simulations.
Monte Carlo simulations have been discussed in the last chapter (section 3.2.2). In this chapter, after the $\delta^{13} C \quad G$. bulloides data was corrected for temperature and glacial/interglacial terrestrial changes $\left(\Delta \delta^{13} C=-0.34 \%\right.$ o $)$. The combined corrected down core $\delta^{13} \mathrm{C}$. bulloides dataset was then run through a Monte Carlo simulation to provide a more statistically significant dataset, which takes into account the analytical error of both the $\delta^{13} C$ and the age model. The dataset for each zone was split into six timeslices (Table 4.3). The standard deviation of each timeslice was used to determine the error for the $\delta^{13} C$ dataset. Measurement error is cited as $0.05 \%$ for $\delta^{13} C$ in foraminifera (Carter et al., 2008). Our age model error was estimated to be $+/-250$ years given the variety of age models used for this study. All simulations were run through 1000 iterations. The simulation was run for each region (Figure 4.8), two intermediate water cores, and one benthic dataset (Figure 4.10) that will be used to compare against. 


\subsubsection{Temporal and Latitudinal changes in $\delta^{13} C$}

Latitudinal changes in $\delta^{13} \mathrm{C}$ can show variation of the STF through time. To show this change, seven $2 \mathrm{ka}$ time slices were chosen throughout our study period (Table 4.2). Each time slice is meant to capture stable, mean conditions and not transitional periods. Data for each zone was averaged in each time slice to give a $\delta^{13} C$ value for the zone. All zones were plotted in each time slice by latitude (middle value of the zone) to give the changing $\delta^{13} \mathrm{C}$ versus latitude through time.

\subsubsection{Cross correlations}

\begin{tabular}{|l|l|}
\hline \multicolumn{2}{|c|}{ Bay of Plenty } \\
\hline Time slice & SD (\%o) \\
\hline LH & 0.287 \\
\hline EH & 0.302 \\
\hline ACR & 0.297 \\
\hline ED & 0.274 \\
\hline LGM & 0.55 \\
\hline G & 0.242 \\
\hline
\end{tabular}

Table 4.4: Standard deviation of $\delta^{13} C$ data used for each time slice in the Monte Carlo simulation for the BoP.

dataset against the others.
To quantify in a more robust method than wiggle matching, a cross correlation was used to gather statistical data on the relationships of zones to various other datasets. These include atmospheric $\mathrm{CO}_{2}$ levels from Antarctic ice cores (Eggleston et al., 2016), $\delta^{13} C_{a t m}$ (Eggleston et al., 2016), benthic (LCDW) and intermediate water $\delta^{13} C$ (Moy et al., 2006; Ronge et al., 2015), and SST curves from each zone (except the BoP, no SST reconstructions available). Each dataset was averaged into $1 \mathrm{ka}$ timeslices with two 500year resolution points at 21.5 and $18.5 \mathrm{ka}$ (Figures 4.8 and 4.10 for zones, $\mathrm{CO}_{2}, \delta^{13} C_{a t m}$, and benthic $\left.\delta^{13} C\right)$. A cross correlation was run in $\mathrm{R}$ to determine the correlation coefficient of each

\section{$4.3 \quad$ Results}

\subsubsection{Zones of study}

\section{Bay of Plenty}

Five cores were collected in this region, four of which (JPC 64, 79, 87, 125) were taken for the study by Schiraldi et al. (2014) and one (H214) by Samson et al. (2005). The trends of the different cores are relatively similar, but have a large spread of $\delta^{13} C$ values (approximately 1\% in places; Figure 4.2b). Glacial values are only in cores JPC 125, 87, and 79. All three record relatively high $\delta^{13} \mathrm{C}$ values prior to the large drop seen at $21 \mathrm{ka}$. A large spike is seen in all 


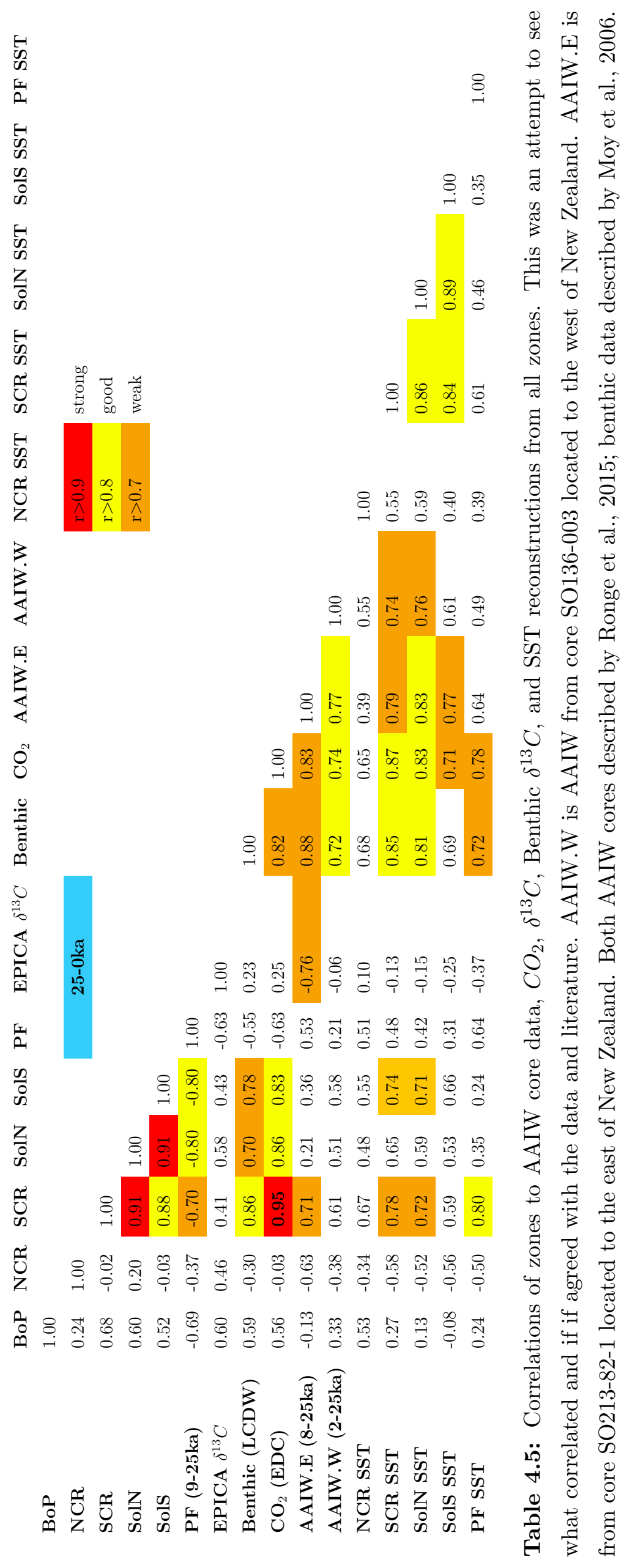


three cores at 20ka immediately prior to the large drop. JPC 125 and 79 record this quite similarly, but 89 does not. JPC 64 begins at approximately $20 \mathrm{ka}$ with low values similar to cores 125,87 , and 79 at the low point of the $\delta^{13} \mathrm{C}$ drop. 125 and 64 record values as low as $1 \%$ below those of 87 and 79 from 20 to 18ka. All cores seem to converge at 17ka, with H214 beginning at $16 \mathrm{ka}$ with relative low values like those of 64 . All cores stay relatively close to each other in values from $15 \mathrm{ka}$ to $5 \mathrm{ka}$. At $5 \mathrm{ka}$, only 125 and 64 have data younger than $5 \mathrm{ka}$, with values differing as much as $0.75 \%$. But they converge to almost identical values in their core tops.

The trend obtained from the Monte Carlo simulation has stable $\delta^{13} \mathrm{C}$ levels in the glacial (21-25ka) at $1.75 \%$. The oldest data point or two seem to suggest a downward $\operatorname{dip}$ in $\delta^{13} \mathrm{C}$ values at $25 \mathrm{ka}$, but whether this continues into the past is uncertain. It is assumed that all data 21-25ka are stable and unchanging.

Between 21ka and 20ka a small increase in $\delta^{13} C$ values is seen. This increase lasts only a couple hundred years and immediately precedes a major drop in $\delta^{13} C$ lasts approximately 2000 years starting at $20 \mathrm{ka} . \delta^{13} C$ levels drop by $0.75 \%$ o to the lowest values we see at $1 \%$ at approximately $18 \mathrm{ka}$. A steady increase is seen from $18 \mathrm{ka}$ to $7 \mathrm{ka}$, although there are two minor reversals during this period. The first begins at approximately $17 \mathrm{ka}$ and lasts until 15ka. A drop of $0.1-0.15 \%$ is seen during this time. This change is quite small and is within the standard deviation in this time period (Table 4.4), so is most likely insignificant. The second slightly larger drop of $0.2-0.25 \%$ occurs at $12 \mathrm{ka}$ and lasts until 10ka. From $7 \mathrm{ka}$, a slight drop in $\delta^{13} \mathrm{C}$ values to $5.5 \mathrm{ka}$ occurs which leads into a gently sloping rise to $4 \mathrm{ka}$ and then a fall to modern.

The Holocene (12-0ka) period has the lowest data density in this region (Figure 4.2a). Due to this, it is assumed that the data sparsity is biasing the data during this period. There are six data points in the past 4000 years in this zone, two of which are coretops. Large time periods separate out these points. The four points older than 1000 years show a general, unchanging trend in the data and the downturn occurs between the coretop and the youngest of these data. The Holocene trend most likely lasts until the commencement of the burning of fossil fuels at the beginning of the industrial revolution (approximately 300 years ago). The coretop data reflect the falling of $\delta^{13} C$ values, but due to the low resolution of the data, show the downward trend occurring at older dates than it actually occurred. Throughout the rest of the time span, data density is high, with the highest density between 18 and 17ka. 


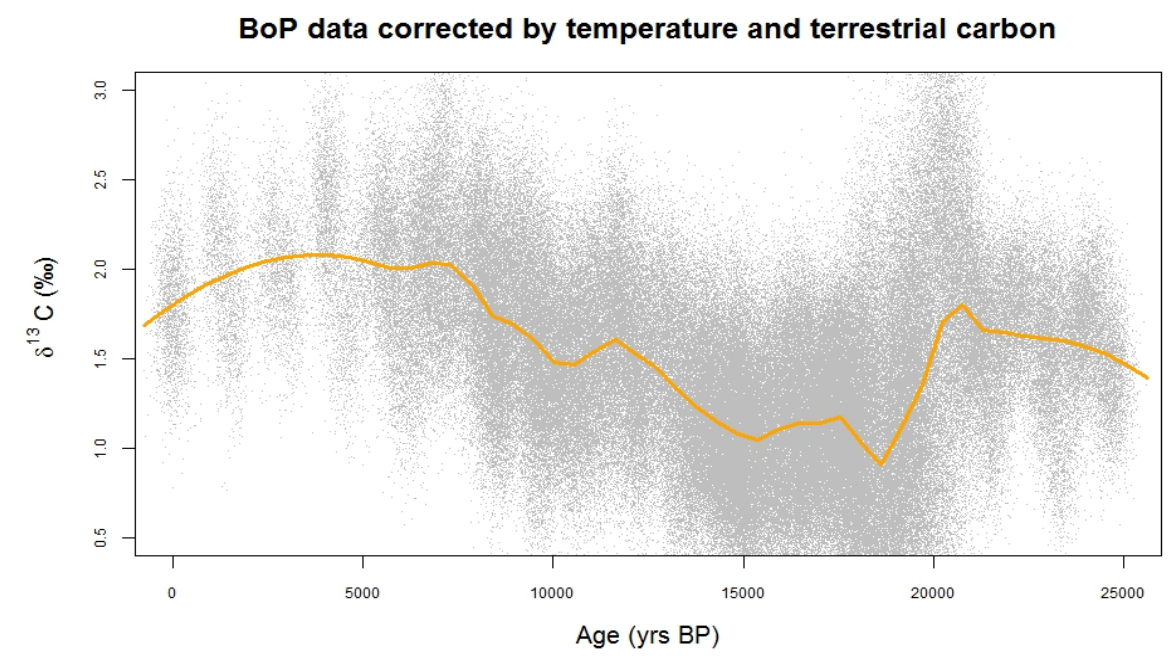

(a) Bay of Plenty Monte Carlo simulation

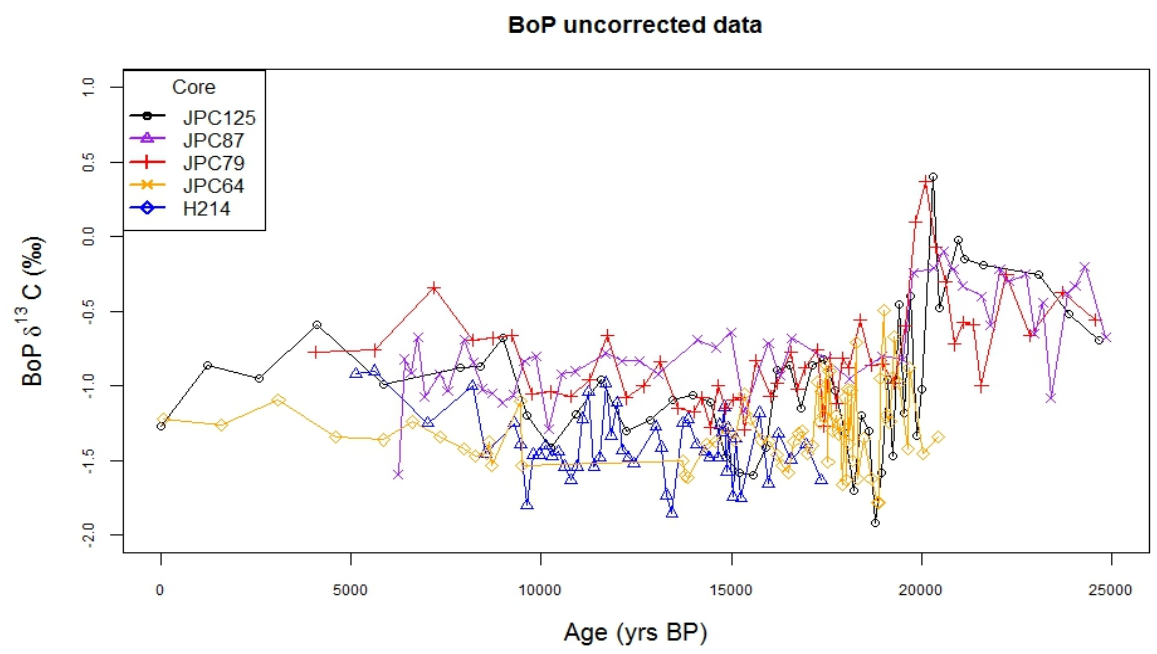

(b) Bay of Plenty uncorrected data

Figure 4.2: a) Monte Carlo simulation of the BoP. High values in the glacial and a large drop at the beginning of the deglacial differentiate the BoP from other regions. b)Uncorrected data from the BoP. High data density is present throughout the study period except the last 5ka. 


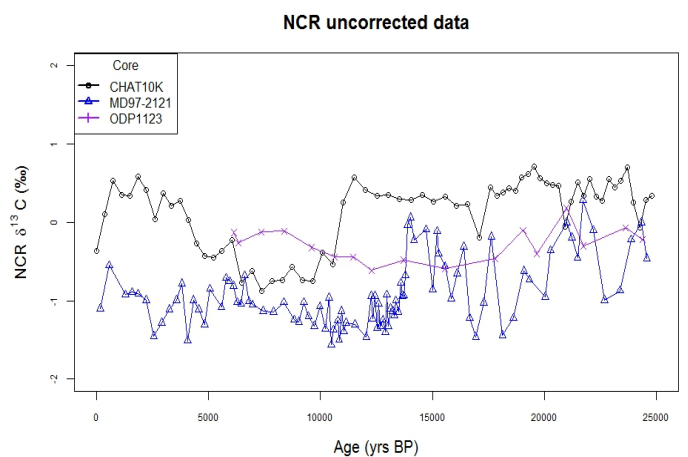

(a) North Chatham uncorrected data

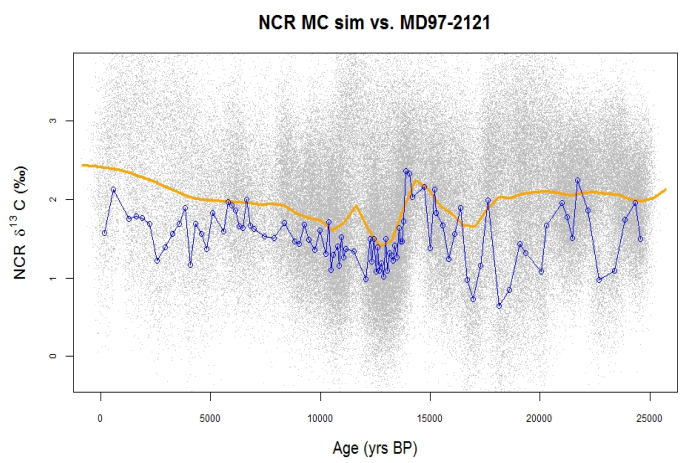

(c) North Chatham Rise versus MD97-2121

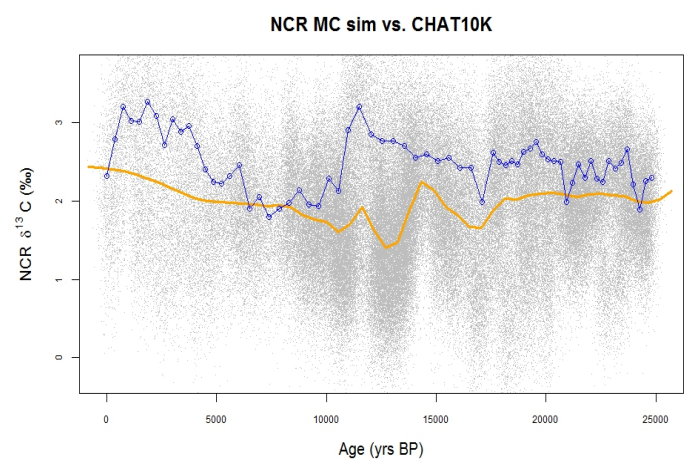

(b) North Chatham Rise versus CHAT10K

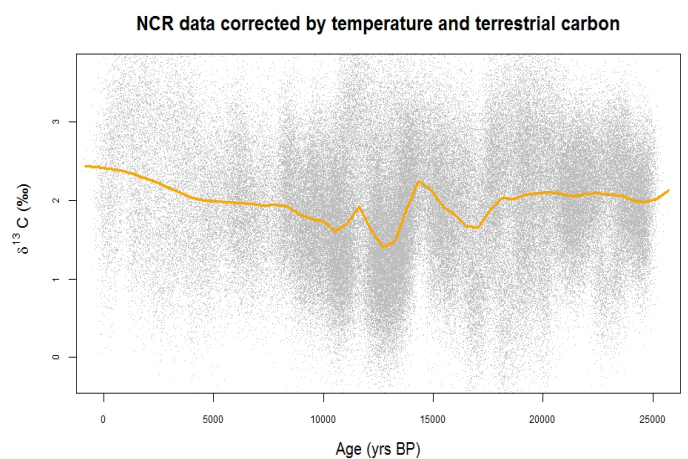

(d) North Chatham Rise Monte Carlo simulation

Figure 4.3: a) Uncorrected NCR data. MD97-2121 is the highest resolution and is a large bias on the final sim. b-c) These two show the relative bias of the two highest resolution cores in the zone. MD97-2121 dominates the signal. D) the final Monte Carlo simulation of the NCR. 


\section{North Chatham Rise}

The NCR is made up of three cores: MD97-2121, ODP-1123, and CHAT10K (Table 4.1). MD97-2121 is by far the highest resolution core of the four (Figure 4.4). ODP1123 generally follows the trend of MD97-2121 until approximately $14 \mathrm{ka}$, where higher values in ODP1123 are seen. CHAT10K has the highest values within the zone, with a $\Delta \delta^{13} C$ between CHAT and MD97 of up to $0.75 \%$, most notably between $14 \mathrm{ka}$ and 10ka. A steep negative trend in the data is seen in both cores (15-13ka), but they are separated by 4000 years (Figure 4.3d).

The trend obtained from the Monte Carlo simulation shows values biased toward MD97-2121 (Figure 4.3c). This is not surprising because of the high resolution of MD97-2121. The influence of CHAT10K is seen at approximately 10ka (Figure 4.3a,b), when the large $\left(>0.5 \%\right.$ o drop in $\delta^{13} C$ is seen in the Monte Carlo simulation and CHAT10K.

\begin{tabular}{|l|l|}
\hline \multicolumn{2}{|l|}{ North Chatham Rise } \\
\hline Time slice & SD $(\%)$ \\
\hline LH & 0.567 \\
\hline EH & 0.533 \\
\hline ACR & 0.578 \\
\hline ED & 0.548 \\
\hline LGM & 0.662 \\
\hline G & 0.431 \\
\hline
\end{tabular}

Table 4.6: Standard deviation of $\delta^{13} C$ data used for each time slice in the Monte Carlo simulation for the NCR.

In the glacial there is a dip in the data $(0.2 \%$ ) that lasts $2 \mathrm{ka}$ from 25 -23ka but since it is much lower than the standard deviation of this time slice, it is not significant (Table 4.5). Due to the noise within the original data it is difficult to define whether this is an edge effect of the simulation or an actual trend. The length of the dip suggests that the low values seen are robust but the upward trend at $25 \mathrm{ka}$ is likely artifact.

These stable values continue to $17.5 \mathrm{ka}$. After which small decline of $0.3 \%$ occurs, but is well within the standard deviation, so most likely not significant. Following this, an increase to a maximum $\delta^{13} C$ value of $2.3 \%$ at $14.5 \mathrm{ka}$ is followed by a sharp decline of $0.5 \%$ at $13 \mathrm{ka}$. This is almost immediately followed by another peak at $12 \mathrm{ka}$ that has a lower value than the previous peak at $2.0 \%$. A small drop in $\delta^{13} C$ to $1.75 \%$ o (11ka) is the final sharp change in the Early Holocene.

$\delta^{13} \mathrm{C}$ values steadily climb from $11 \mathrm{ka}$ to $8 \mathrm{ka}$ where they level off at $2.0 \%$ o until $4 \mathrm{ka}$. At $4 \mathrm{ka}$ a gentle climb is seen to pre-industrial values $(2.5 \%$ ) (Figure 4.3). There is a general trend upward from $4 \mathrm{ka}$ which seems to be biasing from the CHAT10K core. Values from 4ka to the present are much higher than the MD97-2121 core and most likely cause the high values seen in the Monte Carlo 


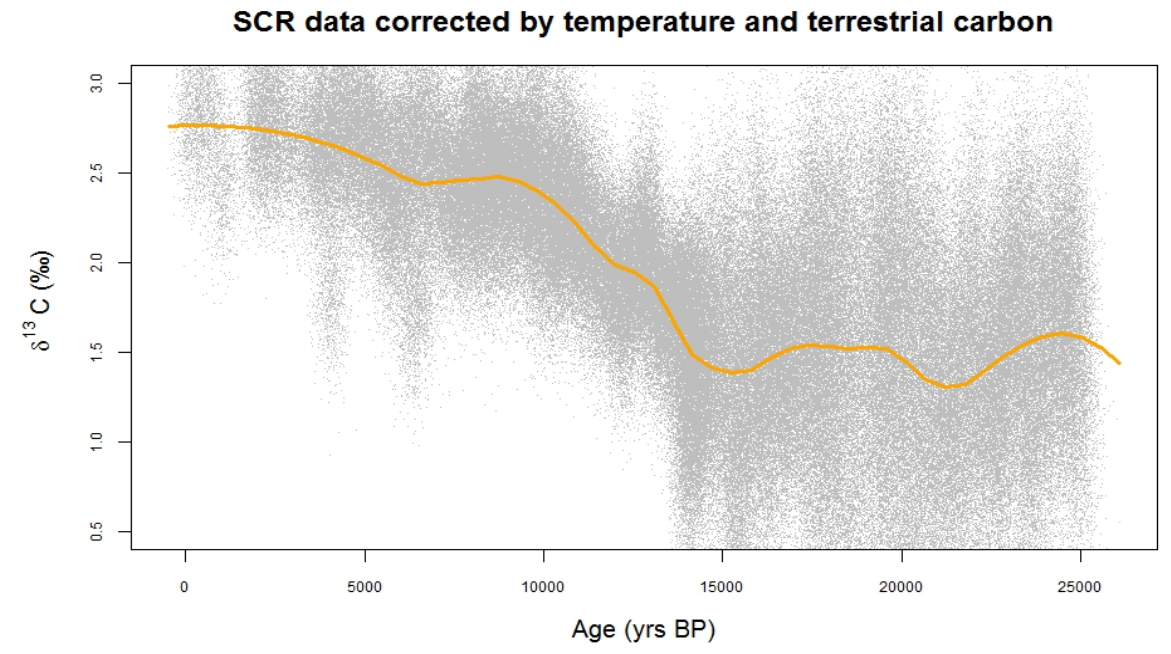

(a) South Chatham Rise Monte Carlo simulation

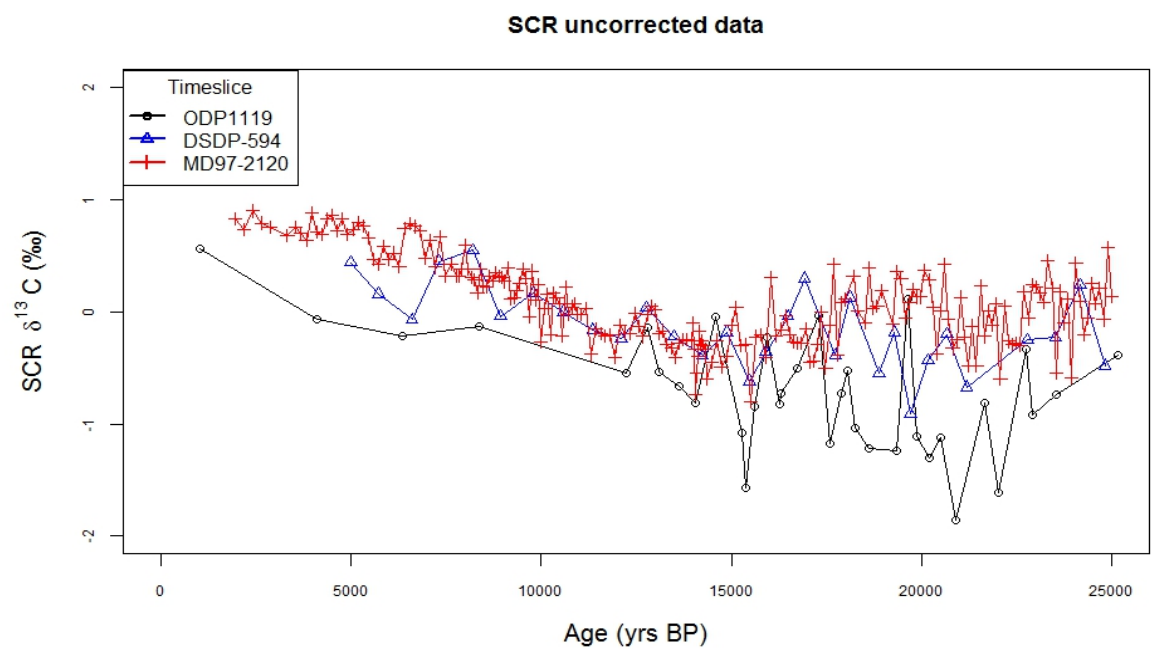

(b) South Chatham Rise uncorrected data

Figure 4.4: Uncorrected data and final Monte Carlo simulation of the SCR. All uncorrected data follows similar trends and agrees relatively well.

sim and are not representative of the downward trend in $\delta^{13} C$ seen in the last 200-300 years.

\section{South Chatham Rise}

The cores used for this zone are MD97-2120, DSDP-594 (Nelson et al., 1993), and ODP-1119 (Carter and Gammon, 2004) (Figure 4.4; Table 1). MD97-2120 is a high resolution stratigraphic history of the zone while the other two cores provide low resolution records. MD97-2120 and DSDP-594 show, generally, the same trend (Figure 4.4). ODP-1119 has lower values throughout the study period, but has a similar trend. The issue with these three cores is that they do not contain data $<1000 \mathrm{ka}$. To fill in this time period, core top data from 
Q208 was taken to fill out this period. This core contains poor age constraint and was not chosen for this study for that reason. The two core top data points are dated at 600 and 200 years but give almost identical $\delta^{13} C$ values, suggesting that the ages are not well constrained. The $\delta^{13} C$ values given are $2.8 \%$, which match well with our pre-industrial model in the SCR zone. Thus, they were included in the Monte Carlo simulation to round out the timeline.

The South Chatham Rise (SCR) is in a unique position: it lies south of the bathymetrically locked STF on the southern slope of the Chatham Rise. This zone will be discussed more in the next chapter. The Monte Carlo simulation is dominated by the MD97-2120 trend since it contains $>75 \%$ of the data for this zone. Low values $(1 \%$ ) persist from $25 \mathrm{ka}$ to $15 \mathrm{ka}$. Minor variations occur through this period. The peak at $24 \mathrm{ka}$ of $1.4 \%$ is the highest of the period. A drop from $24 \mathrm{ka}$ to $21 \mathrm{ka}$ leads to the low of the period of $1 \%$. The $\delta^{13} C$ levels settle at $1.3 \%$ for the remainder of this first period.

\begin{tabular}{|l|l|}
\hline \multicolumn{2}{|l|}{ South Chatham Rise } \\
\hline Time slice & SD $(\%)$ \\
\hline LH & 0.253 \\
\hline EH & 0.246 \\
\hline ACR & 0.212 \\
\hline ED & 0.386 \\
\hline LGM & 0.573 \\
\hline G & 0.427 \\
\hline
\end{tabular}

Table 4.7: Standard deviation of $\delta^{13} C$ data used for each time slice in the Monte Carlo simulation for the SCR.

A steady increase in $\delta^{13} C$ characterizes the time between 15ka and the present. A rapid upward trend occurs between $15 \mathrm{ka}$ and $9 \mathrm{ka}$ with a slight decrease in rate at approximately 14-12ka. The $\delta^{13} \mathrm{C}$ values level off from $9 \mathrm{ka}$ to $6 \mathrm{ka}$ at $2.5 \%$. A gentle climb from $6 \mathrm{ka}$ to $2 \mathrm{ka}$ is followed by a steady $\delta^{13} C$ level at $2.8 \%$ in the late Holocene (Figure $4.4 \mathrm{a}$ ).

\section{Solander Trough North}

The Solander Trough north and south (SolN, SolS respectively) zones cover an important region because of the presence of the STF dissecting the two zones in the modern ocean (Bostock et al., 2015). SolN contains five cores of relatively low resolution (TAN1106-7, 11, 15, 28; TAN0803-09) (Figure 4.5b). By combining these low-resolution cores together a high-resolution history is obtained like that of MD97-2120 in the SCR. All cores agree well with each other and there is little total variation of the dataset (all data are contained within $0.5 \%$ of each other through time) (Figure 4.5). The standard deviations of the glacial, LGM, and early deglacial time slices suggest that they are not as good as others (lower standard deviations in the SCR and BoP (Table 4.4 and 4.6)), but the Early Holocene and ACR are the lowest standard deviations of 
SoIN data corrected by temperature and terrestrial carbon

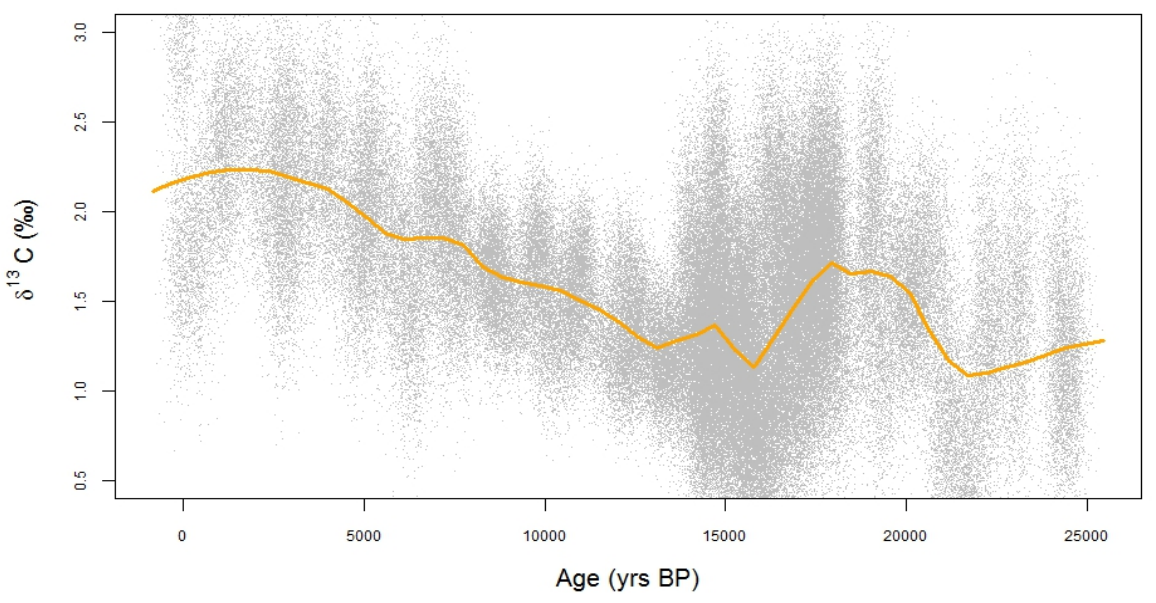

(a) Solander Trough North Monte Carlo simulation

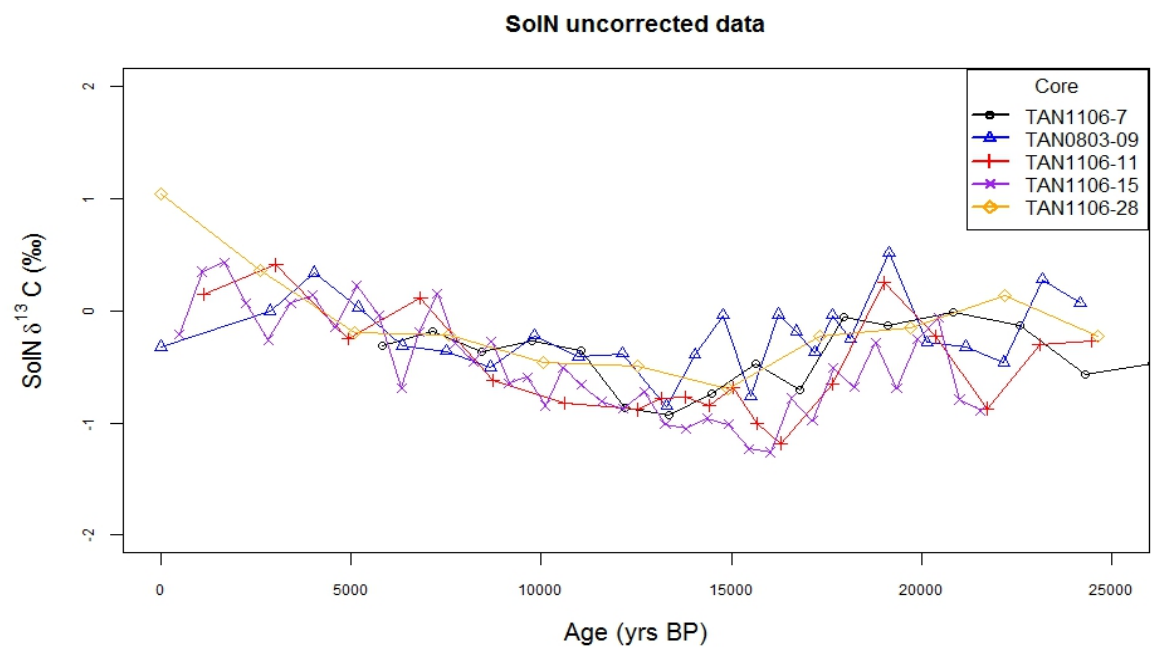

(b) Solander Trough North uncorrected data

Figure 4.5: Uncorrected and Monte Carlo simulation of Solander Trough North. All cores are relatively low resolution, but when put together, create a high resolution history of the region. 
zones with multiple cores.

Glacial $\delta^{13} C$ levels are low at $1 \%$, with a gentle Solander Trough North dip from $25 \mathrm{ka}$ to $22 \mathrm{ka}$, which characterizes the last

\begin{tabular}{|l|l|}
\hline Time slice & SD (\%) $)$ \\
\hline LH & 0.337 \\
\hline EH & 0.197 \\
\hline ACR & 0.196 \\
\hline ED & 0.387 \\
\hline LGM & 0.324 \\
\hline G & 0.376 \\
\hline
\end{tabular}
glacial maximum period. At $22 \mathrm{ka}$ a rise in $\delta^{13} \mathrm{C}$ levels begins and continues until approximately $18 \mathrm{ka}$ to a value of $1.6 \%$. A slight rise to a peak at $18.5 \mathrm{ka}$ (Figures 4.5 and 4.8 ) followed by a sharp decline to $15 \mathrm{ka}$ $\left(1 \%\right.$ ). Followed by a rise in $\delta^{13} C$ values from $15 \mathrm{ka}$ to the present.

Table 4.8: Standard

A small uptick is seen in SolN at 14.5ka with a deviation of $\delta^{13} C$ data slight decline to $12.5 \mathrm{ka}$. A gentle climb in the $\delta^{13} C$ used for each time slice levels follows to $2 \mathrm{ka}$ which is followed by a gentle dein the Monte Carlo simulation for the SolN. cline to modern $\delta^{13} C$ values. Sparse data from $2 \mathrm{ka}$ to the present makes the dip in $\delta^{13} C$ values to the present seem longer than it probably is in this zone. The low resolution of the data stretches the dip to 1000 years rather than the 350 years of post-industrial changes in $\delta^{13} C$ has taken to occur.

\section{Solander Trough South}

The southern Solander Trough is relatively data poor. Three cores are used for this zone (TAN1106-34, 43; TAN0803-27)(Figure 4.6; Table 1). Although relatively low resolution this zone sits south of the STF in the SAW and therefore provides an end member of the $\delta^{13} C$ data for this transect. Like the SolN, these lowresolution cores create a high-resolution dataset when combined. Although there are fewer cores in this zone, they are sufficient to describe the $\delta^{13} C$ trend.

\begin{tabular}{|l|l|}
\hline \multicolumn{2}{|l|}{ Solander Trough South } \\
\hline Time slice & SD $(\%)$ \\
\hline LH & 0.353 \\
\hline EH & 0.358 \\
\hline ACR & 0.394 \\
\hline ED & 0.287 \\
\hline LGM & 0.355 \\
\hline G & 0.501 \\
\hline
\end{tabular}

Table 4.9: Standard deviation of $\delta^{13} C$ data for each time slice in the Monte Carlo simulation for the SolS.

The trend shows a rise from 25ka to $23 \mathrm{ka}$, with a slight fall to $21 \mathrm{ka}$ (rise and fall between $1 \%$ and $1.2 \%$ ). This time period is low resolution for all cores and is generally considered stable and unchanging with small local variations. From $21 \mathrm{ka}$ to $15 \mathrm{ka}$ a large peak is characterized by $1 \%$ climb to the highest $\delta^{13} C$ values at $17 \mathrm{ka}(2 \%)$, this is followed by a fall over the next 2 ka to $1.3 \%$. This begins a period of stability 


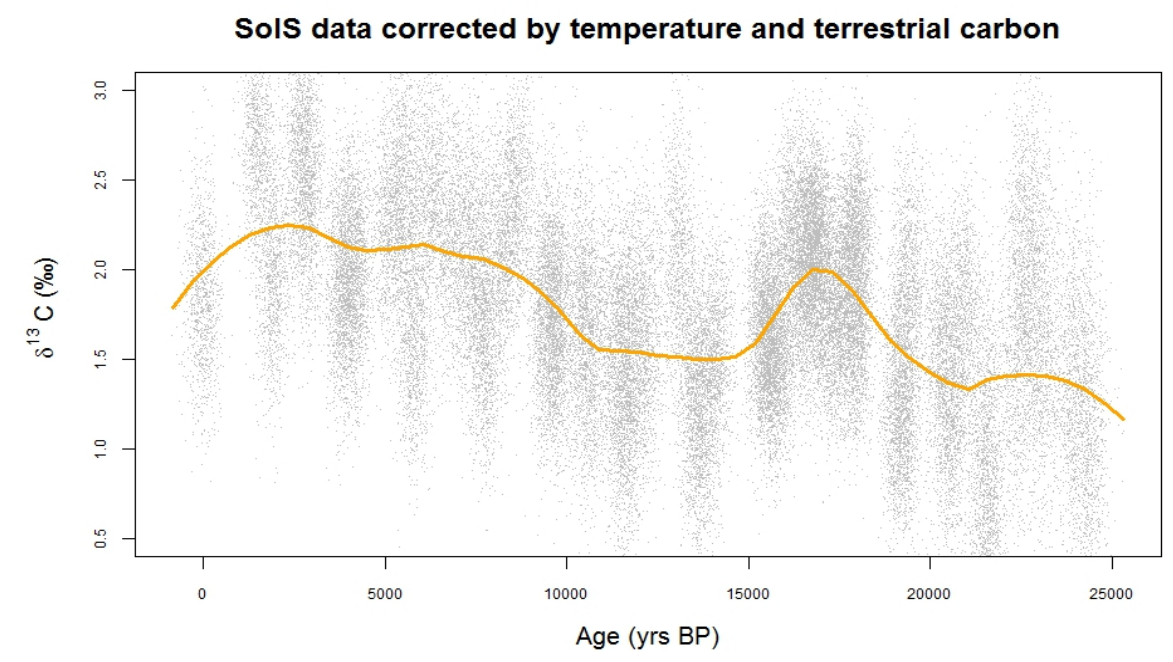

(a) Solander Trough South Monte Carlo simulation

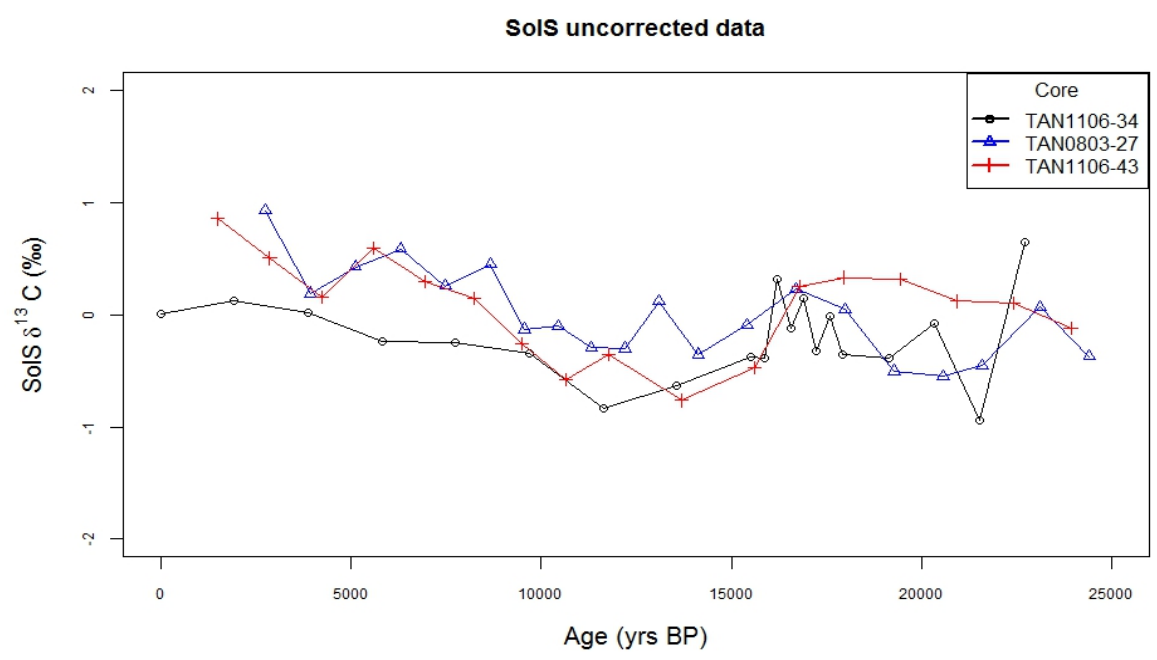

(b) Solander Trough South uncorrected data

Figure 4.6: The data for the Solander Trough South is low resolution and does not have enough cores to get a truly high resolution history. Agreement between the cores is good, so it gives a fairly robust history, even though it lacks the data. 


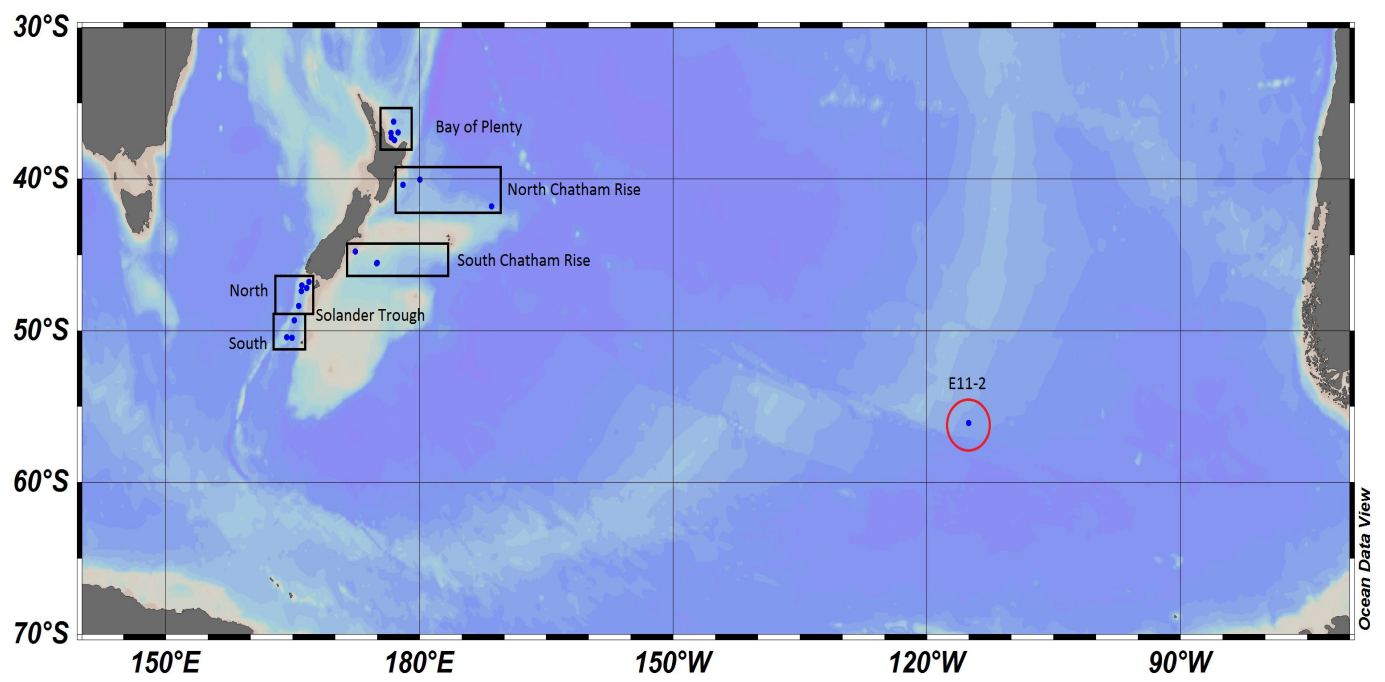

(a) Polar Front core location

PF data corrected by temperature and terrestrial carbon

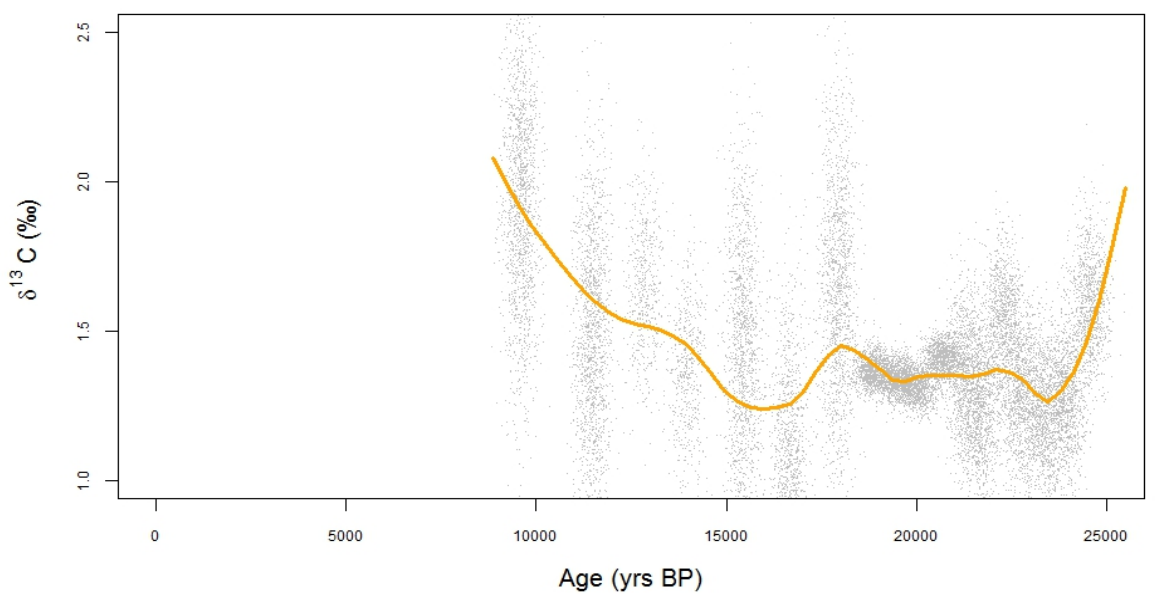

(b) Polar Front Monte Carlo simulation

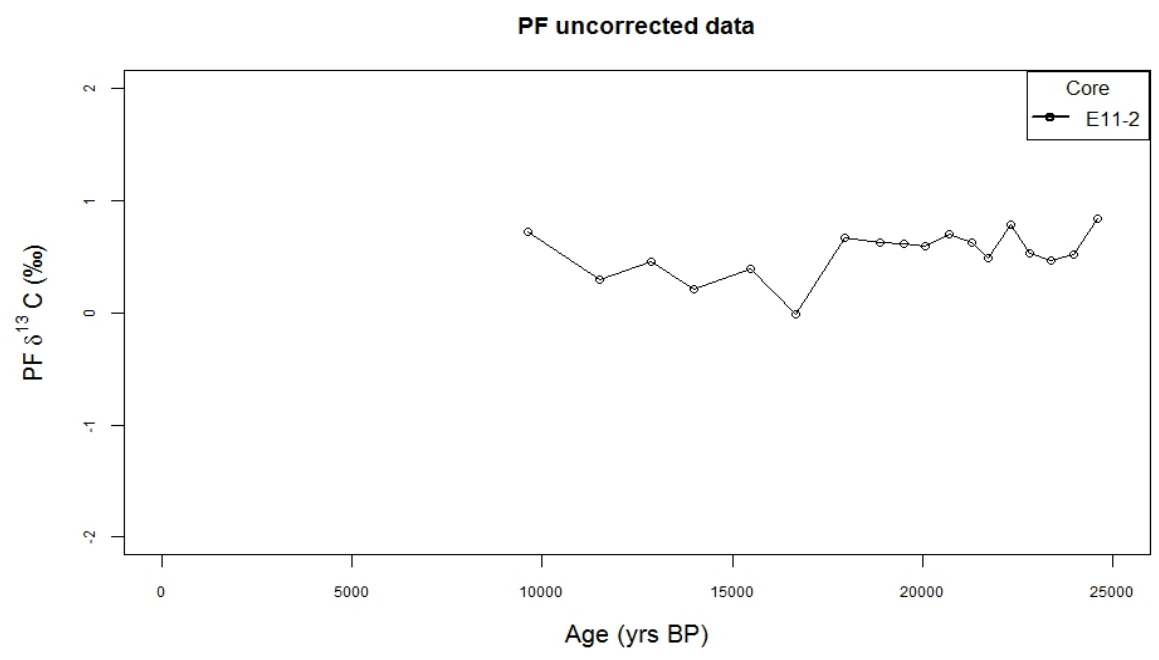

(c) Polar Front uncorrected data

Figure 4.7: Few cores have been taken south of the Polar Front and only one has $G$. bulloides analyzed. (a) Shows the location of the Polar Front core E11-2 in the Eastern Pacific along with other zones for reference. (b) The MC sim of the data from the core. (c) Uncorrected G. bulloides data. 


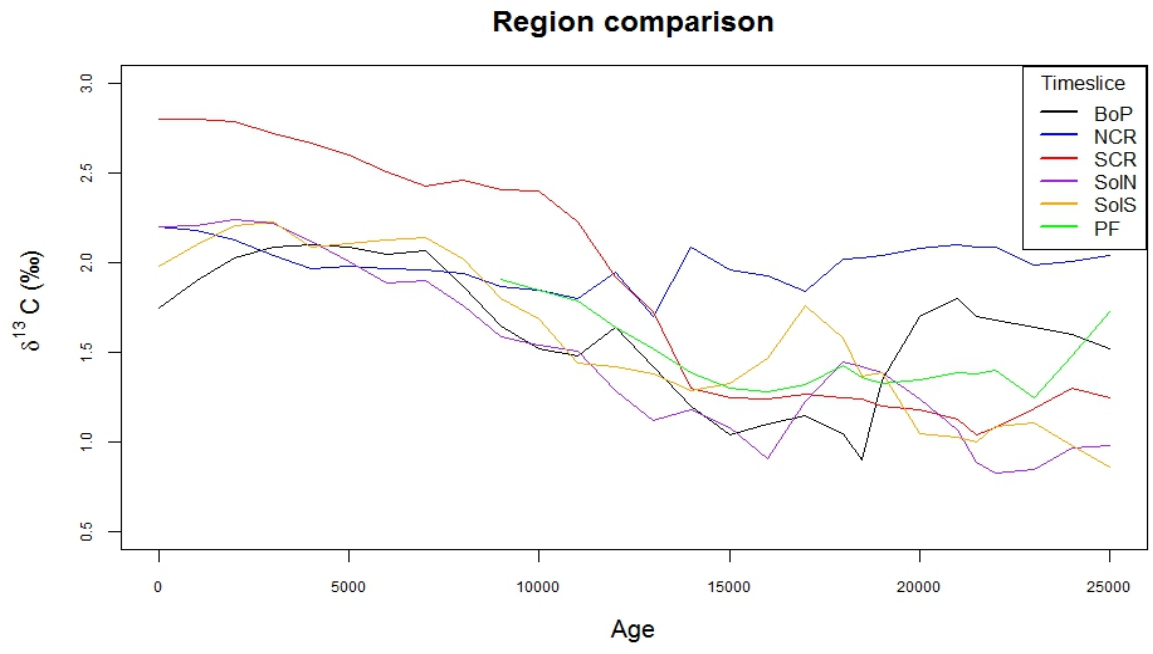

Figure 4.8: Comparison of all zones to each other. All trends rise and level off from 15ka-present. Before 15ka, there is more variability as the zones responded to the deglaciation in different ways. $\delta^{13} C$ is low in the glacial except in the NCR and BoP.

that lasts to $10 \mathrm{ka}$ with a slight rise to $1.5 \%$. A rise from $10 \mathrm{ka}$ to $7.5 \mathrm{ka}$ to $\delta^{13} \mathrm{C}$ levels at $2.2 \%$ occurs and is followed by stable Holocene values of approximately $2 \%$ (Figure 4.6a). A downturn in the data captures the decline in $\delta^{13} \mathrm{C}$ present in the data that is possibly related to the pre-industrial signal, but at poor resolution, as described in the other zones.

\section{Polar Front}

Only one core is available for the PF zone from the Eastern Pacific (Figure 4.7a; Table 4.1). Even though it isn't in the Southwest Pacific it was used to provide an end member for this study. The Polar Front zone has the lowest resolution and poorest constraint of the $\delta^{13} C$ values through the time period (Figure 4.7). Values younger than 9ka are not present and values aged between $17 \mathrm{ka}$ and $9 \mathrm{ka}$ are very low resolution. A small section of points from $20 \mathrm{ka}$ to $17 \mathrm{ka}$ show relatively high resolution and are the best constrained for this region. Data older than $20 \mathrm{ka}$ are better constrained than data earlier than $17 \mathrm{ka}$, and are generally the same resolution as all other cores.

The trend in this zone is characterized by a sharp decline from 25ka to $23 \mathrm{ka}$ from $2.2 \%$ to $1.3 \%$. A small increase to $22 \mathrm{ka}$ at $1.4 \%$ is followed by a period of relative stability until 18ka where another small rise to $1.5 \%$ occurs and is the highest value in this period. A decline from $18 \mathrm{ka}$ to $15 \mathrm{ka}$ from $1.5 \%$ to $1.3 \%$. The time from $15 \mathrm{ka}$ to $9 \mathrm{ka}$ is an upward trend in $\delta^{13} \mathrm{C}$ values from 


\begin{tabular}{|l|l|}
\hline \multicolumn{2}{|c|}{ Polar Front } \\
\hline Time slice & SD $(\%)$ \\
\hline LH & - \\
\hline EH & 0.336 \\
\hline ACR & 0.195 \\
\hline ED & 0.333 \\
\hline LGM & 0.042 \\
\hline G & 0.15 \\
\hline
\end{tabular}

Table 4.10: Standard deviation of $\delta^{13} C$ data used for each time slice in the Monte Carlo simulation for the PF.

$1.3 \%$ to $2 \%$.

\subsection{2 $\quad \delta^{13} C$ versus Latitude}

\section{4-22ka}

The BoP and NCR have the highest $\delta^{13} C$ values in this time slice at $1.6 \%$ and $2 \%$. The SolS and PF follow with levels at $1.3 \%$. The SCR and SolN zones have the lowest values at $1.1 \%$ and $1 \%$, respectively (Figure $4.9 \mathrm{~g}$ ).

\section{0-18ka}

A prominent peak at $41^{\circ} \mathrm{S}$ is the highest value in this time slice at $2 \%$. A small peak is seen at $47^{\circ} \mathrm{S}$ of $1.3 \%$, but is lower than the PF at $1.4 \%$. Lowest values in this time slice are at the SCR or SolS at $1.2 \%$ (Figure 4.9 f).

\section{8-16ka}

Two peaks in $\delta^{13} C$ at $41^{\circ} \mathrm{S}$ and $50^{\circ} \mathrm{S}\left(1.8 \%\right.$ and $1.7 \%$ ) are seen. BoP $\delta^{13} C$ are the lowest at 1.1-1.2\% . SCR, SolN, and PF are between $1.3 \%$ and $1.4 \%$. The PF has the highest $\delta^{13} C$ values behind the two peaks in the NCR and SolS (Figure 4.10e).

\section{5-13ka}

A peak at the $\mathrm{NCR}\left(41^{\circ} \mathrm{S}\right)$ is the prominent feature of the time slice $(1.9 \%)$. There is a drop in $\delta^{13} C$ from the NCR to SolN of $0.9 \%$. Levels at, and south of, SolS are higher than the BoP and uniform to the south at $1.35 \%$. The range of values in this time slice is $1-1.9 \%$ (Figure $4.9 \mathrm{~d}$ ). 


\section{$12-10 \mathrm{ka}$}

This time slice contains all six zones, as do all time slices from here. A peak is prominent at $45^{\circ} \mathrm{S}(2.1 \%)$. A slight rise in $\delta^{13} C$ values with increasing latitude is seen from SolN to the PF (1.45-1.55\%). A rise from the BoP to the SCR is seen from $1.5-2.1 \%$. $\delta^{13} C$ values in this zone range from $1.45-2.1 \%$ (Figure $4.9 \mathrm{c})$.

\section{6-4ka}

Only five zones are represented here as discussed in the previous time slice. The prominent feature is the peak at $45^{\circ} \mathrm{S}(2.2 \%)$. Another high is seen in the SolS zone $(2.2 \%$ ). Values in this time slice range from $1.7-2.2 \%$ (Figure $4.9 \mathrm{~b}$ ).

\section{4-2ka}

This time slice does not contain data from the PF zone. All data younger than $9 \mathrm{ka}$ are absent in this zone. A peak $\left(2.7 \%\right.$ ) at $45^{\circ} \mathrm{S}$ is the prominent feature of this time slice. All data points are $>2 \%$ in this time slice. A small uptick (from 2.1 to $2.3 \%$ ) from the SolN to the SolS zone is seen (Figure 4.9a).

\subsubsection{Correlations}

Correlating the curves of the different zones to benthic $\delta^{13} \mathrm{C}, \mathrm{CO}_{2, a t m}$, and $\delta^{13} C_{a t m}$ will help determine what factors are influencing the $\delta^{13} C$ of the surface ocean. SCR, SolN, and SolS $\delta^{13} C$ all correlate strongly to each other ( $r>0.9$, Table 4.5). This is expected since they are all part of the SAZ and are influenced by the same conditions throughout. Interestingly SCR $\delta^{13} C$ and SST have a strong correlation to atmospheric $\mathrm{CO}_{2}(\mathrm{r}=0.95$ and 0.86 ; Table 4.5). Looking at the 5ka time slices of correlations (Appendix Tables 2-8), this high value comes from the 10-15ka timeslice. Both $\mathrm{CO}_{2}$ and the SCR $\delta^{13} C$ have a large increase from $15-10 \mathrm{ka}$, showing that temperature may be influenced as $\mathrm{CO}_{2}$ rises, which in turn, may be influencing the SCR.

Notable lacks in correlation are seen with the EPICA $\delta^{13} C_{a t m}$ record. $\delta^{13} C_{a t m}$ was expected to have some influence on the surface waters. When broken into 5ka timeslices, strong correlation is seen with EPICA $\delta^{13} C_{a t m}$ in the BoP, SCR, SolN, SolS in the 10-5ka time slice (all r >0.95; appendix table 7). In the same time slice, all zones correlate strongly to each other, except 

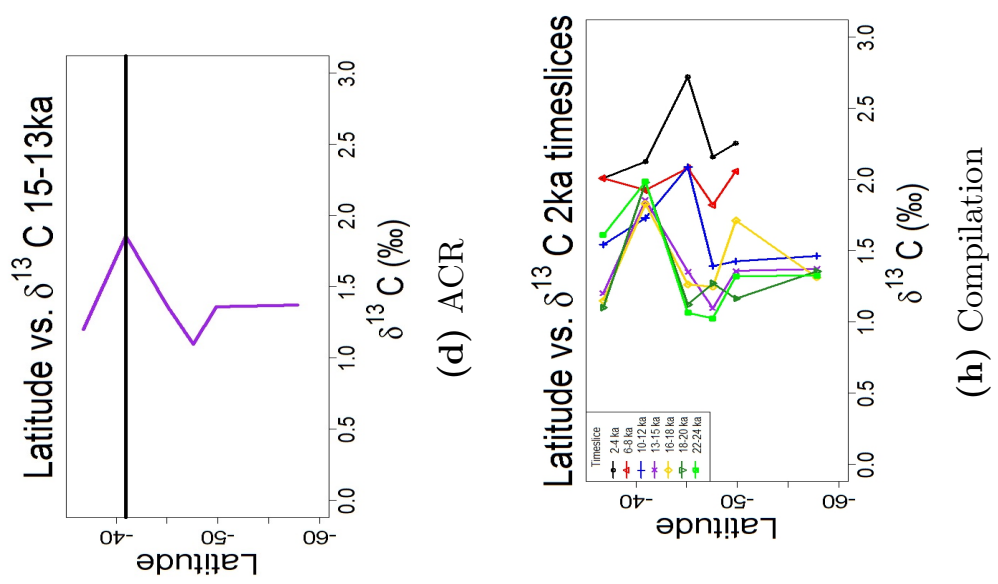

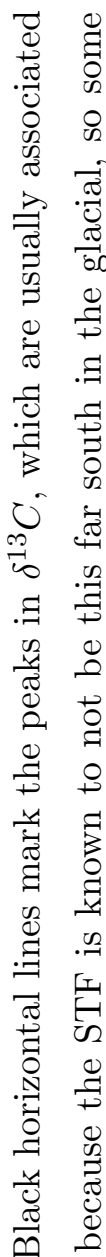
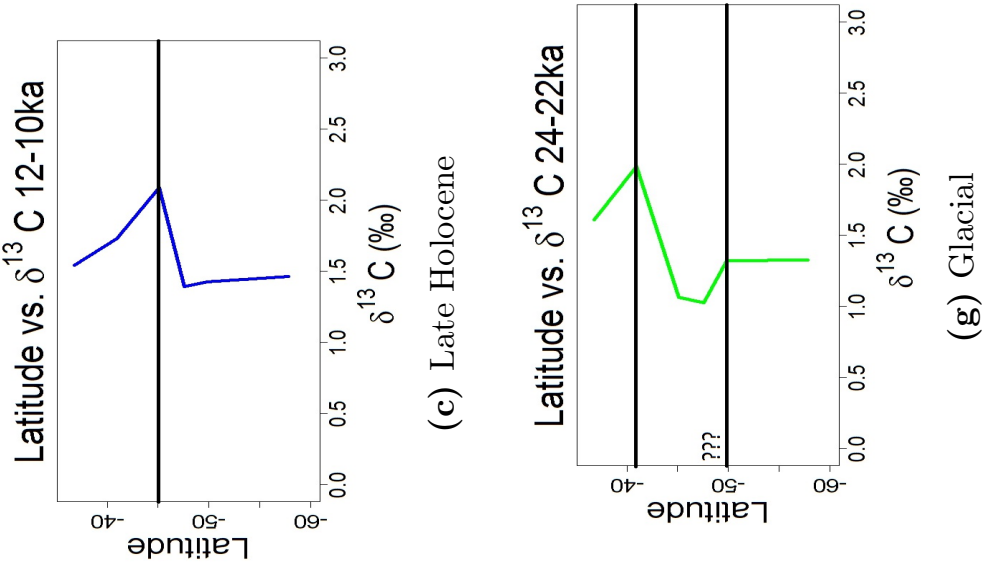

ก
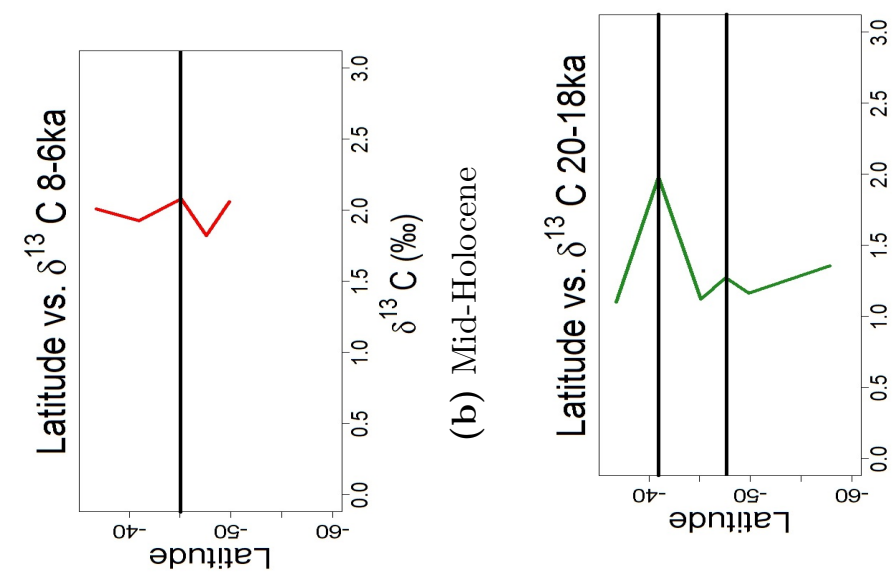

$\sim$
0
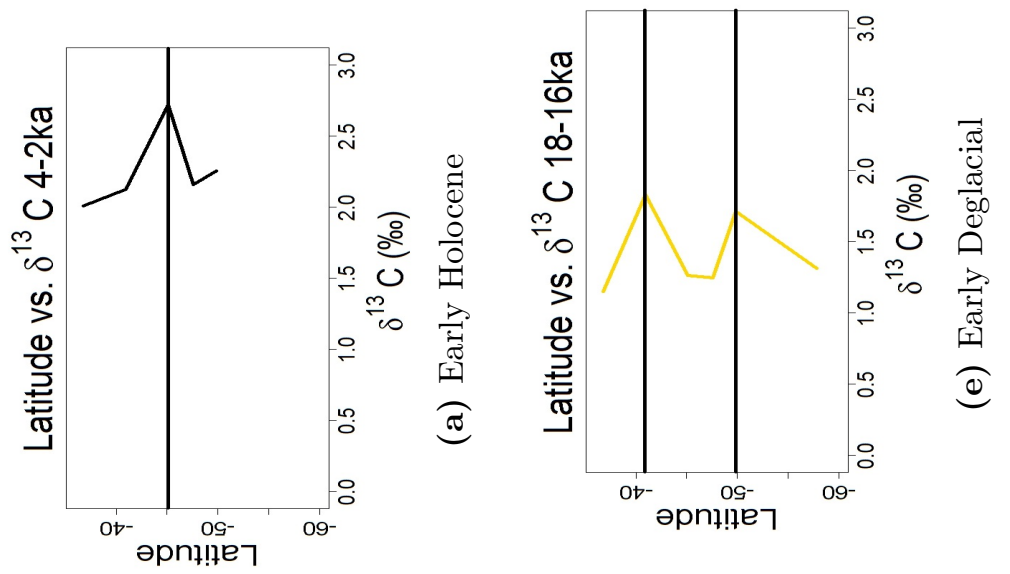

त्ञ

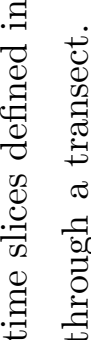

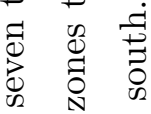

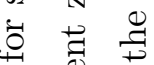
○ $\underset{\infty}{*} \circlearrowright$ 㐘 $\$ 5$

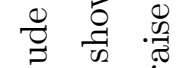
莺 द

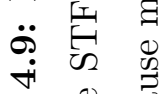
¿

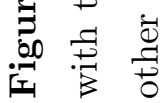


the SCR. Figure 4.9 shows this with the relatively high $\mathrm{SCR} \delta^{13} C$ values in the Holocene possibly due to another shift in the STF (Prebble et al., submitted).

Overall, the correlations show connections between the SCR, SolN, and SolS through the whole study period. Correlations are low in from 25-15ka and high from 15-0ka. They suggest links in different variables throughout the region, but since they are correlations, that does not necessarily mean they are significant.

\subsection{Discussion}

\subsubsection{G. bulloides $\delta^{13} C$ variations around New Zealand}

By comparing the different zones to each other, trends in each may become more visible. Before 15ka (25-15ka), more variability is seen throughout the study region. In the glacial (25-20ka), two regimes are seen: the zones north of the Chatham Rise have elevated $\delta^{13} C$ values that are like the Holocene; and south of the Chatham Rise, low $\delta^{13} C$ values $>0.5 \%$ less than the Holocene. This reflects the surface water regimes during the glacial: STW north of the Chatham Rise and SAW to the south.

The period between 20-15ka is especially varied with different trends in all six zones. The BoP and NCR show similar trends: a drop and small recovery in $\delta^{13} C$. The difference is the magnitude and timing. A large fall $(0.8 \%)$ in the BoP at $20 \mathrm{ka}$ versus a small $(0.3 \%)$ at $18 \mathrm{ka}$ in the NCR. A small increase of $0.2 \%$ is seen in both zones immediately after. The timing is suggestive of two different mechanisms controlling them. In the NCR the timing is similar to that of the $\delta^{13} C_{a t m}$ suggesting partial control by the atmospheric $\delta^{13} C$ (Figure 4.10c).

The drop in $\delta^{13} C$ is similar to that in the atmosphere $(0.4 \%$ in atmopshere, $0.3 \%$ in the $\delta^{13} C_{D I C}$, in the NCR), further suggesting atmospheric influence. The BoP drop is double that of the atmosphere, and approximately $2 \mathrm{ka}$ before. Changes in ocean circulation or biologic productivity are the most plausible causes.

Across all the zones one trend is clear: the rise in $\delta^{13} C$ values beginning at approximately $15 \mathrm{ka}$ that continued to the industrial revolution (Figure 4.10). This compares well with the overall trend in $\mathrm{CO}_{2}$ in the atmosphere as well as the $\delta^{13} C_{a t m}$ through this time period. Correlation data shows that the BoP, SCR, SolN, and SolS from 15ka to present correlates well with either $\mathrm{CO}_{2}$ levels or the $\delta^{13} C_{a t m}$. The BoP, SCR, and PF all have $\delta^{13} C$ beginning to rise at $15 \mathrm{ka}$. The BoP and $\mathrm{PF}$ are characterized by relatively stable conditions 


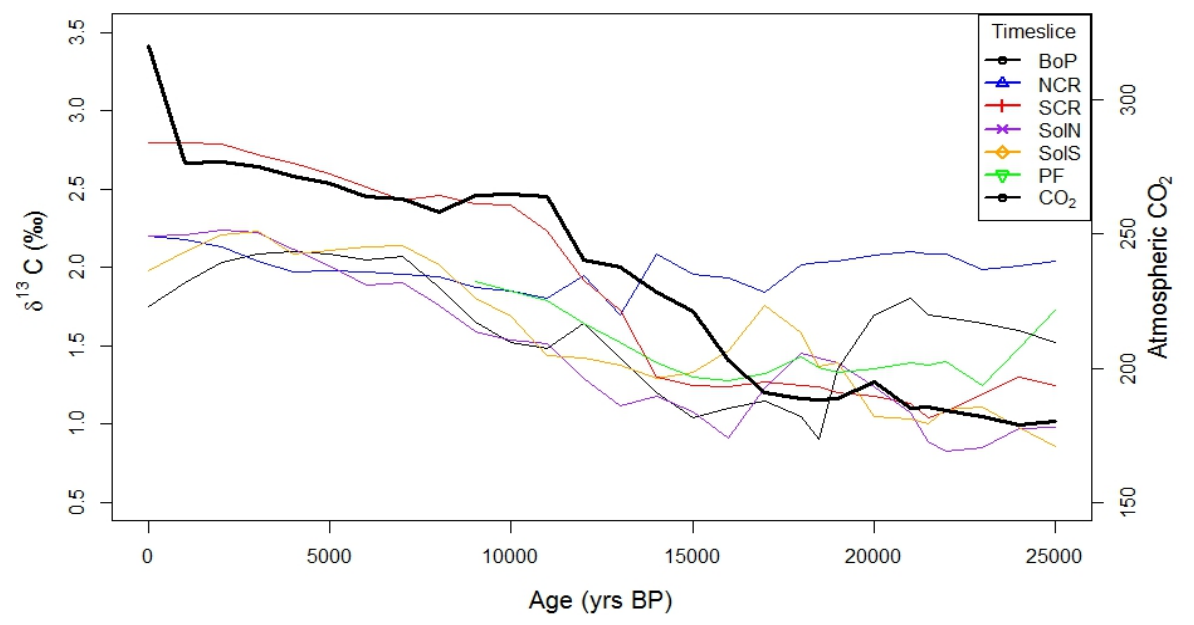

(a) Atmospheric $\mathrm{CO}_{2}$

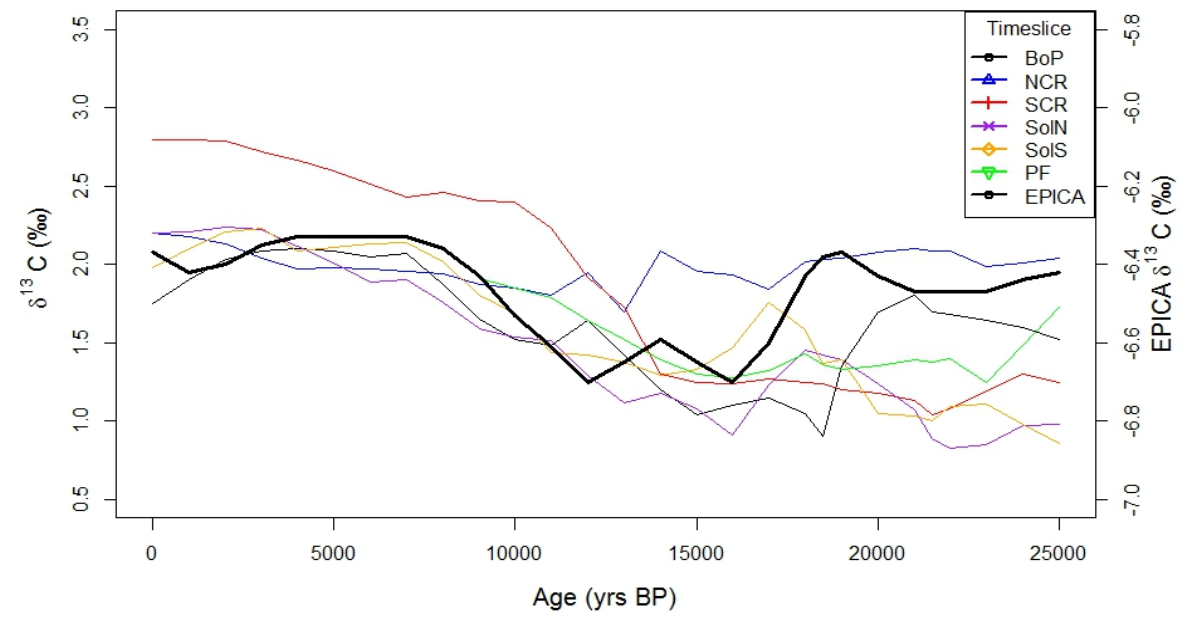

(b) EPICA Dome C $\delta^{13} C_{a t m}$

Figure 4.10: All zones plotted against other data sets a) Atmospheric $\mathrm{CO}_{2}$ versus zone $\delta^{13} C$. Some similarities between the zones and $\mathrm{CO}_{2}$ exist, especially between 15 -20ka. b) EPICA Dome C $\delta^{13} C_{a t m}$ versus $\delta^{13} C$ of the zones. 
throughout the time period, and this may suggest at least a partial control of the $\delta^{13} C_{a t m}$ in these regions through the time period. The SCR is more complex because of its proximity to the STF. It may be that the STF is relatively stable from $15 \mathrm{ka}$ to the present, so $\delta^{13} C_{a t m}$ may be the main control of $\delta^{13} C_{D I C}$ in the SCR from 15ka to the industrial revolution. The rise in $\delta^{13} C$ at $15 \mathrm{ka}$ is coincident with the rise in $\mathrm{CO}_{2}$ levels in the atmosphere, suggesting that $\mathrm{CO}_{2}$ has influence, through some mechanism, on $\operatorname{SCR} \delta^{13} C_{D I C}$.

The NCR, SolN, and SolS zones are similar, but may have more than just $\delta^{13} C_{a t m}$ acting on their respective $\delta^{13} C$ levels. The NCR, while an increasing $\delta^{13} C$ trend characterizes $15 k a-i n d u s t r i a l$ revolution, it is much reduced $(<0.5 \%$ o relative to the other zones $(>0.5 \%$ o). The proximity to the STF and the mixing region of STW and SAW north of the Chatham Rise may keep $\delta^{13} C$ higher than in other zones through high levels of biologic activity. SolN is characterized by a trend beginning at 13ka. The delay from $15 \mathrm{ka}$ may indicate buffering by the STF or some other control. SolS is characterized by a slow increase from 15 -10ka, with a large jump in $\delta^{13} C$ at $10 \mathrm{ka}$, which may be due to influence of the STF or other factors in the region.

The Solander Trough cores are characterized by a large hump in the data: a rise in $\delta^{13} C$ followed by a fall, both of similar magnitude (approximately $+/-$ $0.6 \%$ in both regions). The difference is in the timing of the hump of each region. In the SolN zone, the increase starts at $22 \mathrm{ka}$ and reaches peak $\delta^{13} C$ values at $18 \mathrm{ka}$, with a fall back to glacial values at $16 \mathrm{ka}$. In the SolS, $\delta^{13} C$ begins to rise at $18 \mathrm{ka}$, peaks at $16.5 \mathrm{ka}$, and falls to glacial values at $14 \mathrm{ka}$. This is suggestive of STF influence returning to the region after the northern transit during glacial times. The SolN increase would be first before the SolS in this case, further suggesting the STF as the main influence in this region.

The PF records the drop in $\delta^{13} C_{a t m}$ at $18 \mathrm{ka}(0.2-0.3 \%$ in the $\mathrm{PF})$, which is just inside the standard deviation (Table 4.9), so it may or may not be significant. Low glacial values characterized the period before. This zone may have been relatively stable and reflect $\delta^{13} C_{a t m}$ but PF movement and upwelling may have influenced the core.

\subsection{2 $\quad \delta^{13} C$ versus latitude}

The $\delta^{13} C$ versus latitude, for different time slices, can determine where the $\delta^{13} C$ high normally associated with the STF sits through time (Figure 4.9). In the glacial time slice (24-22ka) the increased signal may be from a northward movement of the SAF and ACC. ACC surface waters may have been near $50^{\circ} \mathrm{S}$ during this time and may have transmitted the higher $\delta^{13} \mathrm{C}$ signal of the 
AASW into the Solander Trough.

In the south, SolS has a secondary high in $\delta^{13} C$ except for the 20-18ka time slice. For the time slices younger than 18ka (18-16, 15-13, 12-10, 8-6, 4-2ka), this high is most likely associated with the STF. The LGM time slice (20-18ka) may be capturing a southward transit of the STF. Since the STF was most likely in the Solander Trough from 18ka, but it started to move south in the later stages of the LGM (Bostock et al., 2015).

In the three most recent time slices $(2-4,6-8,10-12 \mathrm{ka})$ there is one large peak at $45^{\circ} \mathrm{S}$. Since the NCR data point has a lower $\delta^{13} C$ value than the SCR in these time slices, it can be inferred that the STF was most likely at its modern position in these time periods. All older time slices have a $\delta^{13} C$ peak shifted north into the NCR. All these time slices have $>0.5 \%$ differences between the BoP and SCR when compared to the NCR. Since the STF is bathymetrically constrained at the Chatham Rise, increased flow from the south may have moved the mixing zone between the SAW and STW into the NCR zone. A diffuse, wide STF relative to the modern may have been present during this time to account for this change in the latitude of the $\delta^{13} C$ peak.

\subsection{Synthesis}

\subsubsection{Glacial (25-21ka)}

In the glacial near Holocene $\delta^{13} C$ were seen in the BoP and NCR (Figures 4.9 and 4.10). Low $\delta^{13} C$ was seen in the zones to the south (Figure 4.9). PF $\delta^{13} C$ levels were greater than those of the SCR, SolN, and SolS. These values are like the modern values seen near the PF core locations $\left(55-60^{\circ} \mathrm{S}, 160^{\circ} \mathrm{E}\right.$; Figure 2.3a). The location of the PF cores are near the PF in modern times, but in the glacial was most likely south of the PF, suggesting this is most likely a reflection of increased productivity in the $\mathrm{PZ}$ during the glacial possibly from increased dust flux into the region (Martinez-Garcia et al., 2009, 2014; Lamy et al., 2014) but buffered by upwelling of low $\delta^{13} C$ waters.

SolS $\delta^{13} C$ values are similar to those of the PF zone, suggesting similar conditions in these two zones during the glacial (Figures 4.9). This data suggest the ACC possibly pushed as far north as $50^{\circ} \mathrm{S}$ during this time. High values in SolS are not influenced by the STF, since the STF is near $40^{\circ} \mathrm{S}$ to the west of New Zealand during the glacial (Bostock et al., 2015).

SolN and SCR values are similar and the lowest of the glacial (approximately 1\%o; Figure 4.9g). The SCR was slightly higher than SolN, which is probably due to the proximity of SolN to the ACC, and further distance from 
the STF. Cool temperatures in the SAZ during this time may have also limited productivity.

NCR values in the glacial and Holocene are very similar and only differ by $0.2 \%$. In $\delta^{13} C$ versus latitude plots, the $\delta^{13} C$ high associated with the STF is in the NCR during the glacial (Figure 4.9). Since the STF is bathymetrically locked on the southern slope of the Chatham Rise (Orsi et al., 1995), what this suggests is leakage of SAW north of the Rise (Neil et al., 2004) or a wider STF. A broader front and leakage are not mutually exclusive and may both play a role, but it is difficult to determine their relative contribution. Either way, the principle mixing zone of SAW and STW that is south of the Chatham Rise in the modern is north during the glacial.

BoP $\delta^{13} C$ during the glacial $(1.6 \%)$ is similar to the the BoP Holocene $\delta^{13} C$ values (but slightly lower (Figure 4.4 and 4.9)). These high values during the glacial suggest that productivity was at or near present. Schiraldi et al. (2014) suggest SAMW influenced the thermocline of the BoP to bring needed nutrients into the mixed layer. This is unlikely as SAMW is not found in the BoP during the present day, and therefore was unlikely to have been present during the glacial because subtropical circulation was most likely very similar to modern circulation. This region was probably very similar to today, but other independent productivity proxies will be required to confirm this.

\subsubsection{LGM and Early deglaciation (21-15 ka)}

The EPICA Dome $\mathrm{C}$ record of $\delta^{13} C_{a t m}$ records a large decrease in $\delta^{13} C_{a t m}$ between 19 and 18ka (Figure 4.8). This decline is recorded in the $\operatorname{BoP} \delta^{13} C$, but it occurs 1-2ka before the $\delta^{13} C_{a t m}$ change. Schiraldi et al. (2014) suggest that this drop results from a switch in proximal and distal water sources coming into the BoP. $\delta^{18} O$ from the same study show that warmer, saltier waters enter the BoP at the same time as the $\delta^{13} C$ drop (Schiraldi et al., 2014). Schiraldi et al. propose that infiltration of low $\delta^{13} C$ sub-tropical waters begin to increase influence on the BoP at this time, lowering the $\delta^{13} C$. Dust models show that substantial increases of dust flux from Australia covered the entire study region during the LGM (Lamy et al., 2014), but were unlikely to affect the STW productivity during the glacial, as these waters are not depleted in iron.

Small drops in $\delta^{13} C$ are seen in the NCR and SolN, but not to the same magnitude as the BoP. This could be due to the low $\delta^{13} C$ already present in the SolN (Figures 4.5 and 4.9 ) and the proximity of the STF to the NCR. The timing of these small drops is approximately 18ka and fits well with the change in $\delta^{13} C_{a t m}$. Correlation data from this period suggest that the SolN 
was significantly affected $(\mathrm{r}>0.9)$ by a change in $\delta^{13} C_{a t m}$. Correlation between the EPICA $\delta^{13} C_{a t m}$ record and NCR is weaker ( $\mathrm{r}=0.75$; appendix table 5$)$. Local changes in circulation may have more influential roles on $\delta^{13} C_{N C R}$.

The SCR is relatively unchanging. As seen in the latitude versus $\delta^{13} C$ and Monte Carlo simulation, there is a small increase in $\delta^{13} C$ through this period of $0.2-0.3 \%$. This increase is not significantly different than the levels seen in the glacial in the SCR. There is little correlation to the SCR in this interval, so conditions similar to glacial were most likely present during this period.

A steep rise in $\delta^{13} C$ in SolS and a spike in the latitude versus $\delta^{13} C$ at $50^{\circ} \mathrm{S}$ suggest STF influence in the SolS between 16 and 18ka (Figure 4.10 and 4.11). The spike in the SolS during this period is the largest seen throughout the study period, suggesting strong STF influence in this zone. The STF is not thought to be this far south during this period, so a wide, dispersed STF in the Solander Trough may be responsible.

The PF shows a small decline $(0.2 \%)$ in $\delta^{13} C$ values through this period. The decline is roughly coincident with the decrease in $\delta^{13} C_{a t m}$, but only a very weak correlation with the EPICA and benthic records. The EPICA record is close to the significance cut-off of the correlation study $(r=0.69)$, so it may have some influence on the PF.

\subsubsection{ACR and Early Holocene (15-10 ka)}

This period is characterized by rising $\delta^{13} C$ values in all zones except the NCR (Figure 4.8). All zones south of the Chatham Rise have good correlation ( $\mathrm{r}$ $>0.8$ ) with the $\mathrm{CO}_{2}$ record, with the SCR, SolN, and PF all strongly correlated $(\mathrm{r}>0.9)$ to it. PF SST data correlates well with all zones (beside the NCR), as well as the $\mathrm{CO}_{2}$ and benthic records in this period. This suggests that release of $\mathrm{CO}_{2}$ began to affect global temperatures in this period, and increased the lower $\delta^{13} \mathrm{C}$ values either due to the upwelling or changes in productivity throughout the New Zealand region.

The NCR, unlike the other zones, has a major decrease in $\delta^{13} C$ in this period. A major shift also occurred: a southward shift in the position of the $\delta^{13} C$ peak in the latitude versus $\delta^{13} C$ graph. Until 13ka, the peak associated with the STF sits around $42^{\circ} \mathrm{S}$. Then, at $12 \mathrm{ka}$, it jumps south to sit at $45^{\circ} \mathrm{S}$. This marks a shift of the $\delta^{13} C$ peak from the NCR into the SCR. Since the NCR does not correlate well with anything in this period this shift must be the cause of the $\delta^{13} C$ drop seen in the data. 


\subsubsection{Mid to Late Holocene (10ka-present)}

Correlation in the first half of this time slice (10-5ka)(Appendix Table 7) shows the high agreement of all zones to each other and to the EPICA $\delta^{13} C_{a t m}$ (except the SCR). It suggests that large scale circulation and wind changes do not occur and that the $\delta^{13} C_{D I C}$ is primarily controlled by air-sea exchange during this time, with limited changes in biological productivity in each zone. The last half (5ka-present)(Appendix table 8) differs more than the first half possibly due to differing responses to anthropogenic $\mathrm{CO}_{2}$ in each zone, but also related to resolution biases due to the presence, or lack of, core top data. Otherwise, all cores show a gradual climb to pre-industrial values continues for the rest of the Holocene. This compares well to the $\delta^{13} C_{a t m}$, which peaks at $7 \mathrm{ka}$ and then levels off until the industrial revolution at 1750 AD. At 1750, fossil fuel burning drastically increased in the industrial revolution, introducing low $\delta^{13} \mathrm{C}$ $\mathrm{CO}_{2}$ into the atmosphere. Over the last 250 years atmospheric $\mathrm{CO}_{2}$ has risen to levels not since $3 \mathrm{Ma}(>400 \mathrm{ppm})$. At the same time, $\delta^{13} C_{a t m}$ levels dropped to their current levels (chapter 2) over this period.

\subsubsection{Drivers of the $\delta^{13} C$ changes and the carbon cycle}

The main hypotheses that describe the transition between the low atmospheric $\mathrm{CO}_{2}$ glacial and higher atmospheric $\mathrm{CO}_{2}$ interglacial are as follows: a decrease in the efficiency of the biologic pump which reduced $\mathrm{CO}_{2}$ drawdown into the ocean (Watson et al., 2000; Gottschalk et al., 2016); changes in the strength and position of the westerly wind belt which caused increased upwelling of stored $\mathrm{CO}_{2}$ to the surface and exchanged with the atmosphere and transport of low $\delta^{13} C$ value waters to the north (Toggweiler et al., 2006; Anderson et al., 2009); and circulation changes caused a shift from glacial to modern circulation. Recent studies have concluded that multiple causes are the reason for the transition from the glacial (Ferry et al., 2015; Buchanan et al., 2016) and that one variable alone is not enough to explain the 80 ppm CO2 increase from glacial times. I will compare these three hypotheses in this section to determine whether they work well alone or multiple factors are required to explain the $\delta^{13} C G$. bulloides data from the Southwest Pacific region. From this, a history of change from the glacial to modern times will be described based on the conclusions of the following section.

\section{Biologic pump: Nutrient utilization and dust flux}

The biologic pump plays a significant role in transitions into and out of glacial periods. This hypothesis is confirmed by the findings in the SCR, SolN, and 
SolS zones of this study. $\delta^{13} C$ levels in these three zones are significantly lower than in the BoP and NCR, with levels between 1 and 1.5\%, which is at least $0.4 \%$ lower than modern values (Figure 2.3) and $0.8 \%$ lower than Holocene values (Figure 4.9).

These values suggest that, in terms of biology, two regimes persisted to the north and south of the STF during the glacial period around New Zealand. Small increases in $\delta^{13} C$ in the SolN and SolS zones between 20ka and 15ka supports this hypothesis because of drastic movement of the STF to the west and south of New Zealand (Bostock et al., 2015). The STF in the Solander trough swings south of its current position during the early deglaciation (1816ka)(Bostock et al., 2015).

Dust flux has been suggested to play a strong role in the transition from the glacial to the interglacial. Iron fertilization across the world ocean increases biological production which sequesters $\mathrm{CO}_{2}$ in the deep ocean at the beginning of glacial periods, and a decrease in its efficiency is thought to play a significant role in bringing about interglacial periods (Gottschalk et al., 2016; Martinez-Garcia et al., 2014; Anderson et al., 2002). Based on the near modern $\delta^{13} C$ levels in the BoP and NCR, biologic productivity is similar in these two zones. In the south the lower $\delta^{13} C$ values suggest that there is no evidence of higher productivity associated with increased dust during the glacial. An independent productivity and dust proxy would be required to determine if this is occurring. A recent paper by Durand et al., (accepted by EPSL) used a range of productivity proxies such as total organic carbon, opal flux and carbonate flux and showed that there was no increase in productivity during the glacial period in the SAW of New Zealand.

Further evidence shows high dust flux in the Southwest Pacific during the glacial (Lamy et al., 2014), but the latitudinal data from this study suggests that increased productivity was not present during the glacial. Low $\delta^{13} C$ values in the SAZ (SCR and SolN) in the glacial time slice seem to suggest lowered productivity (Figure 4.9g).

Biologic control of atmospheric $\mathrm{CO}_{2}$ has been shown to be strong in the S. Atlantic (Gottschalk et al., 2016; Martinez-Garcia et al., 2014), it is not as strong in the S. Pacific (Bostock et al., 2013). Overall, only about half (40$50 \mathrm{ppm}$ ) of atmospheric $\mathrm{CO}_{2}$ can be attributed to the biologic pump in the glacial/interglacial transition. This suggests different mechanisms of control in global $\mathrm{CO}_{2}$ levels and regional oceanic $\delta^{13} \mathrm{C}$. The factor that controls the Southwest Pacific is less clear than in the S. Atlantic. Other variables must be considered to determine what occurred in the Southwest Pacific. 


\section{Westerly wind belt changes}

A large negative trend is seen in the $\mathrm{BoP}$ at 20ka. This corresponds to the deglacial drop in $\delta^{13} C$, but 2000 years early. It has been shown that sea ice cover is inversely proportional to $\mathrm{CO}_{2}$ levels in the atmosphere (Wolff et al., 2006) so increased upwelling due to the due to the retreat of sea ice is unlikely to be the cause of the BoP $\delta^{13} C \mathrm{C}$ decrease (Schiraldi et al., 2014). Decreases in $\delta^{13} C$ during the glacial (of less magnitude) are seen in the NCR, SolN, and SolS. In the NCR and SolN, decreases occur at approximately 18ka and most likely correspond to increased upwelling of low $\delta^{13} C$ waters and low $\delta^{13} C$ in the atmosphere, and may also be due to the transport of low $\delta^{13} C$ intermediate waters into the SW Pacific region. In SolS, a large increase at $17 \mathrm{ka}$ is followed by a drop in $\delta^{13} C$ to $16 \mathrm{ka}$, but this is delayed from the initial upwelling signal at 18ka (Anderson et al., 2009).. Overall, westerly wind driven upwelling and sea ice play a significant role in climate, but cannot explain the changes in the $\delta^{13} C$ levels during the last $25 \mathrm{ka}$ in the SW Pacific.

\subsubsection{Circulation}

The previous two sections have focused mainly on the Southern Ocean, as that is the region where the significant glacial/interglacial change in the carbon cycle is hypothesized to have occurred in the past 25ka. However, these glacial/interglacial changes in sea ice and westerly winds also had an impact on the local circulation in the SW Pacific region.

The drop in $\delta^{13} C$ in the BoP occurred slightly earlier at 20ka and may have been influenced by changes in northern hemisphere insolation that affected the south Pacific subtropical gyre (Imbrie et al., 1992), however the NCR, SolN, and possibly SolS zones all experience a sharp decrease in $\delta^{13} C$ between 18 and $17 \mathrm{ka}$. This is most likely the combined result of both the retreat of the sea ice and the result of changes in the westerly winds which caused the STF in the Southwest Pacific to shift south (Bostock et al., 2015). The SolN and SolS zones were both overlain by SAW during the glacial, and the NCR was influenced by SAW flowing through the Mernoo trough at the western end of the Chatham Rise (Nelson et al., 1993). At the start of the deglaciation the influence of SAW on these zones was diminished. This is also reflected in the magnitude of the $\delta^{13} C$ change in each of these regions.

Therefore, the SolN may have been much more influenced by SAW before the ACR than the NCR, due to the broad nature of the STF in the Solander Trough at this time. BoP, SCR, SolS, and PF signals did not change because there was no major change in the environments of these zones. Minor changes 
in temperatures may have decreased productivity, but it may not have been significant enough to produce changes in $\delta^{13} C$ of these zones.

Overall, the biologic pump, westerly winds, and circulation changes can explain most, if not all, of the $\delta^{13} C$ changes seen from 25ka to the present in the New Zealand region. This chapter provides more evidence, via planktic foraminiferal $\delta^{13} C$ changes, that all three combined to bring the earth from a glacial period to the current interglacial.

\subsubsection{Conclusion}

This chapter describes down core $\delta^{13} C$ data from the glacial to the present. Six zones of cores were used to identify changes in $\delta^{13} C$ along a latitudinal transect in the New Zealand region of the Southwest Pacific and Southern Ocean. The findings suggest three things: The BoP and NCR were bathed in STW from the glacial to the present, with the NCR having variable levels of SAW influencing $\delta^{13} C$ across the STF. The SCR, SolN, and SolS were bathed in SAW in the glacial and were influenced by changes in the STF in the deglacial. From 15ka to the present, modern conditions existed as evidenced by the similarities between the zones, atmospheric $\mathrm{CO}_{2}$, and $\delta^{13} C_{a t m}$. From these observations, a narrative of the deglaciation becomes apparent: glacial values were locally influenced, but were generally similar to Holocene values north of the STF and low to the south. Through the deglaciation, a drop in $\delta^{13} C$ occurred and manifested itself in different magnitudes and timings around the region. Modern circulation conditions manifested themselves around 15ka and remained unchanged to the present.

\subsubsection{Future work}

- Modern water data

1. More transects in the New Zealand region. Transects like TAN1302 that only gather underway surface data would be good. But full water column transects like those of WOCE and GoSHIPS would resolve the chemical and physical properties of the New Zealand region much better.

2. Higher resolution transects. The most recent transects have resolutions $>2^{\circ}$ in some places. High resolution, better quality data sets would greatly increase the reproducibility and quality of future models of $\delta^{13} C$ and other geochemical proxies.

- More core data is needed. 
1. More cores in general around the polar front. High resolution studies of at least $G$. bulloides to compare to the findings of this study from the polar front region.

2. Different foraminifera species to test findings in G. bulloides. Different species can compare different water column depths to see what the whole ocean response to climate change.

3. More high resolution data sets for better quantification of $\delta^{13} C$ changes in the past.

4. More and novel proxies that independently quantify biologic productivity (opal flux, $\delta^{15} N$, trace element studies, alkenones, etc) in the region to better understand how $\delta^{13} C$ changed through time

- Comparison of SW Pacific $\delta^{13} C$ with other sectors of the Southern Ocean

- Comparison of SW Pacific $\delta^{13} C$ with other models of $\delta^{13} C$ 


\section{Appendix A}

\section{SST reconstruction comparison}

\section{A.1 Methods}

Only seven of the cores in this study have SST reconstructions in them. Three of these have multiple SST reconstructions from various methods . In comparing these different proxy SST techniques, differences in SST for a certain region can be seen. The question then arises which technique should be used to correct the $\delta^{13} \mathrm{C}$ back through time using the Bemis et al. disequilibrium equation? Three types of reconstruction were used: alkenone UK37 biomarker SST estimates (Marlowe et al., 1984), Mg/Ca measured on G. bulloides, and foraminiferal assemblage SST using various statistical techniques (Random Forest (RF), Weighted Annual Partial Least Squares (WAPLS), Artificial Neural Network Technique (ANNT), Modern analogue technique (MAT)). The MAT is the most ubiquitous technique in the cores used for this study. MAT compares modern faunal assemblages to those of the past to infer climate (Hutson, 1980). If faunal assemblage $\mathrm{x}$ is present in climate $\mathrm{y}$ in the present, then it must be present in that same climate going back through time. WAPLS is a similar technique, but uses niche space and ecological optima inputs to calibrate large environmental gradients for given faunal assemblages (ter Braak and Juggins, 1993). RF uses a tree based regression method to determine optimal SST data from faunal assemblages (Bostock et al., 2015; Breiman, 2001). Finally, ANNT techniques use artificial neural network algorithms to predict SST from specific environmental inputs (Malmgren and Nordlund, 1996).

Alkenone SST reconstruction comes from the degree of unsaturation of diand tri- methyl ethyl ketones in various algae (Prahl et al., 1988). The most ubiquitous of which is Emiliania huxleyi (Volkman et al., 1980). To estimate SST from alkenone analyses several different calibration equations have been used such as Prahl et al. (1988), Sikes and Volkman (1993) and Mller et al. (1998). Prahl et al. (1980) tested the temperature dependence of unsaturation 


\begin{tabular}{|l|l|l|}
\hline Core & Zone & Reconstruction type \\
\hline H214 & BoP & MAT \\
\hline MD97-2121 & NCR & Alkenone, MAT, Mg/Ca, WAPL, ANNT \\
\hline MD97-2120 & SCR & Alkenone, Mg/Ca \\
\hline TAN0803-09 & SolN & Alkenone, MAT, Random Forest \\
\hline TAN1106-15 & SolN & Alkenone \\
\hline TAN1106-34 & SolS & MAT \\
\hline E11-2 & PF & Mg/Ca \\
\hline
\end{tabular}

Table A.1: SST reconstructions available in cores.

in a laboratory and compared to alkenone data from the North Pacific. The temperature range found for alkenones was $8-25^{\circ} \mathrm{C}$ in this study. Sikes and Volkman (1993) continued this study by taking water samples (approximately 40) containing E. huxleyi in a transect of the Southern Ocean south of Tasmania. Their findings extended the range of temperature to $4^{\circ} \mathrm{C}$. Müller et al. (1998) created a calibration from alkenone data (150 core tops) in the south Atlantic and applied it to a global ocean database. They found that their results complimented those of Prahl et al. (1988) and that the calibration works well at a temperature range seen throughout the world ocean $\left(0-27^{\circ} \mathrm{C}\right)$.

Only three cores were used to compare the SST reconstructions. This is because these three cores had multiple SST reconstructions, most of the cores had no reconstruction or only one. The three cores we used are MD97-2121, MD97-2120, and TAN0803-09. Table 2 shows the zone these cores are in and the type of reconstructions used in each one.

To compare the SST reconstructions, they were plotted together by core. To do this, each reconstruction was fitted to the uncorrected $\delta^{13} C$ dataset by age model. This was done by matching age model ages to those of the $\delta^{13} C$ age models in each core. The matching age model ages and $\delta^{13} C$ vales were taken out and made into a subset of the $\delta^{13} C$ data that matched with the SST reconstruction ages. Both the $\delta^{13} C$ and SSTs were then input into the Bemis et al. (2000) temperature equation to give a $\delta^{13} C$ curve for that dataset. Once done for each reconstruction in a core, they were plotted against each other and compared (Figure A.1.1).

\section{Results}

The three cores mentioned above contained all the various SST reconstruction techniques found in the cores used in this study. Each was compared to the control curve for best fit and one was chosen as the best reconstruction. This was done to show that differences in techniques are present and that some fit 


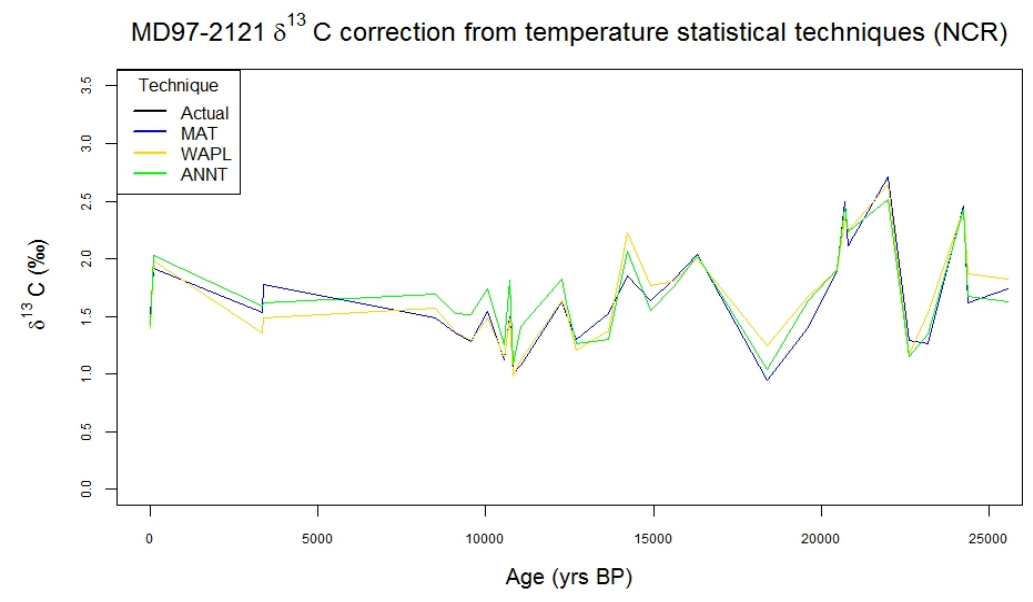

(a) Statistical technique SST MD97-2121

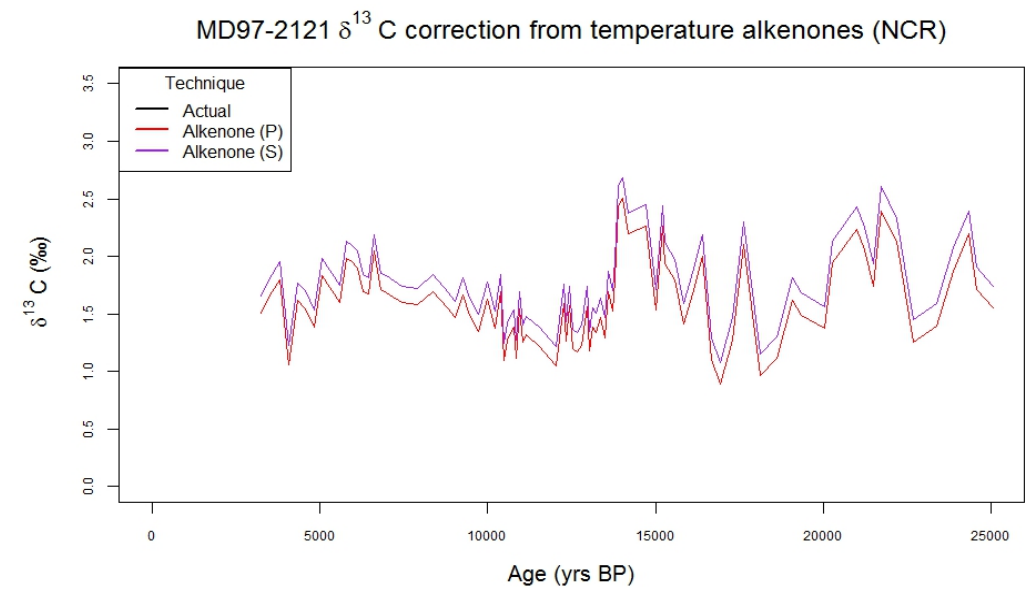

(b) Alkenone MD97-2121

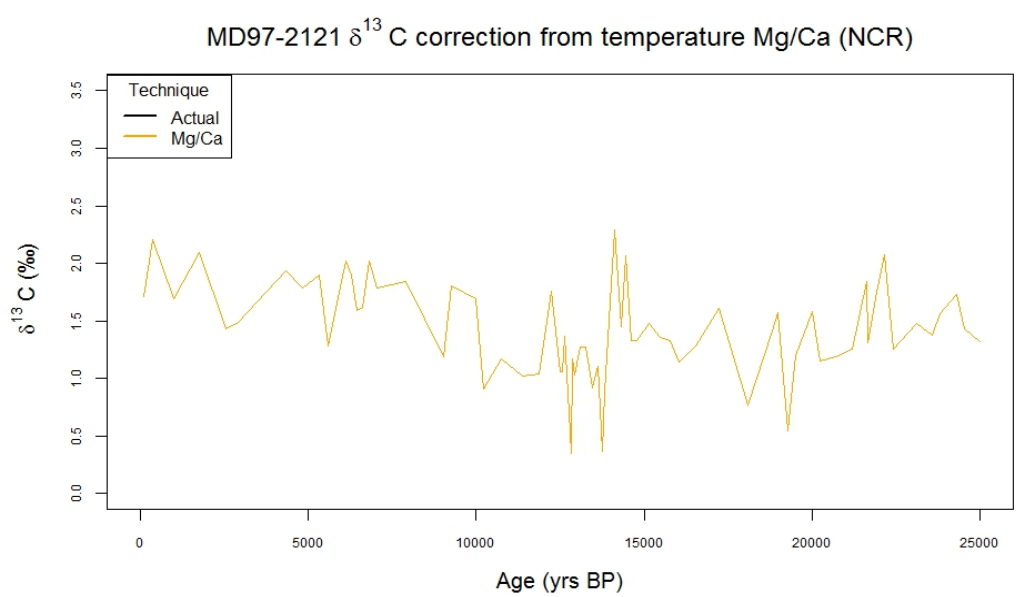

(c) $\mathrm{Mg} / \mathrm{Ca} \mathrm{MD} 97-2121$

Figure A.1.1: SST reconstructions from the core MD97-2121 


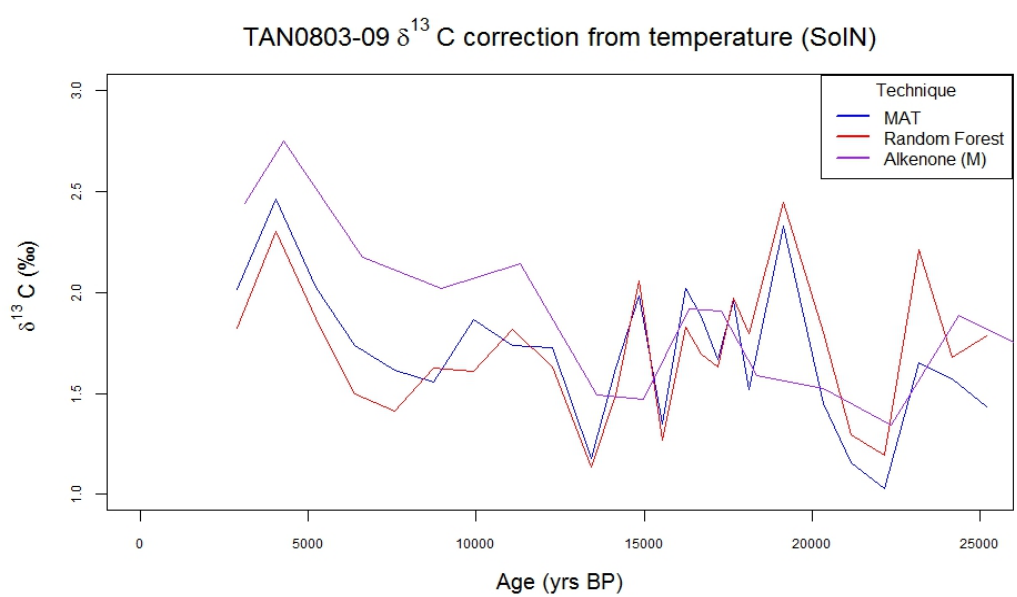

Figure A.1.2: SST reconstruction from core TAN0803-09 from the SolN zone. MAT and RF reconstructions are most similar with alkenone values slightly higher in the ACR and Holocene.

better than others.

The core MD91-2121 has the most reconstructions of the three with six: Prahl and Sikes alkenone SST curves (Pahnke and Sachs, 2006), three foraminiferal assemblage statistical techniques (MAT, WAPL, ANNT; Northcote et al., unpublished), and $\mathrm{Mg} / \mathrm{Ca}$ G. bulloides (Marr et al., 2013; figure A.1.1). As described in the MD97-2120 core, the alkenone reconstructions are the same curve just offset from each other. The statistical techniques each have almost identical trends, with small dissimilarities in their peak maxima and minima. Overall, the three technique suites (alkenone, statistical, and $\mathrm{Mg} / \mathrm{Ca}$ ) show a similar trend: a high around $21 \mathrm{ka}$, a high immediately followed by a low centered around 15ka, and generally stable, unchanging trend from 12ka to the present. All three suites have differing resolutions, but generally follow the same trends.

TAN0803-09 has had two foraminiferal assemblage statistical techniques determined (MAT and Random Forest; Bostock et al., 2015) as well as an alkenone SST using the Muller et al. (1998) calibration (Calvo unpublished). The alkenone dataset is lower resolution than the two foraminiferal assemblage techniques. The MAT and RF techniques show similar trends (Figure A.1.2) to each other. The only deviation in the trend being at 10ka where the MAT shows a small increase in $\delta^{13} C$ while the $\mathrm{RF}$ shows a small decrease. The alkenone reconstruction is like the other two despite the low resolution. The general trend of the alkenone dataset is like the other two, but due to the resolution, it is difficult to compare. The most obvious trend is that alkenone $\delta^{13} C$ is highest from $15 \mathrm{ka}$ to the present while MAT and RF are slightly lower but still quite similar. 


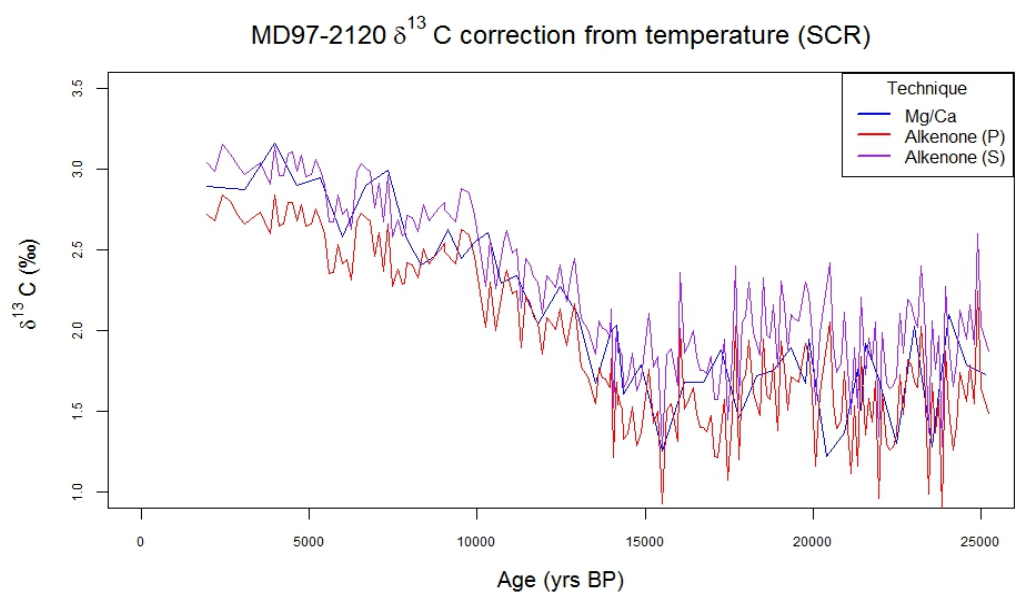

Figure A.1.3: Alkenone and $\mathrm{Mg} / \mathrm{Ca}$ reconstructions from core MD97-2120 in the SCR. All three reconstructions agree well with slight differences due to individual reconstructions or resolution.

Core MD97-2120 again has three reconstructions: alkenone SST curves using the Prahl et al., (1989) and Sikes and Volkman (1993) calibrations (Pahnke and Sachs, 2006) and Mg/Ca G. bulloides SST data (Pahnke et al., 2003)(figure A.1.3). The $\mathrm{Mg} / \mathrm{Ca}$ dataset is the lowest resolution of the three datasets. The Sikes and Prahl corrections are the same curve just slightly offset from each other due to differences in reconstruction equations (Prahl et al., 1988; Sikes and Volkman, 1993). The general trend of these two reconstructions is a stable, unchanging period from $25 \mathrm{ka}$ to $15 \mathrm{ka}$ and a gradual climb to the present. Although lower resolution, the $\mathrm{Mg} / \mathrm{Ca}$ reconstruction shows the same general trend. Points seem to plot closer to the Sikes reconstruction from 15ka to the present and as a middle value between the two alkenone reconstructions between $25 \mathrm{ka}$ and $15 \mathrm{ka}$.

Overall, differences in techniques and resolution cause small dissimilarities between the reconstructions of a given core. They all seem to have good agreement on the general trend of SST within the general regions. For the purposes of this study, any reconstruction will work for the paleo SST. The core MD91-2121 has the most reconstructions of the three with six: Prahl and Sikes alkenone SST curves (Pahnke and Sachs, 2006), three foraminiferal assemblage statistical techniques (MAT, WAPL, ANNT; Northcote et al., unpublished), and $\mathrm{Mg} / \mathrm{Ca}$ G. bulloides (Marr et al., 2013; figure A.1.1). As described in the MD97-2120 core, the alkenone reconstructions are the same curve just offset from each other. The statistical techniques each have almost identical trends, with small dissimilarities in their peak maxima and minima. Overall, the three technique suites (alkenone, statistical, and $\mathrm{Mg} / \mathrm{Ca}$ ) show a similar trend: a high around $21 \mathrm{ka}$, a high immediately followed by a low 
centered around 15ka, and generally stable, unchanging trend from $12 \mathrm{ka}$ to the present. All three suites have differing resolutions, but generally follow the same trends.

Overall, differences in techniques and resolution cause small dissimilarities between the reconstructions of a given core. They all seem to have good agreement on the general trend of SST within the general regions. For the purposes of this study, any reconstruction will work for the paleo SST.

\section{A.2 Correlations}

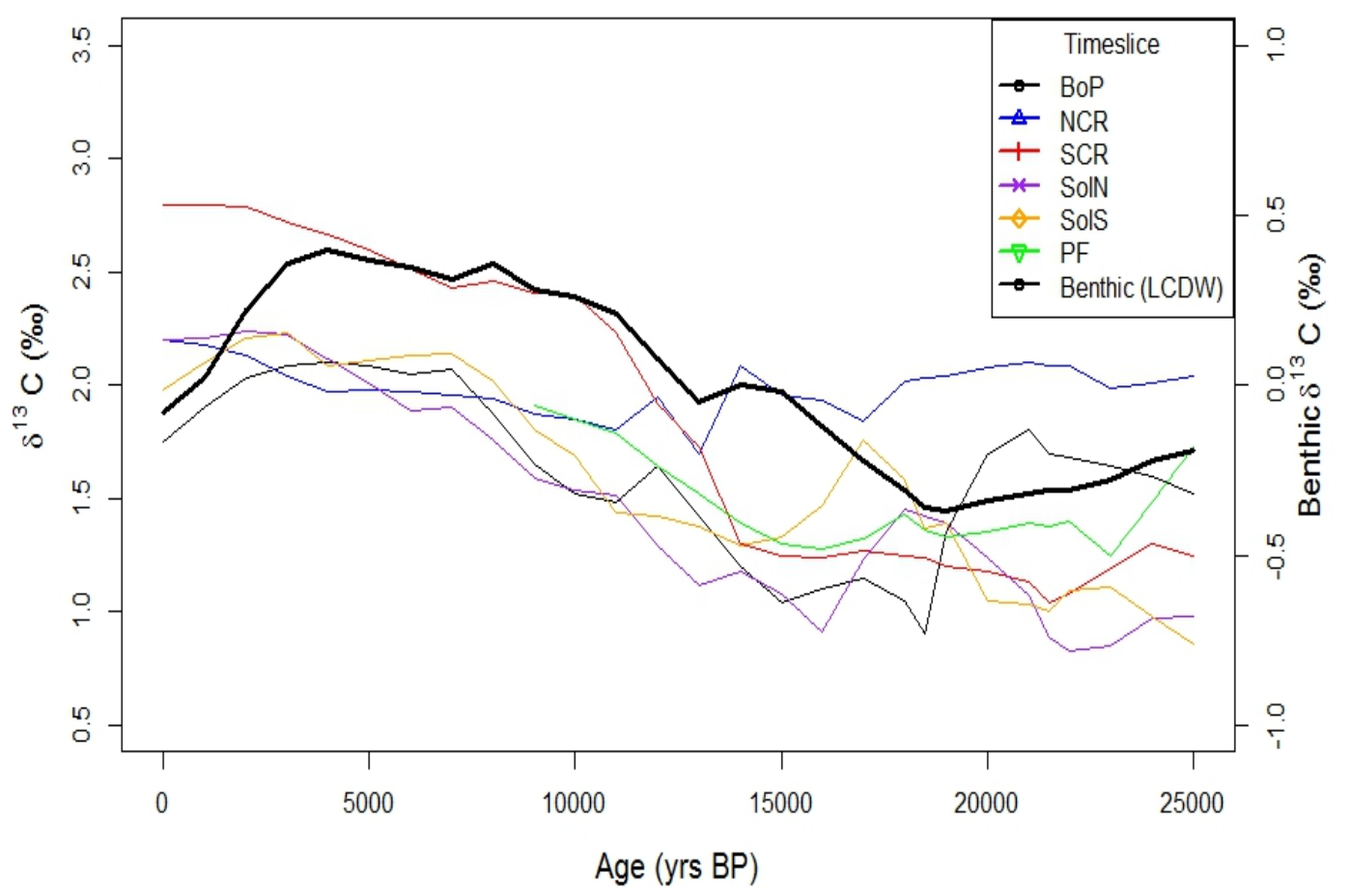

Figure A.2.1: Benthic data compared to all six zones. Benthic data used in all correlations. 


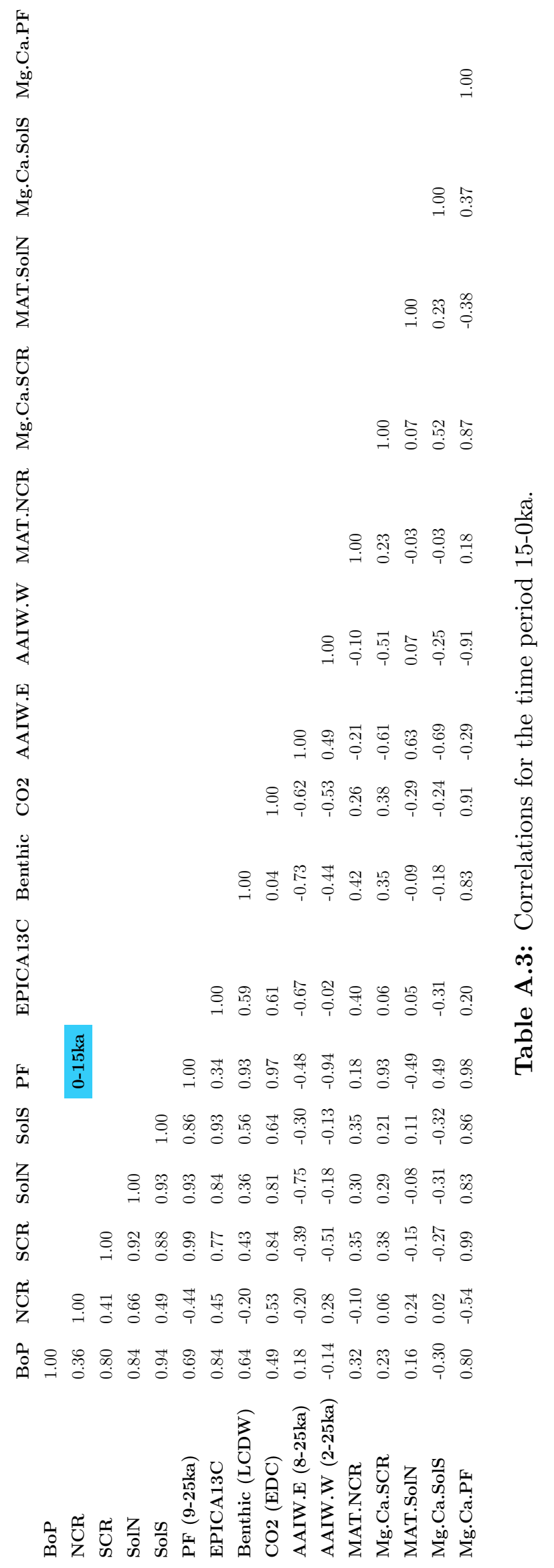




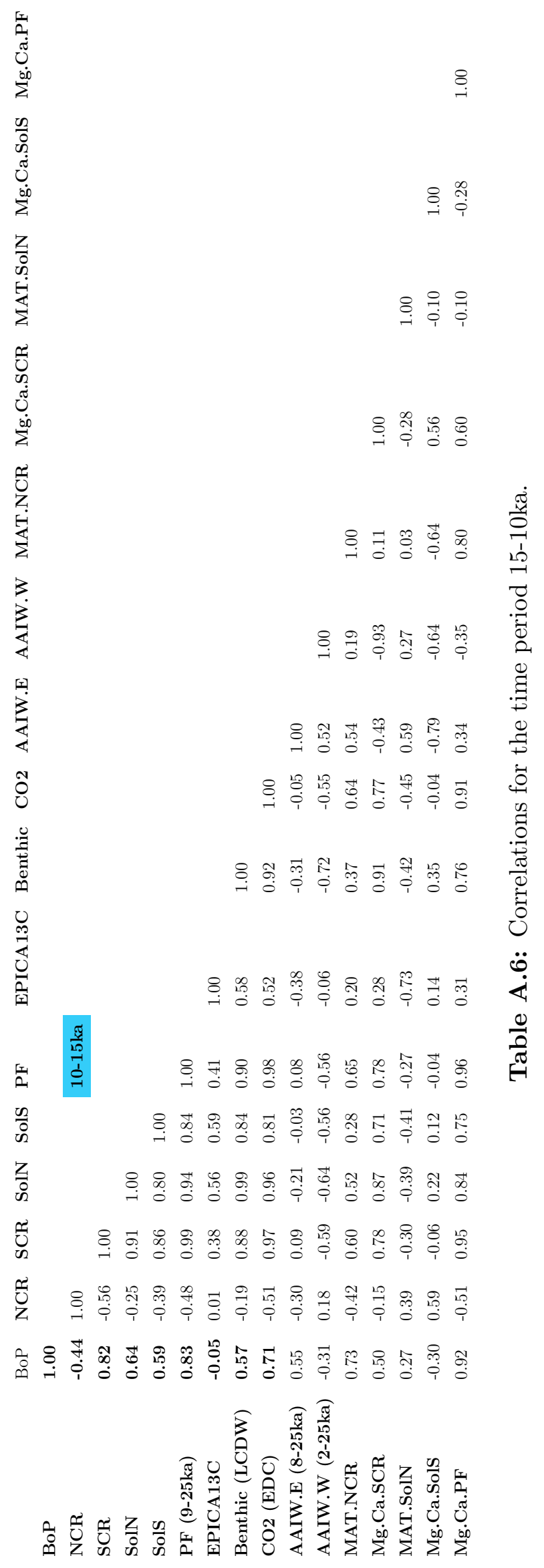




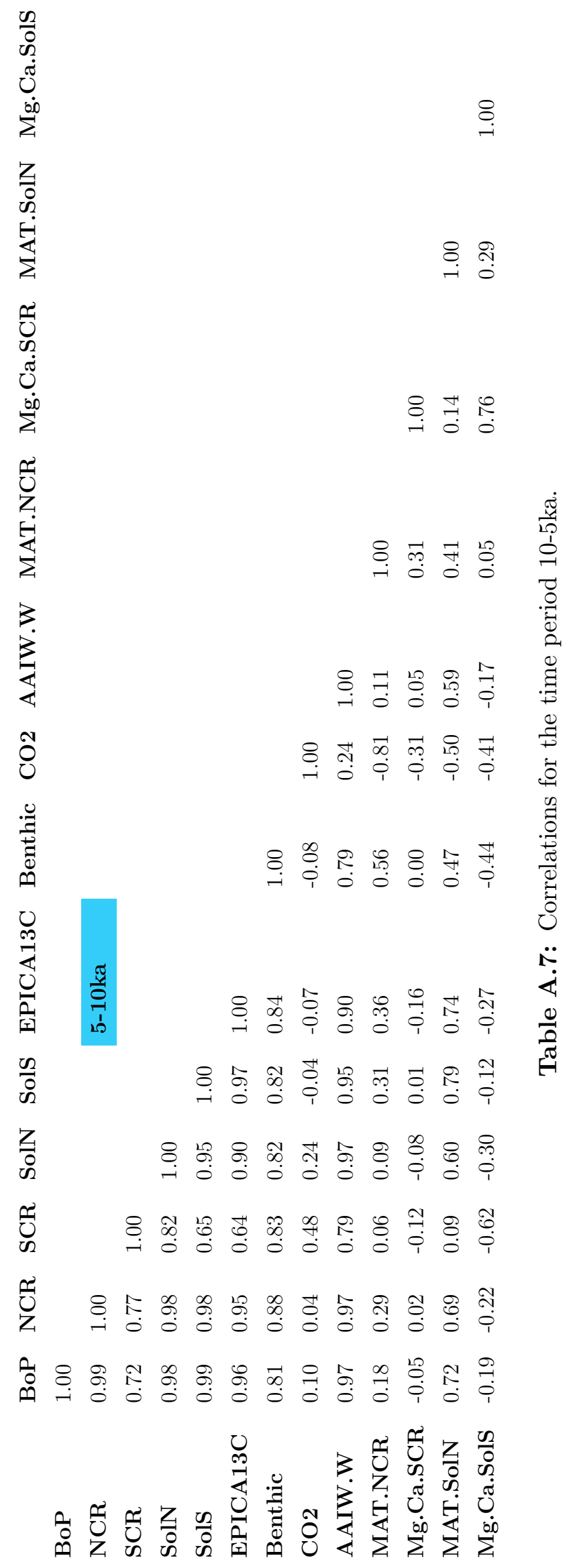




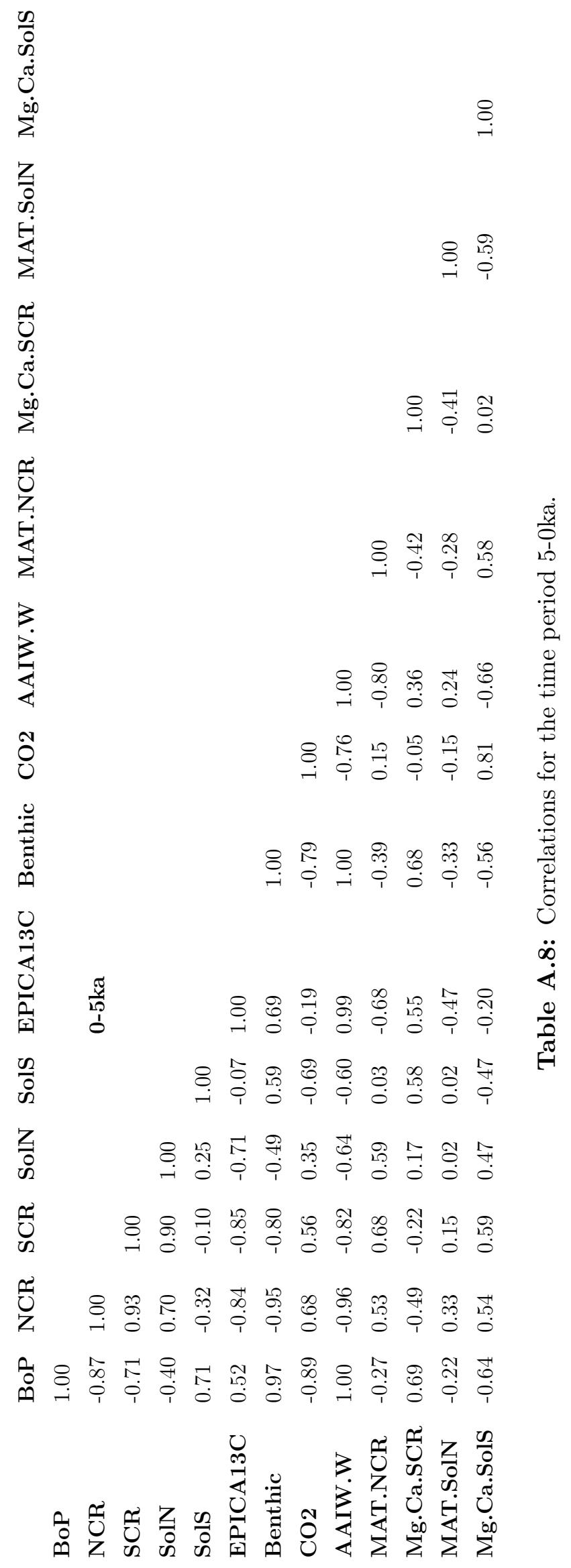




\section{Bibliography}

[1] Anderson, Robert F., et al. "The Southern Ocean's biological pump during the last glacial maximum." Deep Sea Research Part II: Topical Studies in Oceanography 49.9 (2002): 1909-1938.

[2] Anderson, R. F., et al. "Wind-driven upwelling in the Southern Ocean and the deglacial rise in atmospheric $\mathrm{CO}_{2}$." science 323.5920 (2009): 1443-1448.

[3] Anderson, Robert F., et al. "Biological response to millennial variability of dust and nutrient supply in the Subantarctic South Atlantic Ocean." Philosophical Transactions of the Royal Society of London A: Mathematical, Physical and Engineering Sciences 372.2019 (2014): 20130054.

[4] Basak, Chandranath, et al. "Neodymium isotopic characterization of Ross Sea Bottom Water and its advection through the southern South Pacific." Earth and Planetary Science Letters 419 (2015): 211-221.

[5] Bass, Adrian M., et al. "Continuous shipboard measurements of oceanic $\delta^{18} O, \delta D$ and $\delta^{13} C$ DIC along a transect from New Zealand to Antarctica using cavity ring-down isotope spectrometry." Journal of Marine Systems 137 (2014): 21-27.

[6] Bemis, Bryan E., et al. "Temperature influence on the carbon isotopic composition of Globigerina bulloides and Orbulina universa (planktonic foraminifera)." Marine Micropaleontology 38.3 (2000): 213-228.

[7] Bentov, Shmuel, Colin Brownlee, and Jonathan Erez. "The role of seawater endocytosis in the biomineralization process in calcareous foraminifera." Proceedings of the National Academy of Sciences 106.51 (2009): 2150021504.

[8] Bijma, Jelle, Jonathan Erez, and Christoph Hemleben. "Lunar and semilunar reproductive cycles in some spinose planktonic foraminifers." Journal of foraminiferal research 20.2 (1990): 117-127. 
[9] Boer, Agatha M., et al. "The control of the Southern Hemisphere Westerlies on the position of the Subtropical Front." Journal of Geophysical Research: Oceans 118.10 (2013): 5669-5675.

[10] Bonneau, M. C., C. Vergnaudgrazzini, and W. H. Berger. "Stable isotope fractionation and differential dissolution in recent planktonic-foraminifera from Pacific box-cores." Oceanologica Acta 3.3 (1980): 377-382.

[11] Bostock, Helen C., et al. "Carbon isotope evidence for changes in Antarctic Intermediate Water circulation and ocean ventilation in the southwest Pacific during the last deglaciation." Paleoceanography 19.4 (2004).

[12] Bostock, Helen C., Bradley N. Opdyke, and Michael JM Williams. "Characterising the intermediate depth waters of the Pacific Ocean using $\delta^{13} C$ and other geochemical tracers." Deep Sea Research Part I: Oceanographic Research Papers 57.7 (2010): 847-859.

[13] Bostock, Helen C., et al. "Deep-water carbonate concentrations in the southwest Pacific." Deep Sea Research Part I: Oceanographic Research Papers 58.1 (2011): 72-85.

[14] Bostock, Helen C., et al. "A review of the AustralianNew Zealand sector of the Southern Ocean over the last $30 \mathrm{ka}$ (Aus-INTIMATE project)." Quaternary Science Reviews 74 (2013a): 35-57.

[15] Bostock, Helen C., et al. "Reviewing the circulation and mixing of Antarctic Intermediate Water in the South Pacific using evidence from geochemical tracers and Argo float trajectories." Deep Sea Research Part I: Oceanographic Research Papers 73 (2013b): 84-98.

[16] Bostock, Helen C., et al. "Changes in the position of the Subtropical Front south of New Zealand since the last glacial period." Paleoceanography 30.7 (2015): 824-844.

[17] Boyd, Rhilip W., et al. "A mesoscale phytoplankton bloom in the polar Southern Ocean stimulated by iron fertilization." Nature 407.6805 (2000): 695.

[18] Breiman, Leo. "Random forests." Machine learning 45.1 (2001): 5-32.

[19] Buchanan, Pearse J., et al. "The simulated climate of the Last Glacial Maximum and insights into the global marine carbon cycle." Climate of the Past 12.12 (2016): 2271. 
[20] Butzin, Martin, Matthias Prange, and Gerrit Lohmann. "Radiocarbon simulations for the glacial ocean: the effects of wind stress, Southern Ocean sea ice and Heinrich events." Earth and Planetary Science Letters 235.1 (2005): 45-61.

[21] Cao, Zhe, et al. "Learning to rank: from pairwise approach to listwise approach." Proceedings of the 24 th international conference on Machine learning. ACM, 2007.

[22] Carter, R. M., Paul R. Gammon, and L. Millwood. "Glacialinterglacial (MIS 110) migrations of the subtropical front across ODP Site 1119, Canterbury Bight, Southwest Pacific Ocean.” Marine Geology 205.1 (2004): 29-58.

[23] Carter, Lionel, et al. "Southwest Pacific modulation of abrupt climate change during the Antarctic Cold Reversal-Younger Dryas." Palaeogeography, Palaeoclimatology, Palaeoecology 260.1 (2008): 284-298.

[24] Chase, Zanna, et al. "Accumulation of biogenic and lithogenic material in the Pacific sector of the Southern Ocean during the past 40,000 years." Deep Sea Research Part II: Topical Studies in Oceanography 50.3 (2003): 799-832.

[25] Chiswell, Stephen M., et al. "Physical oceanography of the deep seas around New Zealand: a review." New Zealand Journal of Marine and Freshwater Research 49.2 (2015): 286-317.

[26] Coale, Kenneth H., et al. "Southern Ocean iron enrichment experiment: carbon cycling in high-and low-Si waters." science 304.5669 (2004): 408-414.

[27] de Nooijer, Lennart Jan, et al. "Biomineralization in perforate foraminifera." Earth-Science Reviews 135 (2014): 48-58.

[28] Denton, George H., et al. "The last glacial termination." Science 328.5986 (2010): 1652-1656.

[29] Epstein, Samuel, and Toshiko Mayeda. "Variation of $\delta^{18} O$ content of waters from natural sources." Geochimica et cosmochimica acta 4.5 (1953): 213-224.

[30] Erez, Jonathan, and Susumu Honjo. "Comparison of isotopic composition of planktonic foraminifera in plankton tows, sediment traps and sediments." Palaeogeography, Palaeoclimatology, Palaeoecology 33.1-3 (1981): 129-156. 
[31] Fairbanks, Richard G., et al. "Radiocarbon calibration curve spanning 0 to 50,000 years $\mathrm{BP}$ based on paired $230 \mathrm{Th} / 234 \mathrm{U} / 238 \mathrm{U}$ and $14 \mathrm{C}$ dates on pristine corals." Quaternary Science Reviews 24.16 (2005): 1781-1796.

[32] Ferrari, Raffaele, et al. "Antarctic sea ice control on ocean circulation in present and glacial climates." Proceedings of the National Academy of Sciences 111.24 (2014): 8753-8758.

[33] Ferry, Alexander J., et al. "First records of winter sea ice concentration in the southwest Pacific sector of the Southern Ocean." Paleoceanography 30.11 (2015): 1525-1539.

[34] Friedrich, Oliver, et al. "Influence of test size, water depth, and ecology on $\mathrm{Mg} / \mathrm{Ca}, \mathrm{Sr} / \mathrm{Ca}, \delta^{18} \mathrm{O}$ and $\delta^{13} \mathrm{C}$ in nine modern species of planktic foraminifers." Earth and Planetary Science Letters 319 (2012): 133-145.

[35] Gervais, Frank, Ulf Riebesell, and Maxim Y. Gorbunov. "Changes in primary productivity and chlorophyll a in response to iron fertilization in the Southern Polar Frontal Zone." Limnology and Oceanography 47 (2002): 1324-1335.

[36] Gottschalk, Julia, et al. "Biological and physical controls in the Southern Ocean on past millennial-scale atmospheric $\mathrm{CO}_{2}$ changes." Nature communications 7 (2016).

[37] Heath RA 1985a. "A review of the physical oceanography of the seas around New Zealand1982." New Zealand Journal of Marine and Freshwater Research 19: 79124.

[38] Hemleben, Christoph, Michael Spindler, and O. Roger Anderson. Modern planktonic foraminifera. Springer Science \& Business Media, 2012.

[39] Hertzberg, Jennifer E., et al. "Evidence for a biological pump driver of atmospheric $\mathrm{CO}_{2}$ rise during Heinrich Stadial 1." Geophysical Research Letters 43.23 (2016).

[40] Honjo, Susumu, et al. "Particle fluxes to the interior of the Southern Ocean in the Western Pacific sector along 170 W." Deep Sea Research Part II: Topical Studies in Oceanography 47.15 (2000): 3521-3548.

[41] Hutson, W.H. "The Agulhas Current during the Late Pleistocene: analysis of modern faunal analogs." Science, 207 (1980), pp. 6466 
[42] Imbrie, John, et al. "On the structure and origin of major glaciation cycles 1. Linear responses to Milankovitch forcing." Paleoceanography 7.6 (1992): 701-738.

[43] Jouzel, J., et al. "The two-step shape and timing of the last deglaciation in Antarctica." Climate Dynamics 11.3 (1995): 151-161.

[44] King, Alexandra L., and William R. Howard. "Seasonality of foraminiferal flux in sediment traps at Chatham Rise, SW Pacific: implications for paleotemperature estimates." Deep Sea Research Part I: Oceanographic Research Papers 48.7 (2001): 1687-1708.

[45] King, Alexandra L., and William R. Howard. "Planktonic foraminiferal $\delta^{13} C$ records from Southern Ocean sediment traps: New estimates of the oceanic Suess effect." Global biogeochemical cycles 18.2 (2004).

[46] Kohfeld, K. E., et al. "Southern Hemisphere westerly wind changes during the Last Glacial Maximum: paleo-data synthesis." Quaternary Science Reviews 68 (2013): 76-95.

[47] Lambeck, Kurt, and John Chappell. "Sea level change through the last glacial cycle." Science 292.5517 (2001): 679-686.

[48] Lamy, Frank, et al. "Increased dust deposition in the Pacific Southern Ocean during glacial periods." Science 343.6169 (2014): 403-407.

[49] Lisiecki, L. E., and M. E. Raymo. "LR04 global Pliocene-Pleistocene benthic $\delta^{18} O$ stack." IGBP PAGES/world data center for paleoclimatology data contribution series 8 (2005).

[50] Lisiecki, Lorraine E., Maureen E. Raymo, and William B. Curry. "Atlantic overturning responses to Late Pleistocene climate forcings." Nature 456.7218 (2008): 85-88.

[51] LynchStieglitz, Jean, et al. "The influence of airsea exchange on the isotopic composition of oceanic carbon: Observations and modeling." Global Biogeochemical Cycles 9.4 (1995): 653-665.

[52] Malmgren, Bjrn A., and Ulf Nordlund. "Application of artificial neural networks to chemostratigraphy." Paleoceanography 11.4 (1996): 505-512.

[53] Marlowe, I. T., et al. "Long chain unsaturated ketones and esters in living algae and marine sediments." Organic Geochemistry 6 (1984): 135-141. 
[54] Marr, J. P., L. Carter, H. C. Bostock, A. Bolton, and E. Smith (2013), Southwest Pacific Ocean response to a warming world: Using $\mathrm{Mg} / \mathrm{Ca}, \mathrm{Zn} / \mathrm{Ca}$, and $\mathrm{Mn} / \mathrm{Ca}$ in foraminifera to track surface ocean water masses during the last deglaciation, Paleoceanography, 28, 347362, doi:10.1002/palo.20032.

[55] Martin, John H. "Glacialinterglacial $\mathrm{CO}_{2}$ change: The iron hypothesis." Paleoceanography 5.1 (1990): 1-13.

[56] MartnezGarcia, Alfredo, et al. "Links between iron supply, marine productivity, sea surface temperature, and $\mathrm{CO}_{2}$ over the last 1.1 Ma." Paleoceanography 24.1 (2009).

[57] Martnez-Garca, Alfredo, et al. "Iron fertilization of the Subantarctic Ocean during the last ice age." Science 343.6177 (2014): 1347-1350.

[58] McCartney, M.S., 1977: "Subantarctic Mode Water." A Voyage of Discovery, M.V. Angel, Ed., Deep-Sea Res. 24(suppl.), 103-119.

[59] McCave, I. N., Lionel Carter, and Ian Robert Hall. "Glacialinterglacial changes in water mass structure and flow in the SW Pacific Ocean." Quaternary Science Reviews 27.19 (2008): 1886-1908.

[60] McNeil, B. I., R. J. Matear, and B. Tilbrook. "Does carbon 13 track anthropogenic $\mathrm{CO}_{2}$ in the Southern Ocean?." Global biogeochemical cycles 15.3 (2001): 597-613.

[61] McNichol, A. P., R. J. Schneider, K. F. von Reden, A. R. Gagnon, K. L. Elder, R. M. Key, and P. D. Quay, "Ten Years After-The WOCE AMS Radiocarbon Program," Nucl. Instrum. Methods Phys., Sect. B, 172, 479484, 2000.

[62] Millero, Frank J., and Alain Poisson. "International one-atmosphere equation of state of seawater." Deep Sea Research Part A. Oceanographic Research Papers 28.6 (1981): 625-629.

[63] Morris, Michele, Basil Stanton, and Helen Neil. "Subantarctic oceanography around New Zealand: preliminary results from an ongoing survey." New Zealand Journal of Marine and Freshwater Research 35.3 (2001): 499-519.

[64] Moy, Andrew D., William R. Howard, and Michael K. Gagan. "Late Quaternary palaeoceanography of the circumpolar deep water from the South Tasman Rise." Journal of Quaternary Science 21.7 (2006): 763-777. 
[65] Müller, Peter J., et al. "Calibration of the alkenone paleotemperature index U $37 \mathrm{~K}$ based on core-tops from the eastern South Atlantic and the global ocean $\left(60^{\circ} \mathrm{N}-60^{\circ} \mathrm{S}\right) . "$ Geochimica et Cosmochimica Acta 62.10 (1998): 1757-1772.

[66] Naish, Timothy, et al. "Obliquity-paced Pliocene West Antarctic ice sheet oscillations." Nature 458.7236 (2009): 322-328.

[67] NASA Goddard Space Flight Center, Ocean Biology Processing Group; (2014): Sea-viewing Wide Field-of-view Sensor (SeaWiFS) Ocean Color Data, NASA OB.DAAC, Greenbelt, MD, USA. http://doi.org/10.5067/ORBVIEW-2/SEAWIFS_OC.2014.0. Accessed 2017/01/31. Maintained by NASA Ocean Biology Distibuted Active Archive Center (OB.DAAC), Goddard Space Flight Center, Greenbelt MD.

[68] Neil, Helen L., Lionel Carter, and Michele Y. Morris. "Thermal isolation of Campbell Plateau, New Zealand, by the Antarctic Circumpolar Current over the past 130 kyr." Paleoceanography 19.4 (2004).

[69] Nelson, Campbell S., et al. "Oceanographic and climatic changes over the past 160,000 years at Deep Sea Drilling Project Site 594 off southeastern New Zealand, southwest Pacific Ocean." Paleoceanography 8.4 (1993): 435458.

[70] Ninnemann, Ulysses S., and Christopher D. Charles. "Changes in the mode of Southern Ocean circulation over the last glacial cycle revealed by foraminiferal stable isotopic variability." Earth and Planetary Science Letters 201.2 (2002): 383-396.

[71] Northcote, Lisa C., and Helen L. Neil. "Seasonal variations in foraminiferal flux in the southern ocean, Campbell Plateau, New Zealand." Marine Micropaleontology 56.3 (2005): 122-137.

[72] Orsi, Alejandro H., Thomas Whitworth, and Worth D. Nowlin. "On the meridional extent and fronts of the Antarctic Circumpolar Current." Deep Sea Research Part I: Oceanographic Research Papers 42.5 (1995): 641-673.

[73] Pahnke, Katharina, et al. "340,000-year centennial-scale marine record of Southern Hemisphere climatic oscillation." Science 301.5635 (2003): 948952.

[74] Pahnke, Katharina, and Rainer Zahn. "Southern Hemisphere water mass conversion linked with North Atlantic climate variability." Science 307.5716 (2005): 1741-1746. 
[75] Peterson, Carlye D., Lorraine E. Lisiecki, and Joseph V. Stern. "Deglacial wholeocean $\delta^{13} C$ change estimated from 480 benthic foraminiferal records." Paleoceanography 29.6 (2014): 549-563.

[76] Petit, Jean-Robert, et al. "Climate and atmospheric history of the past 420,000 years from the Vostok ice core, Antarctica." Nature 399.6735 (1999): 429-436.

[77] Prahl, Fredrick G., Laurel A. Muehlhausen, and Debra L. Zahnle. "Further evaluation of long-chain alkenones as indicators of paleoceanographic conditions." Geochimica et Cosmochimica Acta 52.9 (1988): 2303-2310.

[78] Quay, P. D., B. Tilbrook, and C. S. Wong, "Oceanic uptake of fossil fuel $\mathrm{CO}_{2}$ : Carbon-13 evidence", Science, 256, 74 79, 1992.

[79] Quay, Paul, and John Stutsman. "Surface layer carbon budget for the subtropical N. Pacific: 13C constraints at station ALOHA." Deep Sea Research Part I: Oceanographic Research Papers 50.9 (2003): 1045-1061.

[80] Robinson, Rebecca S., and Daniel M. Sigman. "Nitrogen isotopic evidence for a poleward decrease in surface nitrate within the ice age Antarctic." Quaternary Science Reviews 27.9 (2008): 1076-1090.

[81] Robinson, Rebecca S., et al. "Diatombound ${ }^{15} N /{ }^{14} N$ : New support for enhanced nutrient consumption in the ice age subantarctic." Paleoceanography 20.3 (2005).

[82] Rojas, Maisa, et al. "The Southern Westerlies during the last glacial maximum in PMIP2 simulations." Climate Dynamics 32.4 (2009): 525-548.

[83] Rojas, Maisa. "Sensitivity of Southern Hemisphere circulation to LGM and 4x $\mathrm{CO}_{2}$ climates." Geophysical Research Letters 40.5 (2013): 965-970.

[84] Ronge, Thomas A., et al. "Pushing the boundaries: Glacial/interglacial variability of intermediate and deep waters in the southwest Pacific over the last 350,000 years." Paleoceanography 30.2 (2015): 23-38.

[85] Rothlisberger, Regine, et al. "Dust and sea salt variability in central East Antarctica (Dome C) over the last 45 kyrs and its implications for southern highlatitude climate." Geophysical Research Letters 29.20 (2002).

[86] Sabine, Christopher L., et al. "The oceanic sink for anthropogenic $\mathrm{CO}_{2}$." Science 305.5682 (2004): 367-371. 
[87] Samson, Catherine R., Elisabeth L. Sikes, and William R. Howard. "Deglacial paleoceanographic history of the Bay of Plenty, New Zealand." Paleoceanography 20.4 (2005).

[88] Schiraldi, Benedetto, et al. "Southwest Pacific subtropics responded to last deglacial warming with changes in shallow water sources." Paleoceanography 29.6 (2014): 595-611.

[89] Schmittner, A., and Christopher J. Somes. "Complementary constraints from carbon $\left({ }^{13} C\right)$ and nitrogen $\left({ }^{15} N\right)$ isotopes on the glacial ocean's softtissue biological pump." Paleoceanography 31.6 (2016): 669-693.

[90] Sigman, Daniel M., Mathis P. Hain, and Gerald H. Haug. "The polar ocean and glacial cycles in atmospheric $\mathrm{CO}_{2}$ concentration." Nature 466.7302 (2010): 47-55.

[91] Sikes, Elisabeth L., and John K. Volkman. "Calibration of alkenone unsaturation ratios (Uk'37) for paleotemperature estimation in cold polar waters." Geochimica et Cosmochimica Acta 57.8 (1993): 1883-1889.

[92] Smith, Robert O., et al. "Interaction of the subtropical front with topography around southern New Zealand." Deep Sea Research Part I: Oceanographic Research Papers 76 (2013): 13-26.

[93] Sloyan, Bernadette M., and Stephen R. Rintoul. "The Southern Ocean limb of the global deep overturning circulation." Journal of Physical Oceanography 31.1 (2001): 143-173.

[94] Sokolov, Serguei, and Stephen R. Rintoul. "Circumpolar structure and distribution of the Antarctic Circumpolar Current fronts: 1. Mean circumpolar paths." Journal of Geophysical Research: Oceans 114.C11 (2009a).

[95] Sokolov, Serguei, and Stephen R. Rintoul. "Circumpolar structure and distribution of the Antarctic Circumpolar Current fronts: 2. Variability and relationship to sea surface height." Journal of Geophysical Research: Oceans 114.C11 (2009b).

[96] Sonnerup, Rolf Erik. Reconstructing the oceanic Seuss effect. Diss. 1999.

[97] Spero, Howard J., et al. "Effect of seawater carbonate concentration on foraminiferal carbon and oxygen isotopes." Nature 390.6659 (1997): 497500 .

[98] Spero, Howard J., and David W. Lea. "The cause of carbon isotope minimum events on glacial terminations." Science 296.5567 (2002): 522-525. 
[99] Stephens, Britton B., and Ralph F. Keeling. "The influence of Antarctic sea ice on glacialinterglacial $\mathrm{CO}_{2}$ variations." Nature 404.6774 (2000): 171174 .

[100] Suess, Hans E. "Radiocarbon concentration in modern wood." Science 122.3166 (1955): 415-417.

[101] ter Braak, Cajo JF, and Steve Juggins. "Weighted averaging partial least squares regression (WA-PLS): an improved method for reconstructing environmental variables from species assemblages." Twelfth International Diatom Symposium. Springer Netherlands, 1993.

[102] Toggweiler, J. Robbie, Joellen L. Russell, and Steve R. Carson. "Midlatitude westerlies, atmospheric $\mathrm{CO}_{2}$, and climate change during the ice ages." Paleoceanography 21.2 (2006).

[103] Tomczak, Matthias, and J. Stuart Godfrey. Regional oceanography: an introduction. Elsevier, 2013.

[104] Watson, A. J., et al. "Effect of iron supply on Southern Ocean $\mathrm{CO}_{2}$ uptake and implications for glacial atmospheric $\mathrm{CO}_{2}$." Nature 407.6805 (2000): 730-733.

[105] Wolff, Eric W., et al. "Southern Ocean sea-ice extent, productivity and iron flux over the past eight glacial cycles." Nature 440.7083 (2006): 491-496.

[106] Zeebe, Richard E. "An explanation of the effect of seawater carbonate concentration on foraminiferal oxygen isotopes." Geochimica et Cosmochimica Acta 63.13 (1999): 2001-2007.

[107] Zhang, J., P. D. Quay, and D. O. Wilbur. "Carbon isotope fractionation during gas-water exchange and dissolution of CO2." Geochimica et Cosmochimica Acta 59.1 (1995): 107-114. 